Andrews University

Digital Commons @ Andrews University

\title{
A Comparative Study Of The Effects Of Learning Style Prescriptions And/Or Modality-Based Instruction On The Spelling Achievement Of Fifth-Grade Students
}

Nancy D'Isa Turner

Andrews University

Follow this and additional works at: https://digitalcommons.andrews.edu/dissertations

Part of the Educational Assessment, Evaluation, and Research Commons, and the Educational Methods Commons

\section{Recommended Citation}

Turner, Nancy D'Isa, "A Comparative Study Of The Effects Of Learning Style Prescriptions And/Or ModalityBased Instruction On The Spelling Achievement Of Fifth-Grade Students" (1992). Dissertations. 745. 


\section{INFORMATION TO USERS}

This manuscript has been reproduced from the microfilm master. UMI films the text directly from the original or copy submitted. Thus, some thesis and dissertation copies are in typewriter face, while others may be from any type of computer printer.

The quality of this reproduction is dependent upon the quality of the copy submitted. Broken or indistinct print, colored or poor quality illustrations and photographs, print bleedthrough, substandard margins, and improper alignment can adversely affect reproduction.

In the unlikely event that the author did not send UMI a complete manuscript and there are missing pages, these will be noted. Also, if unauthorized copyright material had to be removed, a note will indicate the deletion.

Oversize materials (e.g., maps, drawings, charts) are reproduced by sectioning the original, beginning at the upper left-hand corner and continuing from left to right in equal sections with small overlaps. Each original is also photographed in one exposure and is included in reduced form at the back of the book.

Photographs included in the original manuscript have been reproduced xerographically in this copy. Higher quality $6^{\prime \prime} \times 9^{n}$ black and white photographic prints are available for any photographs or illustrations appearing in this copy for an additional charge. Contact UMI directly to order.

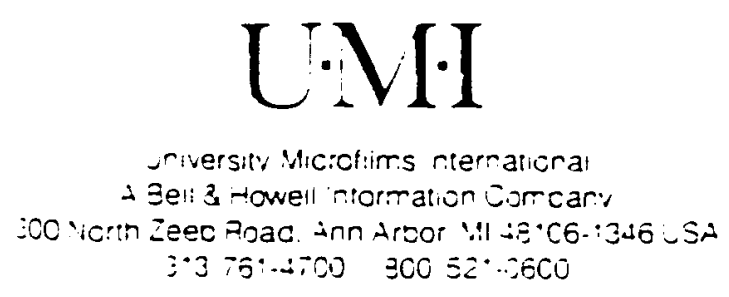


A comparative study of the effects of learning style prescriptions and/or modality-based instruction on the spelling achievement of fifth-grade students

\author{
Turner, Nancy D'Isa, Ed.D. \\ Andrews University, 1992
}

Copyright (C)1992 by Turner, Nancy D'Isa. All rights reserved.

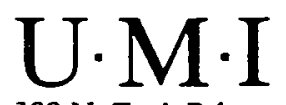

300 N. Zeeb Rd.

Ann Arbor, MI 48106 
Andrews University

School of Education

\title{
A COMPARATIVE STUDY OF THE EFFECTS OF LEARNING STYLE PRESCRIPTIONS AND/OR MODALITY-BASED INSTRUCTION ON THE SPELIING ACHIEVEMENT \\ OF FIFTH-GRADE STUDENTS
}

\author{
A Dissertation \\ Presented in Partial Fulfillment \\ of the Requirements for the Degree \\ Doctor of Education
}

by

Nancy D'Isa Turner

June 1992

Reproduced with permission of the copyright owner. Further reproduction prohibited without permission. 
Copyright by Nancy D'Isa Turner 1992

All Rights Reserved

Reproduced with permission of the copyright owner. Further reproduction prohibited without permission. 


\section{A COMPARATIVE STUDY OF THE EFFECTS OF LEARNING \\ STYLE PRESCRIPTIONS AND/OR MODALITY-BASED \\ INSTRUCTION ON THE SPELIING ACHIEVEMENT \\ OF FIFTH-GRADE STUDENTS}

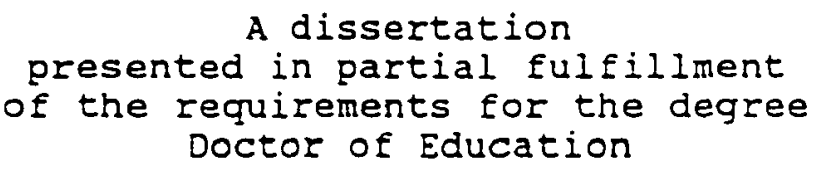

by

Nancy D'Isa Turner

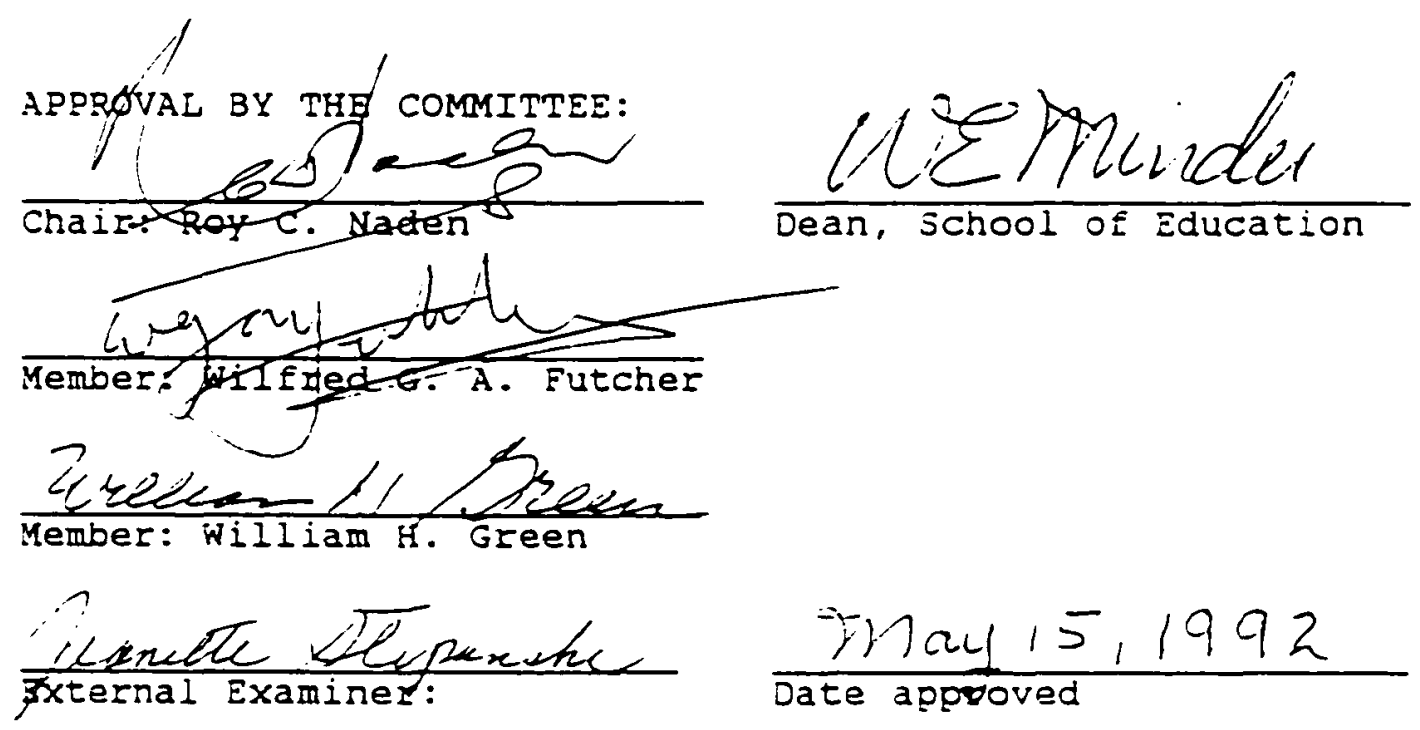




\title{
ABSTRACT
}

\section{A COMPARATIVE STUDY OF THE EFFECTS OF LEARNING STYLE PRESCRIPTIONS AND/OR MODALITY-BASED INSTRUCTION ON THE SPELLING ACHIEVEMENT \\ OF FIFTH-GRADE STUDENTS}

\author{
by \\ Nancy D'Isa Turner
}

Chair: Roy C. Naden 


\title{
ABSTRACT OF GRADUATE STUDENT RESEARCH \\ Dissertation
}

\author{
Andrews University \\ School of Education
}

\begin{abstract}
Title: A COMPARATIVE STUDY OF THE EFFECTS OF LEARNING STYLE PRESCRIPTIONS AND/OR MODALITY-BASED INSTRUCTION ON THE SPELLING ACHIEVEMENT OF FIFTH-GRADE STUDENTS

Name of researcher: Nancy D'Isa Turner

Name and degree of faculty chair: Roy C. Naden, Ed.D. Date completed: June 1992
\end{abstract}

\begin{abstract}
Problem
Learning style has been studied extensively across the United States since the early 1970s. Much research has involved Rita and Kenneth Dunns' model and associated Learning style Inventory. In 1991, Robert Zenhausern developed the Homework Disc software program which correlates with the Dunns' work and yields learning style prescriptions for students. The use of these study strategies at the elementary level has not been broadly examined. Therefore, this study investigated the effects of prescriptions on spelling achievement of fifth-grade students.
\end{abstract}




\section{Method}

A total of 65 students ( 33 males, 32 females) in three intact groups participated in this study. The control Group received instruction and studied in a traditional manner, an Instructional Group received modality-based instruction determined by preferences on the Learning style Inventory, and an Individualized Group received similar instruction and independently applied prescription information.

Four null hypotheses were formulated. The first three dealt with differences between pre- and posttests of the three groups and were analyzed using repeated measures analysis of variance and a priori tests. The final hypothesis concerned differences among adjusted posttest means of the three groups and was tested by both 3 -way and 1-way analysis of covariance. Newman-keuls tests were additionally done to identify the location of identified differences.

Results

1. Modality-based instruction alone did not significantly increase spelling achievement.

2. Spelling achievement was significantly increased $(p<.05)$ when students independently applied learning style prescription information to completion of homework in addition to receiving modality-based instruction in the classroom. 


\begin{abstract}
Conclusions
Learning style, experience, and personality are intricately connected, making complete individualization in the classroom nearly impossible. Therefore, students should be taught how to capitalize on their own preferences in order to increase learning.
\end{abstract}


This dissertation is lovingly dedicated to my husband, Jay, whose unfailing patience, support, and encouragement has always been an inspiration to me. 
TABLE OF CONTENTS

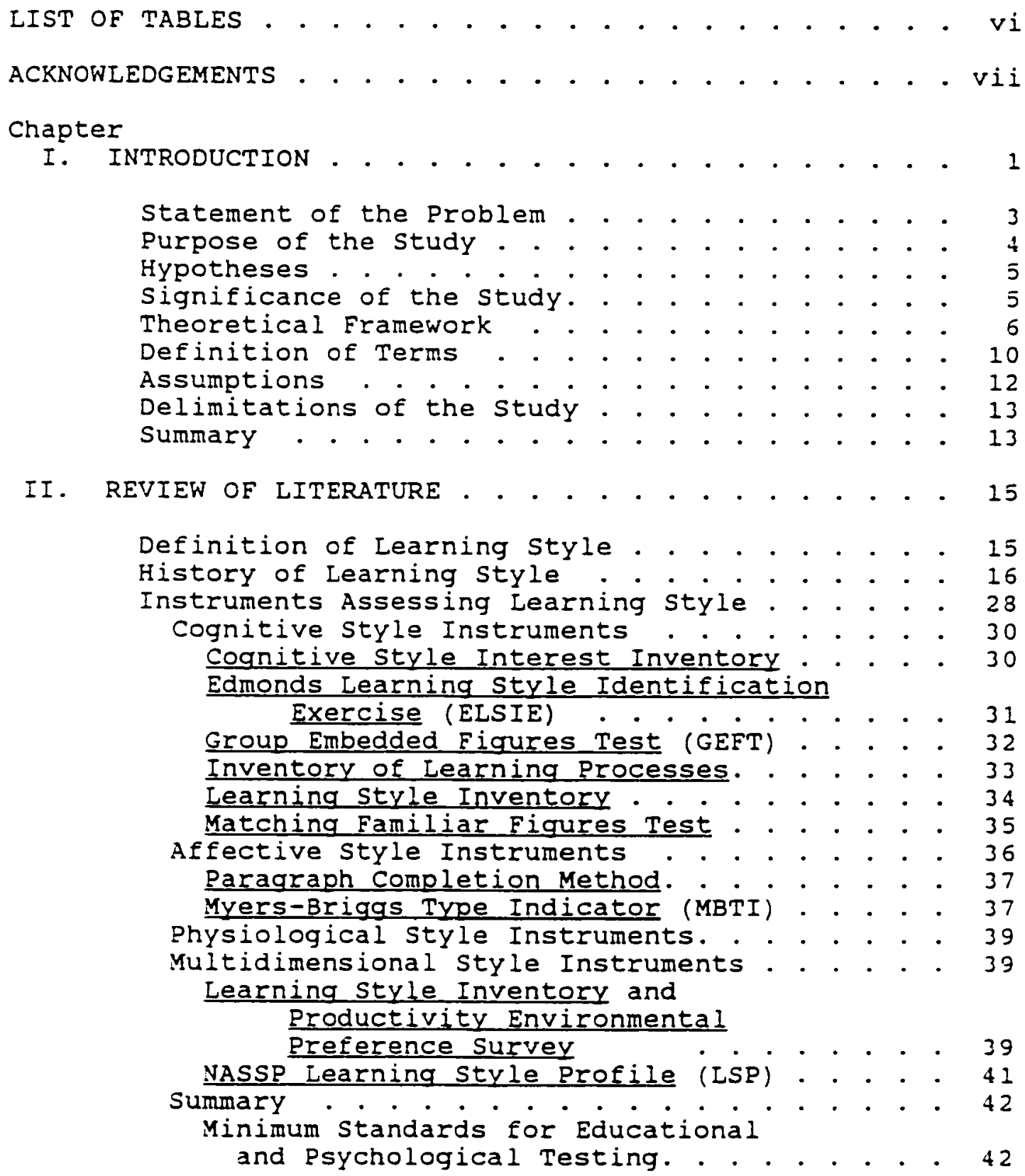

ii $i$

Reproduced with permission of the copyright owner. Further reproduction prohibited without permission. 
Suitability for the Purpose of and

Grade Level Involved in This Study . . . . 43

Research with the Learning Style Inventory . . . 44

Environmental stimuli. . . . . . . . . . . 45

Emotional Stimuli . . . . . . . . . . . . . 47

Sociological stimuli... . . . . . . . . . 49

Physical Stimuli. . . . . . . . . . . . . 50

Psychological stimuli. . . . . . . . . . . . 54

Learning style Controversy . . . . . . . . . . 56

Learning style and Metacognition . . . . . . . 62

Significance of Metacognition as a

Metacognition and speliing ........... . 66

Sumary . . . . . . . . . . . . . . 67

III. METHODOLOGY. . . . . . . . . . . . . . . . 70

Type of study . . . . . . . . . . . . . . . . 70

Description of the Population. . . . . . . . . . 70

Instrumentation . . . . . . . . . . . . . . . . 72

Development of the LSI . . . . . . . . . . . 73

Reliability and validity... . . . . . . 73

Procedure for Collecting Data. . . . . . . . . . 75

Null Hypotheses and Statistical Analysis . . . . 77

IV. RESULTS. . . . . . . . . . . . . . . . . . . . . 79

Introduction . . . . . . . . . . . . . . . . 79

Sample . . . . . . . . . . . . . . . . . . . . 79

Pretest Data. . . . . . . . . . . . . . . . . . 81

Group Comparisons. . . . . . . . . . . . 82

Males and Females. . . . . . . . . . . . . 84

Total Group. . . . . . . . . . . . . . . 84

Separate Groups. . . . . . . . . . . . . . . 87

Total Group. . . . . . . . . . . . . . . . . . 89

Treatment Procedure. . . . . . . . . . . . . . 89

Classroom Activities. . . . . . . . . . . 92

Class Reactions . . . . . . . . . . . . . 93

Homework . . . . . . . . . . . . . . . . 96

Testing the Hypotheses . . . . . . . . . . . . 97

Hypotheses 1-3 . . . . . . . . . . . . . . . 97

Hypothesis 4 . . . . . . . . . . . . . . . . 104

Qualitative Observations . . . . . . . . . 108

Reactions to Classroom Instruction. . . . . 108

Instructional Group. . . . . . . . . . . 108

Individualized Group. . . . . . . . . . . . 110

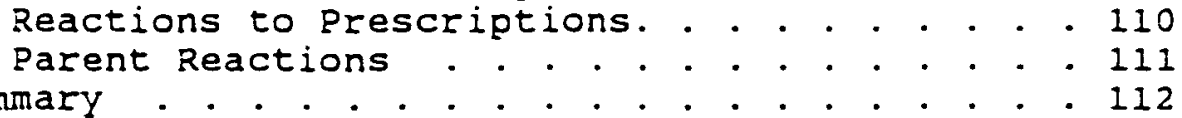

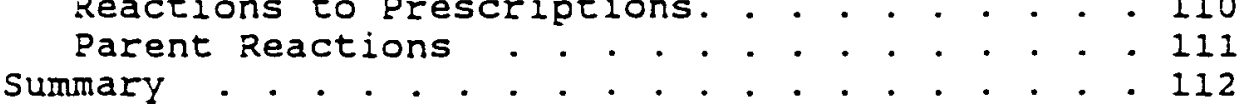

iv

Reproduced with permission of the copyright owner. Further reproduction prohibited without permission. 
V. SUMMARY, CONCLUSIONS,

IMPLICATIONS, AND RECOMMENTATIONS . . . . . . . . 114

Summary . . . . . . . . . . . . . . . . . 114

Purpose . . . . . . . . . . . . . . . . 114

Overview of Related Literature . . . . . . . 115

Sampling, Design, and Instrumentation. . . . . 118

Discussion of Findings . . . . . . . . . . . . 119

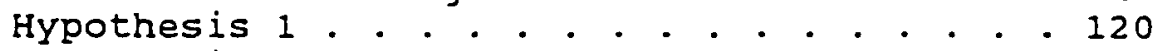

Hypothesis 2. . . . . . . . . . . . . . . . 121

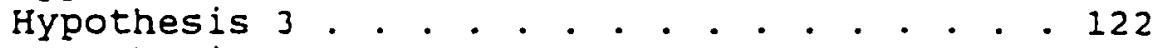

Hypothesis 4. . . . . . . . . . . . . . . . 123

Conclusions . . . . . . . . . . . . . . . . 124

Implications . . . . . . . . . . . . . . . . 125

Recommendations for Further Study. . . . . . . 126

APPENDICES . . . . . . . . . . . . . . . . . . . 127

A Permission and Correspondence Forms. . . . . . 128

B Sample Learning Style Prescription,

Group profiles . . . . . . . . . . . . . . . 139

C Sample Student Activities . . . . . . . . . 152

D Data File... . . . . . . . . . . . . 155

REFERENCE LIST . . . . . . . . . . . . . . . . . . 159

VITA . . . . . . . . . . . . . . . . . . . . 171 
1. Sample Group According to Treatment and Gender. . . 80

2. Tally on Standard Scores Indicating a High or Low Preference for All Sub-groups and Total Group . . 83

3. Perceptual Preferences of Experimental Groups by Percentage. . . . . . . . . . . . . . . . . . 90

4. Weekly Instructional Minutes of Experimental Groups According to Perceptual Preferences. . . . 91

5. Pre- and Posttest Means for Control, Instructional, and Individualized Groups . . . . 99

6. Repeated Measures ANOVA Table for Control Group. . 99

7. Repeated Measures ANOVA Table for Instructional Group . . . . . . . . . . . . . . . . . . 100

8. Repeated Measures ANOVA Table for Individualized Group . . . . . . . . . . . . . . . . . 100

9. Results of A Priori Tests for Control, Instructional, and Individualized Groups . . . . 100

10. Original Means for Control, Instructional, and Individualized Groups by Gender . . . . . . . . . 105

11. 3-Way ANCova: Adjusted Means for Control, Instructional, and Individualized Groups by Gender. . . . . . . . . . . . . . . 105

12. 3-hay Ancova Table. . . . . . . . . . . . . 106

13. Summary of ANCOVA for Separate Posttests (Adjusted Means). . . . . . . . . . . . . . 106 


\section{ACKNOWLEDGEMENTS}

The completion of this document would not have been possible without the assistance and encouragement of professors, family, and friends. It is with heartfelt thanks that I acknowledge the following:

Dr. Roy C. Naden, chairman of the dissertation committee, for his untiring encouragement and special efforts to carefully edit, share his ideas, and help me meet my personal deadines.

Dr. Wilfred G. A. Futcher, member of my committee, for his inspiration, guidance, and assistance with the statistical analysis of the data.

Dr. William H. Green for his interest and helpful input as committee member.

Mrs. Bonnie Proctor for her editorial expertise.

Mr. James Hendress, principal of the participating elementary school, and teachers Mrs. Marjorie Riemenschneider, Mrs. Anne-Marie Nussbaum, and Mr. Bill Staunton for their cooperation and help during collection of the data.

My daughters, Katie and Erin, for their understanding and patience while mom was working. My parents, Erank and Mary Kay D'Isa, for their vii 
constant love, support, and example of what great educators can be; my sister, Janie, for her words of encouragement;

all family members for their interest and confidence in me. Above all, God, for providing me with the strength

and will necessary to see this project through to an end. May this experience help in improving the quality of education for all children. 
CHAPTER I

\section{INTRODUCTION}

The success or failure of students in school has been attributed to various factors. Historically and well into the twentieth century (circa 1970), it was widely believed that social, economic, and political conditions could legitimately distract a student and inhibit learning (Dunn \& Dunn, 1978). In the last 20 years, however, the blame for unsatisfactory learning has shifted to schools, teachers, and instructional methods/programs. A consequence of this shift has been an increased awareness and involvement of both parents and the general public who realize the importance of a high-quality education and insist on it for all children. There is now a new emphasis on meeting individual learning needs.

At the federal level, there has been the development of PL 94-142, "The Education for All Handicapped Children Act" (1975), which mandated appropriate assessment, Individualized Educational Plans (IEP'S), mainstreaming, and due process rights for parents. The "least restrictive environment" for any student might include the regular 
classroom, resource room, self-contained special education classroom, special day school, or residential school. In addition, there have been recent provisions for the gifted, bilingual, and culturally different. Teachers are expected to meet a greater variety of student needs by utilizing various models of instruction such as lecture, direct instruction, mastery learning, inquiry, discovery, computerassisted instruction, cooperative learning, and concept formation (Joyce \& Weil, 1986).

An important related activity has been research into the concept of "learning style," or how one best learns. Although divergently defined by researchers, learning style encompasses the notion that individuals have certain characteristics which result in preferred ways of understanding, interacting with, and responding to the learning situation. During the last 2 decades, learning style has been studied at more than 60 institutions of higher learning across the country (Dunn, 1989). As a result, there is an abundance of literature supporting its usefulness in classrooms at the elementary, secondary, and post-secondary levels. Leading researchers in this area include Dunn and Dunn (1978), Gregorc (1982a), Hill (1976), Hunt (1971), Kolb (1976), Ramirez and Castaneda (1974), and Schmeck, Ribich, and Ramanaiah (1977).

It is imperative that educators continue to examine 
learning styles and to extend and refine knowledge of this unique method of individualizing learning. Understanding both theoretical information and classroom application is vital if each student's learning needs are to be met.

\section{Statement of the problem}

Tests and inventories to assess students' learning styles have been developed by several educational researchers (i.e., Dunn, Dunn, \& Price, 1975; Gregorc, 1982a; Kolb, 1976; McCarthy, 1980; Keefe \& Monk, 1986). Each instrument refiects the model of learning style held by its author(s). However, there has been some controversy among researchers concerning the instructional modifications necessary to incorporate assessed style and enhance learning. While cognitive psychologists advocate retraining a child for maximum achievement, those espousing a diagnostic-prescriptive view ("adaptationists") assert that higher levels of learning can be attained by matching learning styles with instructional methods and programs (Keefe; 1988). The matching of methods and styles has been supported by various studies, particularly those utilizing the Dunn and Dunn model and corresponding Learning style Inventory by Dunn et al. (1975).

Dunn and Dunn have hypothesized that matching learning style traits with complementary approaches and environments in studying and completing homework would 
increase achievement. The Homework Disc has been developed by zenhausern (1991) as an aid in this process. The computer software program was designed for students in grades 3-12 to facilitate study and homework completion according to preferred learning styles. A correlate of the Learning style Inventory by Dunn et al., it yields a printout of individual prescriptions that provide specific strategies for students.

Little research has been done on the prescribed study strategies of the Homework Disc. Knapp (1990) completed a study at the post-secondary level, but it is vital that the efficacy of learning style prescriptions be examined at other levels. This study looked at the phenomenon at the elementary level.

\section{Purpose of the study}

The purpose of this study was to examine the effects on spelling of modality-based instruction and learning style prescriptions of the Homework Disc. Achievement data of a control group which was studying in a traditional way was compared with the data of experimental groups who were studying/learning either according to group style infcrmation provided by standard Learning style Inventory feedback ("profiles"), or according to profile plus prescription information. 
Hypotheses

The subjects in this study were divided into three groups: Group 1 was the control group; Group 2 was an experimental group which received the Learning style Inventory, group profile, and instruction modified to match the group's perceptual preferences; and Group 3 was an experimental group which received the Learning style Inventory, group profiles, modified instruction, and independently applied Homework Disc prescription information.

Hypothesis 1. There is no difference between preand posttest achievement means of students in Group 1.

Hypothesis 2. There is a slight difference between pre- and posttest achievement means of students in Group 2 . Hypothesis 3. There is a significant difference between pre- and posttest achievement means of students in Group 3 .

Hypothesis 4. There is a significant difference among adjusted posttest means of the three groups where the posttest is adjusted for pretest means.

\section{Significance of the study}

Students' monitoring of their own preferred learning styles and cognitive processes is one component of "metacognition," which has been linked to improved achievement (Pennel1, 1985). It is anticipated that 
information derived from this study can be used to help students at the elementary level develop metacognitive skills and be more cognizant of ways to increase individual study efficiency.

Also, by adding to the knowledge base related to the use of learning styles at the elementary level, this study will provide a springboard for further research on the application of the Dunns' Learning Style Inventory profile information and correlated prescriptions to study strategies.

\section{Theoretical Framework}

By the late 1970s, several researchers had emerged as leaders in the learning styles movement. The National Learning styles Network (a learning styles resource center located at st. John's University of New York) was cosponsored by st. John's University and the National Association of Secondary School Principals (NASSP). Conferences were held in the early 1980 s and the NASSP formed a national task force on learning styles composed of researchers and practitioners. "The goals of the task force were to study the field in depth, evaluate current assessment technology, and develop a conceptual and psychometric model for state-of-the-art instrumentation" (Keefe, 1985, p. 140).

All of the existing models of style were studied and 
a consensus definition of learning style was eventually

reached. Previously established by Keefe and Languis in

1983, the accepted definition included

tha composite of characteristic cognitive, affective, and physiological factors that serve as relatively stable indicators of how a learner

perceives, interacts with, and responds to the learning environment. Learning style is demonstrated in that pattern of behavior and performance by which an individual approaches educational experiences. Its basis lies in the structure of neural organization and personality which both molds and is molded by human development and the learning experiences of both home, school, and society. (cited in Keefe, 1985, p. 141)

Keefe also stated that the task force accepted the following existing definitions of the three style dimensions:

1. Cognitive styles--information processing habits. . Which represent a person's typical modes of thinking, remembering, and problem solving (Messick, 1969)

2. Affective styles--motivational processes (attention, expectancy, incentive) viewed as the learners' typical modes of arousing, directing and sustaining behavior (Keefe, 1979)

3. Physiological styles--biologically based modes of response founded on sex related differences, personal nutrition and health, and accustomed reaction to the physical environment (Keefe, 1979) (Keefe, 1985, p. 141)

Different models of learning style include elements of one, two, or all three of these dimensions in varying degrees. From these, the task force chose assorted cognitive, affective, and physiological factors for in-depth study. Twenty-four elements were ultimately included in the NASSP learning style paradigm, and are assessed by the NASSP Learning style profile. 
The task force also recognized the role of learning theory in developing a conceptual model. It was believed that the three style dimensions (cognitive, affective, and physiological) "control or are controlled by an individual's information processing system" (Keefe, 1985, p. 141). Group members then searched for an acceptable model of learning which would effectively relate learning styles to information processing and which would serve as the underlying rationale for learning styles theory and instrument development. The accepted model was the General Operations model of Charles Letteri (1982) as shown in Eigure 1:



Figure 1. Information processing-general operations 
According to Letteri (1988), "There are six specific operational (information processing) phases that are directly related to learning: perceptual modality, perceptual memory, filter system, short-term memory, working memory, and long-term memory" (p. 30). He specifically related particular elements of the cognitive dimension of learning style to these various phases of information processing and pointed to the affective and physiological supports for learning.

The relationships among learning style, information processing, and classroom application also had to be addressed by the task force. To do this, it was necessary to reconcile a long-standing difference of opinion regarding modifications necessary for maximum learning. As was previously mentioned, cognitive psychologists emphasized retraining the child, whereas diagnostic/prescriptive experts (adaptationists) postulated that it was best to modify the learning environment. After much debate, the task force acknowledged the validity of both positions depending on the learner's age, developmental maturity, and level of skill. A compromise position was ultimately supported by members of the task force. Knowledge of a conceptual model of learning styles theory and application is imperative when considering the utilization of any design in the classroom. It specifically 
relates to the Dunns' model, as Keefe (1979) suggested: "The Dunns' work has been synergistic, drawing together cognitive, affective, and physiological styles from research and school applications" (p. 16). The Dunns' model includes 21 elements in five stimuli categories, many of which are included within the task force paradigm.

\section{Definition of Terms}

Elements are factors which have a positive, negative, or neutral effect on one's learning style. Within the Dunns' paradigm, there are 21 elements classified into five stimuli categories (Dunn, Dunn, \& Price, 1987).

High Preference for an element indicates that an individual prefers that element in order to maximize learning. High preference is indicated by a standard score of 60 or over on the Learning styles Inventory by Dunn et al. (1975). Very high preference is shown by a score over 80 (Dunn et al., 1987).

Homework Disc is a software package which interfaces with the Learning Style Inventory and yields a printout of study strategies for students (Zenhausern, 1991).

Homework Dise Prescriptions are printouts derived from the Homework Disc software which provide students with study strategies which complement learning style preferences as identified by the Learning style Inventory (Zenhausern, 1991). 
Learning style describes "characteristic cognitive, affective, and physiological behaviors that serve as relatively stable indicators of how learners perceive, interact with, and respond to the learning environment" (Keefe, 1979, p. 4).

Learning style Inventory is a comprehensive instrument which assesses how individuals in grades 3 through 12 prefer to learn (Dunn et al., 1987).

Learning style profiles are records of individuals' or groups' high, low, and neutral learning style preferences. Each profile includes a graph which indicates the standard score obtained by a student for each element (Dunn et al., 1987).

Low Preference for an element indicates minimal desire for that element when learning and is shown by a standard score of $20-40$ on the Learning Style Inventory. A score of 0-19 indicates a very low preference.

Although they affect how people learn, Low Preferences are the opposite of the element's name. Thus, if the element is Noise and the score is below 40, that person needs the opposite of Noise when trying to learn; Quiet is needed. (Durn et al., 1987)

Metacognition is knowledge about one's own cognitive system. There are two closely related types: knowing about cognition and monitoring cognition (Armbruster \& Brown, $1984)$.

Stimuli are broad categories of factors which affect 
learning style. According to Dunn et al. (1987), there are five stimuli areas:

1. Enviconmental stimuli include sound, light, temperature, and design.

2. Emotional stimuli include motivation, persistence, responsibility, and structure.

3. Sociological Stimuli refer to the ways students prefer to be grouped for instruction: alone, in pairs, in teams, with colleagues, with the teacher, or in varied ways (e.g., no particular preference for any of the above).

4. Physical stimuli include intake, time of day, mobility needs, and perceptual preferences.

5. Psychological stimuli include global/analytical processing, hemisphericity, and impulsive/reflective thinking.

The Learning style Inventory by Dunn et al. assesses an individual's preferences in the environmental, emotional, sociological, and physical categories. It does not measure underlying psychological factors.

\section{Assumptions}

It was assumed in this study that each individual has specific cognitive, affective, and physiological characteristics which are the result of a unique interplay between both nature and environment. Learning style is composed of these parts and is reflected in learner 
behavior. Recognition of and attention to learning style is a vital aspect of success in school.

\section{Delimitations of the study}

The following conditions were used in developing

this study:

1. The study was restricted to fifth-grade students at Prairie Vista Elementary School within the Penn-HarrisMadison School Corporation of Northern Indiana.

2. Students' learning styles were assessed using only the Learning Style Inventory by Dunn et al. (1975).

3. Learning style variables were restricted to the preferences which are a part of the Dunns' learning style model and which are assessed through the Learning Style Inventory.

4. Strategies for studying were those provided by Zenhausern's Homework Disc.

\section{Summary}

Chapter 1 began with an introduction which outlined the importance of individualized instruction in classrooms at all levels. This was followed by a statement of the problem, purpose of the study, research hypotheses, significance of the study, theoretical framework, definition of terms, assumptions, and delimitations.

Chapter 2 presents a review of the literature 
related to learning styles. Chapter 3 discusses the methodology, sample, instrumentation, procedures, null hypotheses, and proposed statistical analysis procedures. Chapter 4 presents an analysis of the data, and Chapter 5 contains a summary of the findings, conclusions, implications, and recommendations for future research. Appendices and a bibliography complete this report. 
CHAPTER II

REVIEW OF LITERATURE

\section{Definition of Learning style}

In the 1930s, Gordon W. Allport coined the term "cognitive style" to describe a quality of living and adapting which is influenced by distinctive personality types (cited in Keefe, 1979). Until the early 1980s, the terms "cognitive style" and "learning style" were used synonymously in the literature.

However, the recent consensus definition of learning style developed by the NASSP task force stated "the composite of characteristic cognitive, affective, and physiological factors that serve as relatively stable indicators of how a person perceives, interacts with, and responds to the learning environment" (Keefe, 1985, p. 140). Thus, learning style can now be thought of as a broad term encompassing three specific aspects. Cognitive style, as defined by Messick in 1969 (and accepted by the task force), is the way one perceives, thinks, remembers, and problem solves and as such is only one of the three aspects of learning style. 


\section{History of Learning Style}

Although there has been a profound focus on individualization within the last 20 years, the idea that people learn differently is not new (Fizzell, 1982). Over 2,500 years ago, Hindus proposed that people could choose between four basic techniques of practicing religion: active vs. passive and emotional vs. thoughtful (Fizzell, 1984).

In the late 1700 s and early 1800s, zesearchers began actively to examine divergent aspects of human traits in an effort to understand and to predict behavior (claxton \& Murrel1, 1987).

But for most of this century, research on learning style has been conducted within the field of psychology. German psychologists were considering style around 1900. According to Guild and Garger (1985), Carl Jung's work on "psychological types" is probably the best known. Psychological types are patterns of behavior which guide how one perceives, directs energy and attention, and makes judgments. Jung defined individuals as introverts or extroverts with four mental processes: intuiting, sensing, thinking, and feeling (Jung, 1923). Jung's work was later applied by Briggs and Myers (1977) in developing the MyersBriggs Trpe Indicator.

As previously mentioned, Allport, an American 
psychologist, coined the term "cognitive style" in the 1930s. The theories of Allport and other researchers were based upon studies of the influence of perception on learning. In 1939, while working with the partially blind, Lowenfeld found a difference in "visual" and "haptic" (from the Greek haptos, meaning "laying hold of") types.

Lowenfeld and Brittain (1975) described these terms:

The visually-minded person is one who acquaints himself with his environment primarily through the eyes and feels like a spectator. The person with haptic tendencies, on the other hand, is concerned primarily with his own body sensations and subjective experiences which he feels emotionally. (p. 275)

Most important, Lowenfeld found that the partially blind were just as likely as the sighted to have visual or haptic strengths. Therefore, it appears that the visual and haptic are psychological rather than physical types.

During this same period of time, Klein spoke of "levelers" and "sharpeners," the former emphasizing a retreat from objects, people, or situations, and the latter aggressively pushing themselves socially forward (cited in Guild \& Garger, 1985).

After World War II, much research on learning styles was conducted at Brooklyn College, the Menninger Foundation, and the Fels Institute. At Brooklyn College, Witkin spoke of people as being "field dependent" or "field independent," terms identifying an individual's ability to perceive a figure with or without the ground. Witkin and his 
colleagues came to believe that these perceptual functions were only one part of an individual's psychological make-up (Witkin, Dyk, Faterson, Goodenough, \& Karp, 1962).

While witkin focused his attention on the single dimension of field dependence/independence, Holzman, Gardner, and their colleagues at the Menninger Foundation identified several "control principles:" differentiation vs. undifferentiation, leveling vs. sharpening, equivalence range, tolerance for unrealistic experiences, and flexible vs. constructed control (cited in Sperry, 1972). For this group, personality organization was made up of these control principles and it accounted for an individual's mode of perceiving, remembering, and thinking.

Kagan and his associates at the Fels Institute researched two styles of conceptualization: analytic and non-analytic (Kagan, Moss, \& Siegel, 1963). This led to the identification of the reflective person (inclined to analyze a concept) and the impulsive person (inclined to make quick responses). Kagan developed the Matching Familiac Figures Test (1964) to identify these types. Like witkin, Holzman, Gardner, and other researchers, Kagan's work focused on personality of individuals as influenced by perception. Research on individual differences diminished during the late 1950s and early 1960s. This was largely due to the fact that a relationship between cognitive style and school 
19

success could not be proven, whereas intelligence and achievement were found to be highly correlated. In 1963, however, Carroll conducted an experiment in which he used a variety of teaching approaches in which students were able to have as much time as they needed for task completion. Under these conditions, aptitude was not a major factor in determining achievement (Carroll, 1963). Carroll's findings supplied the impetus for the emergence of "mastery learning," an educational movement more fully developed by Bloom (1968). Bloom criticized the traditional classroom approach to instruction and evaluation of students which usually resulted in a normal distribution of grades. Mastery learning was the alternative he espoused:

Most students (perhaps over 90 percent) can master what we have to teach them, and it is the task of instruction to find the means which will enable our students to master the subject under consideration. our basic task is to determine what we mean by mastery of the subject and to search for the methods and materials which will enable the largest proportion of our students to attain such mastery. (p. 1)

Mastery learning advocates follow a criterion-referenced approach to grading, in which "grades are determined by comparing the extent to which each student has attained a defined standard (or criterion) of achievement or performance" (Biehler \& Snowman, 1990, p. 630). Instructional objectives are utilized to identify expected student behaviors. Thus, by offering students needed time, 
20

instruction, and materials, the mastery approach "is more likely to lead to understanding and to encourage transfer than any approach that permits only one try and reports results only in terms of relative position" (Biehler \& Snowman, p. 634).

Clearly, Carroll's experiment and mastery learning are examples of individualization and are related to the concept of learning styles. Indeed, implications for the field of education were profound. Since the late 1960s, educators have been actively engaged in understanding and recognizing individual differences and in building a theory of learning and instruction based on it.

Kolb's research has been influential in the learning styles field. He suggested that learning style is a result of heredity equipment, past experience, and the demands of the present environment combining to produce individual orientations that give differential emphasis to the four basic learning modes postulated in experiential learning theory: concrete experience, reflective observation, abstract conceptualization, and active experimentation (Kolb, 1979). He developed the Learning Style Inventory in 1976 that identified four types of learners (converger, diverger, assimilator, and accommodator). Mccarthy chose Kolb's model of the learning process and Torrance's conception of hemispheric specialization in developing her 
"4-MAT" system (McCarthy, 1980). She also identified four types of learners (innovative, analytic, dynamic, and common sense). Gregorc (1982b) recognized two specific mediation abilities, perception (abstract vs. concrete) and ordering (sequential vs. random) which determine one's style. The Gregorc style Delineator is similar in format to Kolb's instrument and it also identifies four types of learners: (1) concrete-sequential learners acquire knowledge through hands-on experience; (2) concrete-random learners use trial and error and experimental approaches; (3) abstractsequential learners prefer rational, sequential approaches and will learn better from authorities; and (4) abstractrandom learners prefer to receive information in an unstructured manner.

An examination of the Kolb, Mccarthy, and Gregorc models uncovers conceptions that are strikingly similar. Their paradigms categorize people into four categories based on two bipolar continua. The same insights into the learning process are evident in the descriptions developed by these researchers. While it is recognized that people function more comfortably within a particular category of learning style, emphasis is put on the ability to "flex"--to strengthen other abilities so that the demands of a variety of learning tasks can be met. Mccarthy's system is most extensive and valuable for classroom use in that she 
includes specific activities which would develop characteristics of the four types of learners in all students.

One of the earliest educational researchers, Hill (1970), investigated how individuals derive meaning from their environment. His model of learning style is part of his conceptual framework for education known as the "educational sciences." In this system, cognitive style is the fifth of seven sciences which were developed to provide a common language in the field of education. Hill explained that the concept of cognitive style is expressed as a Cartesian product of four sets, just as Guilford's model of the intellect was a product of three sets. The four sets are the first four sciences in his model: symbols and their meaning, cultural determinants, modalities of inference, and memory-concern. Each of these sets is composed of a series of elements which interact with factors in the other sets to form an individual's cognitive style. An individual's style can be assessed by Hill's Cognitive style Interest Inventory (1976). Unlike Kolb, McCarthy, or Gregorc, Hill identified 330 types of people through the minute analysis of traits (Fizzell, 1982). It appears that it would be difficult to respond to all of these variations within a classroom. Therefore, Hill's model may be an idealistic conception of individualized learning. 
Hunt approached learning style in the early 1970 s as those educational conditions under which students are most likely to learn. The basis of his model of "Conceptual Level" (CL) is a description of students in terms of their need for structure:

Low structure is exemplified by student-centered approaches, discovery learning, and presentation of examples before presentation of the principle (inductive teaching). . . . High structure is exemplified by teacher-centered approaches, learning through lecture, and presenting the rule or principle before the examples. (Hunt \& Sullivan, 1974, p. 214)

Generally, there is an inverse relation between conceptual Level and degree of structure. "Low CL learners profit more from high structure and high $C L$ learners profit more from low structure or, in some cases, are less affected by variation in structure" (Hunt, 1971, p. 44). Hunt's assessment instrument is called the paragraph completion Method (PCM). Analysis of learning style calls for a subjective appraisal of individuals' responses to six lead sentences (DeBello, 1989). In this way, the PCM is different from a majority of other inventories which utilize rank-ordering or Likert scales. Specific training in the scoring and interpretation of results is required; this fact may make this instrument impractical for some school situations.

In 1972, Rita and Kenneth Dunn published Practical Aporoaches to Individualizing Instruction. They became 
leaders in the learning styles field developing a multidimensional model consisting of five stimuli groups and 21 subcategories or elements. (The original model had only four stimuli areas; in the early 1980s, the psychological group was added to environmental, emotional, sociological, and physiological areas.) Together with Price, they developed the Learning style Inventory (1975) for children in grades $3-12$ and the Productivity Environmental Preference Survey (1979) for adults. Rita Dunn continues, at writing, as director of the Learning Styles Network at St. John's University. This organization conducts research and disseminates information on learning and teaching styles. Drawing from the work of the Dunns, Carbo developed a Reading style Inventory (1981) for identifying students' preferred ways of reading in order to match instructional approaches and materials (Carbo, 1986). Also like the Dunns, Barbe and Swassing (1979) and Reinert (1982) stressed identification of perceptual modality strengths in their respective models. Canfield and Lafferty (1970) emphasized modality preferences as well as conditions, content, and expectations.

Ramirez and Castaneda (2974) based their research on the Witkin Model, in that they looked at field-sensitivity/ field independence. Field independence was considered positive because these features are prized by schools. The 
traits included were analytic characteristics such as attention to detail and sequential processing. Ramirez and Castaneda also incorporated cultural differences into their theory, focusing on the Mexican American and Anglo-American populations. They asserted that "differences in cultural values are reflected in socialization practices, which in turn result in differences in cognitive style between Mexican American and Anglo-American children" (Ramirez \& Castaneda, 1974, p. 79). Their assessment instrument is called the Child Rating Form, and is found in their book Cultural Democracy, Bicognitive Development, and Education. This instrument is a "direct observation format, yielding frequency of behavior scales that could be completed by the teacher or older children in a self-report survey" (DeBello, 1989, p. 13).

Letteri (1982) focused on information processing and stressed traits on a bipolar continuum, one extreme being correlated with analytic characteristics and the other with global characteristics. Students displaying analytic characteristics were found to be successful in school and were called Type 1 learners. In contrast, Type 3 learners had below-average academic performance and were global, impulsive, and non-focused. The Type 2 learner fell between these two extremes. Letteri's Cognitive style profile (1975) identifies these types of learners and, based on this 
information, retraining of the child is recommended where appropriate. The goal of augmentation is "to train the individual in those areas of the cognitive style profile shown to be deficient and to assist the individual to transfer these new strategies to all areas of academic achievement" (Letteri, 1982, p. 77).

This focus on information processing and belief in augmentation was shared by schmeck et al. (1977) who developed the Inventory of Learning processes. The notion of learner flexibility is in contrast with the instructional matching view held by researchers including the Dunns, Carbo, and Hill. As previously mentioned, the issue was evaluated by the NASSP task force who ultimately supported the validity of both positions depending on the learner's age, developmental maturity, and level of skill.

The Fuhrmann-Jacobs model (developed by Fuhrmann and Grasha in 1983) emphasized social interaction and involved three styles: dependent, collaborative, and independent (cited in Claxton \& Murrell, 1987). No one style is better than the others; "each is appropriate for different contexts or situations" (p. 42). Teachers need to be aware of learners' needs and the teaching techniques which best meet these needs. For example, dependent learners profit most when the teacher acts as the expert or authority and when lecture is the predominant mode of instruction. Group 
problem solving activities are most beneficial for collaborative learners, while independent learners prefer an unconstrained, student-centered environment. Varying degrees of social interaction are easy to realize in the classroom; thus, this model is applicable at any grade level.

Finally, in 1986, Keefe and Monk published the NASSP Learning style profile as "second-generation technology, building on the research and design of earlier work in the field" (Keefe, 1988, p. 7). It identified cognitive styles, perceptual response tendencies, and study/instructional preferences of middle and senior high school students. An analysis of the development of the learning styles field reveals two changes within the educational setting. First, while the early psychologists (i.e., Jung, Allport, witkin, Kagan) saw style as an innate, psychological trait, educational researchers (i.e., kolb, Hill, Hunt, the Dunns, and Ramirez and Castaneda) were more likely to emphasize the interaction of individual characteristics with environmental influences in determining learning style. Second, many educational researchers have gone beyond interpretation of why people perceive the world as they do, to how their perceptions might be enhanced. Their recognition of the value of instructional modification has clearly influenced pedagogy. 
Thus, the learning styles field has experienced a transition from psychological to educational focus. With the advent of mastery learning developed by Bloom in the late 1960s, educational researchers had new insight into individual differences. Knowledge of the components and impact of learning style further aided in the recognition of and attention to students' learning needs. Learning style diagnosis provides powerful leverage in analyzing and assisting students of all achievement levels.

\section{Instruments Assessing Learning Style}

Several researchers have analyzed a variety of learning style models with accompanying instruments and categorized them. Fizzell (1982) identified "global perspectives" like those developed by Gregorc (1982a), Kolb (1976), or Mccarthy (1980), models which are based on general traits; "cognitive mapping" like the Hill (1970) model with its minute analysis of many traits; and "schooloriented approaches" like the Dunn and Dunn (1978) model which tries to balance individual trait analysis against possibilities in structuring schools (p. 3). Curry (1983) conceptualized learning style dimensions as three layers of an onion: "personality dimensions" are the controlling innermost layer and include models of Witkin (1962), Briggs and Myers (1977), and Kagan (1963); "information processing dimensions," the middle layer, have been studied by Hunt 
(1971), Kolb (1976), Schmeck, Ribich, and Ramaniah (1977); and "instructional preference dimensions," the outermost layer, include models of Canfield and Lafferty (1970), Dunn and Dunn (1978), and Hill (1976). Claxton and Murrell (1987) expanded this model by adding "social-interaction dimensions" as a fourth category which includes the Fuhrmann and Grasha (1983) model (cited in Claxton \& Murrell, 1987). Keefe (1982) and DeBello (1989) developed taxonomies of learning style instruments which directly collaborate with the present conception of learning style as outlined by the NASSP task force. In accordance with the national task force's incorporation of cognitive, affective, and physiological style dimensions into the consensus definition of learning style, Keefe and DeBello examined existing instruments and categorized them by these three dimensions singly and also by a multidimensional type which includes all three. The following section provides a description of instruments in these four areas as well as citations of reliability and validity as reported in curry's 1987 or 1990 review of various researchers' psychometric analyses of learning style instruments. In addition, curry summarized evidence of reliability and validity according to the number of studies presenting these variables:

The evidence was considered "strong" if there were ten or more well designed studies collectively presenting acceptable results across a variety of types of reliability and validity; "good" with 4 or more such 


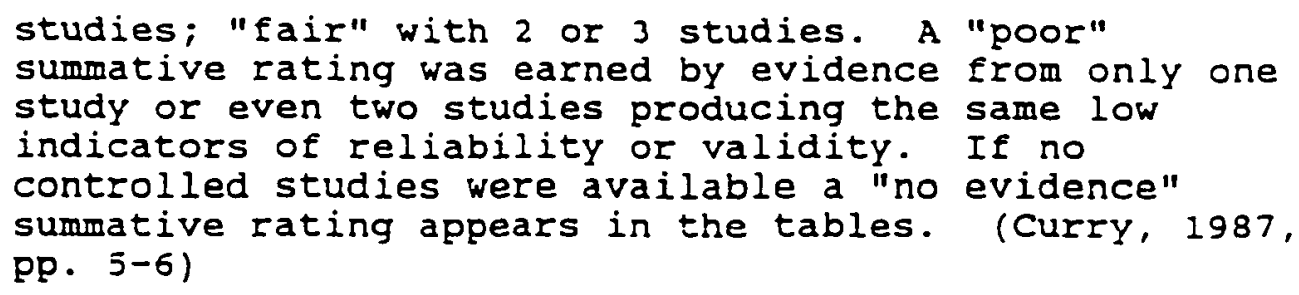

This rating system provides one means of comparing instruments. They must also be evaluated with regard to suitability for the particular purpose of and grade level involved in the study at hand.

\section{Cognitive Style Instruments}

Cognitive style has been defined as the way in which one perceives, thinks, remembers, and problem solves (Messick, 1969). Instruments measuring cognitive style assess such abilities.

\section{Cognitive style Interest Inventory}

iill defined cognitive style as the way in which an individual searches for meaning; it is based on the processing of theoretical and qualitative symbols, modalities of inference, cultural determinants, and memoryconcern. The cognitive style Interest Inventory (1976) is a self-report instrument involving rank-ordering which measures abstractions; visual, tactile, and auditory perceptions; motor coordination; and social interaction. Based on the information derived from this inventory, a "cognitive map" of the individual's learning style 
31

preferences is established and can be used for educational planning. This inventory was designed for use with elementary through adult levels. Curry (1987) reported that this instrument had no reliability or validity evidenced:

The author argues that each of the usual reliability estimation methods is inappropriate for application to "style" measurements. . . The author argues that the interactive nature of "styles" within contexts of operation and measurements a priori vitiates the sense of validity indications. (p. 28)

It is incumbent on a test developer to describe the reliability and validity of an instrument. Therefore, Hill's argument regarding reliability and validity makes the use of this instrument highly questionable.

\section{Edmonds Learning style Identification} Exercise (ELSIE)

The ELSIE was developed by Reinert in 1976 and is used to identify perceptual modality preferences. Reinert (1982) explained that ELSIE is composed of 50 one-word items read aloud to students who then are asked to characterize their reactions to the words according to a forced choice among four alternatives: (1) visualization or creation of a mental picture, (2) alphabetic letters in writing (the word spelled out), (3) sound, or (4) activity (an emotional or physical feeling about the word). DeBello (1989) asserted that the ELSIE does not have a strong research base. The 1987 Curry analysis showed the ELSIE to have poor reliability and no validity evidence. She cited only two 
sets of reports for reliability as presented by Reinert in 1976: one showed a test/retest reliability average to be .98 (indicating little error) and the other did not state correlations but concluded that an individual's overall profile of response remains constant. This appears to be a subjective conclusion, given that it is not based on reported statistical evidence.

\section{Group Embedded Figures Test (GEFT)}

The GEFT (1971) is one of several embedded figures tests developed by Witkin, based on the Embedded Figures Test. This test requires the subject "to separate an item from the field in which it is incorporated, but does not involve orientation toward the upright, nor does it involve body position in any way" (Witkin, Lewis, Hertzman, Machover, Meissner, \& Wapner, 1954, p. 83). The GEFT utilizes picture mazes in an attempt to assess cognitive functioning. Analytical ability is measured directly; global ability is inferred. This test is short and easy to administer (Keefe, 1982). Curry (1987) reported the GEFT to have strong reliability and good validity evidence and specific findings were given. Reliability evidence included an average split half coefficient of .82 as reported by Witkin, Oltman, and Karp (1971) and an average testlretest coefficient of .85 as reported by Kepner and Neimark (1984). These correlations indicate an acceptable level of 
reliability for learning style instruments, as McMillan and Schumacher (1984) stated, "An acceptable range of reliability coefficients for most instruments is 0.70 to $0.90 "$ (p. 127). Construct validity information provided by Witkin in 1967 (cited in Curry, 1987) reported on a wide range of studies relating performance on the GEFT to other disembedding functions, psychological differentiation, body concepts, nature of defenses, forms of pathology, physiological reactivity, and family and cultural activities. Hence, the GEFT probably provides a meaningful measure of field dependence/independence.

\section{Inventory of Learning Processes}

Schmeck, Ribich, and Ramaniah (1977) defined learning style as a pattern of information processing which the individual uses to prepare for a test of memory. Most important, this information processing is viewed as a

continuum; one extreme is characterized by shallow/ repetitive processing and the other by deep/elaborative processing. Neither extreme is a separate style, but rather a point in the continuum which can be changed (schmeck \& Lockhart, 1983). The original Inventory of Learning Processes was refined in 1984 . Both formats consisted of true/false items arranged in four scales: synthesisanalysis, study methods, fact retention, and elaborative processing. Designed solely for college students, it was 
recognized by curry (1987) as having strong reliability and validity evidence. The KR-20 reliability coefficient was reported by schmeck et al. (1977) as .70 and test/retest reliability as .83 . Both of these are within the acceptable range (McMillan \& Schumacher, 1984). Construct validity (average $=.34$ ) was illustrated through correlations with other scales: curiosity, achievement, anxiety, and imagery. Predictive validity (average $=.44$ ) was also exhibited, as Inventory of Learning Process scores can be used to predict scores on other trait tests (Schmeck \& Ribich, 1978, cited in Curry, 1987). These validity coefficients also fall within an acceptable range.

\section{Learning Style Inventory}

According to Kolb (1976), various combinations of the four basic modes of concrete experience, reflective observation, abstract conceptualization, and active experimentation result in four types of learning styles. The "converger" displays abstract corceptualization and active experimentation and possesses strength in the practical application of ideas. The "diverger" is best at concrete experiences and reflective observation and excels at viewing concrete situations from many perspectives. Abstract conceptualization and reflective observation are strengths of the "assimilator," who prefers to create theoretical models. The "accommodator" is strong in 
carrying out plans and being involved in new experiences; learning abilities lie in the areas of concrete experience and active experimentation.

Kolb's self-report inventory consists of items in sets which are rank-ordered and which represent the four learning modes. An individual usually has strong tendencies in one of the four learning style areas, although characteristics from any of the other three types may be possessed as well. In 1987, Curry summarized the Learning Style Inventory as having strong reliability evidence but only fair validity evidence. Among several citations of acceptable reliability, Kolb in 1985 (cited in Curry, 1990) reported an Alpha average $r$ of .79 . Construct validity information cited relationships with a few existing tests: aptitude, creativity, and personality. Correlation with other tests measuring similar traits is needed to more strongly support construct validity.

\section{Matching Familiar Figures Test}

Kagan (1964) developed this test to identify individuals as reflective or impulsive. It is composed of 12 visual items, each involving meaningful line drawings and requiring a match to an available target. Each item is timed and scored for accuracy of the match. The scoring positions each respondent on a bipolar scale purporting to measure conceptual tempo or a tendency to venture answers 
with cursory or careful search.

only two reliability studies were cited by Curry

(1987) for this instrument. In 1968, Yando reported split half reliability of .70 . Average test/retest reliability was also reported as .70 by Yando and Kagan in 1970 (cited in Curry, 1987). Concerning validity, Messer (1976) reported correlation with a few similar measures (average = .57) (cited in curry, 1987). All of these correlations are at an acceptable level. Curry summarized the available studies as representing fair reliability and validity evidence.

While there are obvious differences among these cognitive style instruments, a comparison reveals that the majority identify at least two categories of individuals: (1) an analytic, reflective type who is likely to profit from traditional schooling, and (2) a global, impulsive type who may require alternative activities and instruction.

\section{Affective Style Instruments}

Affective style was defined in chapter 1 as "motivational processes viewed as the learners' typical modes of arousing, directing, and sustaining behavior" (Keefe, 1979, p. 11). One instrument which measures affective style alone is the paragraph Completion Method by Hunt (cited in Keefe, 1982); others include the assessment of affective style with one or both of the other dimensions. 
Paragraph Completion Method (PCM)

The PCM (1971) consists of six sentence stems which the learner is directed to complete. It assesses conceptual complexity and the need for structure which are a part of each person's conceptual level. Kunt identified low, high, and intermediate conceptual levels and described the different educational settings required of each for success (Hunt \& Sullivan, 1974).

Only a few studies have reported on reliability and validity of the PCM; therefore, the available evidence was summarized by Curry as fair. In 1978, Hunt et al. (cited in Curry, 1990) reported test-retest reliability average of .50, an unacceptable level. Construct validity information cited correlations with integrative complexity (.49), with ego identity $(.37)$, and with anxiety $(-.56)$. The first two validity correlations indicate reasonably good positive relationships with similar measures. The latter correlation of -.56 signifies a good negative relationship between conceptual level and anxiety. Since they are different constructs, this correlation supports construct validity.

\section{Myers-Brigas Type Indicator (MBTI)}

The MBTI, developed by Briggs and Myers (1977), is a measure of personality dispositions and preferences and is based on Carl Jung's theory of "psychological types" (Myers \& Mccaulley, 1985). Jung identified two bipolar mental 
processes: (1) sensing vs. intuition (a preference for perceiving meaning), and (2) thinking vs. feeling (the manner of expressing values and commitment). According to Keefe (1982), sensing vs. intuition is a cognitive element, and thinking vs. feeling, an affective element. Jung also includes in his theory two fundamental approaches to life: extraversion and introversion; these are identified as affective elements by Keefe. The MBTI adds a fourth dimension: judging vs. perceiving, which can be considered either cognitive or affective and identifies the dominant preference in approaching reality (Myers \& Mccaulley, 1985). Thus, the MBTI looks at various style dimensions in identifying individuals as 1 of 16 types.

Curry summarized the MBTI as having good reliability and strong validity evidence. In 1990, split half reliability was reported as .86 and test/retest reliability as .78; both of these are acceptable levels. Concerning validity, it was stated that the "patterns of correlation support constructs" (Curry, 1990, p. 54). Predictive validity was indicated as well, in that MBTI scores can be used to predict specialty choice, modes of practice, professional activities, board certification, professional appointments, society memberships, and urban or rural residence (McCaulley, 1977/78, cited in Curry, 1990). 
Physiological style Instruments

Physiological styles are "biologically based modes

of response that are founded on sex-related differences, personal nutrition or health, and accustomed reaction to the physical environment" (Keefe, 1979, p. 15). No assessment instrument deals with these factors alone. However, Dunn and Dunn have included in their inventory time of day preferences, need for mobility, and environmental elements. similarly, the NASSP Learning Style Profile incorporates physiological elements which originated in the Dunn and Dunn model.

Multidimensional style Instruments

The Learning style Inventory (1975) and Productivity Environmental preference Survey (1979) by Dunn et al. and also the NASSP Learning style Profile established by Keefe and Monk (1986), incorporate the cognitive, affective, and physiological style dimensions.

Learning style Inventory and productivity Environmental preference survey

Originally developed by Dunn et al. in 1975, the Learning Style Inventory (ISI) assesses four of the five basic stimuli areas of Dunn and Dunn's learning style model (psychological stimuli are not included). In two forms, it is a "comprehensive approach to the identification of how 
students in grades $3-12$ prefer to function, learn, concentrate, and perform during educational activities" (Dunn et al., 1987, p. 6). The LSI has been revised several times $(1978,1984,1986)$ and the format has changed. The most recent version includes 104 items to which the student, in grades 3 and 4 , answers true, false, or unsure, and in grades 5 through 12 , by way of a 5-point likert scale (strongly disagree--strongly agree). The instrument can be administered in 30 minutes, and the answer sheets are computer-scored by Price Systems in Lawrence, Kansas. For each element, students obtain a score on a standard score scale (mean of 50 , standard deviation of 10) which indicates the degree to which that element is a high preference (6080), low preference $(20-40)$, or neither $(40-60)$. An individual profile presents this information in graphs. other types of summaries provide data on an entire class. Consistency scores are calculated for individuals based on their responses to questions which are repeated throughout the inventory. The higher the score, the more confidence can be held in interpreting responses. A $70 \%$ score is the minimum required for meaningful results (Dunn et al., 1987).

Curry (1987) reported that the ISI had good reliability and validity evidence. As cited in curry (1990), Dunn, Dunn, and Price (1987) reported an internal 
reliability (Hoyt average $r$ ) of .76. Studies indicating predictive validity were indicated (for details see chapter 3).

In 1979, Dunn et al. developed the productivity Environmental Preference Survey for adults, which consists of 100 items and also utilizes a 5-point likert scale. scoring and results are obtained in the same manner as the Learning style Inventory (Price, Dunn, \& Dunn, 1979). Curry has also rated this instrument as having good reliability and validity evidence, based on the number of available studies indicating acceptable coefficients.

NASSP Learning style Profile (ISP)

The NASSP Learning style Profile was developed in four phases from the fall of 1983 to early 1986 by Keefe and Monk. After much research, 24 subscales were included as a part of the instrument representing cognitive skills, perceptual responses, and study and instructional preferences. According to Keefe (1988), the task force's conceptual model of cognitive, affective, and physiological style dimensions was supported, in part, "by factor analytic investigation of the Learning style Profile items" (p. 14). The 24 elements were derived from the models of other researchers, including witkin, Reinert, and the Dunns. The LSP can be utilized with students in the 6 th to 12 th grades (Keefe, 1988). 
42

In 1988, Keefe and Monk (cited in Curry, 1990) reported an internal reliability level of .59 and 30-day test-retest reliability of .48 . These correlations do not indicate acceptable levels of reliability. Concerning validity, some scales have no data, while others have been correlated with related existing scales.

Summary

This section has presented characteristics of various instruments used to assess learning style. The contention is that the Learning style Inventory (ISI) by Dunn et al. (1975) is appropriate for this study. Ultimately, the appropriateness of the instruments probably should be based on the following criteria: (1) minimum standards for educational and psychological testing, and (2) suitability for the purpose of and grade level involved in the study at hand.

\section{Minimum Standards for Educational} and Psychological resting

According to Curry (1990), "a statement of the minimum standards for educational and psychological testing was jointly issued by the American Psychological Association, the American Educational Research Association and the National Council for Measurement in Education in 1985" (p. 8). Validity was noted as the most important consideration, followed by reliability. Curry (1987) 
zeported that the ISI by Dunn et al. had both good reliability and validity evidence, as measured by the number of well-designed studies collectively presenting acceptable results. As was noted in this section, many other instzuments do not demonstrate these standards. Hence, Curfy (1990) warned that there is a "tendency" in the learning styles field not to pursue a continuing pattern of hypothesis formation, testing, and modification, but rather to rush prematurely into print and marketing with only preliminary indications of these variables.

Suitability for the Puroose of and Grade Level Involved in This Study

The Dunn et al. model and inventory appear to be most suitable for the purpose of this study, which is to examine the effects on spelling of learning style prescripeions of the Homework Disc (Zenhausern, i991) in Eifth-grade students. In using the prescriptions, students made cognitive, affective, and/or physiological modifications in their approach to studying. As a multidimensional instrument, the LSI assessed these three dimensions of learning style.

Since the LSI was developed for use with elementary as well as secondary school students, it is proper for use with fifth-grade students. Also, it is relatively inexpensive and easy to administer and score. 
Based on validity, reliability, and suitability for the purpose of and students involved in this study, the ISI was deemed to be the learning style instrument most appropriate in this situation.

\section{Research with the Learning style Inventory}

The Learning Style Inventory (Dunn et al., 1975) examines "stimuli" and "elements" which either promote or inhibit mastery. There are four basic stimulus strands: environmental, emotional, sociological, and physical. As previously mentioned, psychological stimuli which are included in the Dunns' model of learning style, are not assessed by the inventory.

Each stimulus strand is divided into elements, and each element affects people differently. Thus, while some people are affected positively, others remain unaffected or are affected negatively. Restak (1979) and Thies (1979) studied whether certain characteristics of learning style are biological or are developed through experience. They found that individual responses to sound, light, temperature, design, perception, intake, chronobiological highs and lows (time of day), mobility needs, and persistence appear to be biological, whereas sociological preferences, motivation, responsibility (conformity), and need for structure are thought to be developmental. The following paragraphs describe recent research on each of the four stimuli areas 
utilizing the Learning style Inventory. A section on psychological stimuli is also included, since this area has been assessed by other instruments and results correlated to findings of the Learning style Inventory.

\section{Enviconmental stimuli}

Sound, light, temperature, and design are the four elements within this category. The effects of sound as a component of learning style range on a continuum from those needing total silence for study to those who need noise (Dunn \& Dunn, 1978). A doctoral dissertation by Pizzo (1981) reported the results of an experimental study which matched or mismatched sound/quiet preference and environment during a test situation. When the students' learning styles with regard to this element were matched with environment, they performed significantly better $(p<.01)$ than when mismatched. Affect also was positively impacted. Implications of this study are valuable; however, modification of sound in the classroom environment is a complicated task, given that many partitions or headsets are required during study activities.

Dunn, Krimsky, Murray, and Quinn (1985) conducted a review of research on the effects of light on children's achievement and behavior. They reported on the 1968 findings of Wurtman who emphasized that environmental lighting exerts profound effects on humans. This fact. 
together with the 1977 notion of Cronbach and Snow that persons possess traits which forecast chances of success under specific treatments (aptitude/treatment/interaction) and with Rosenfeld's 1977 descriptions of how to alter instructional environments to make them more responsive to students' characteristics, prompted Krimsky (1982) to investigate the relationship of light preference to learning. Utilizing the Gates-MacGinitie Reading Test to assess reading speed and accuracy, he matched and mismatched learning style preference for light. It was found that scores on both reading speed and accuracy were significantly higher $(p<.01)$ when tested in matched conditions. Furthermore, according to Dunn, Cavanaugh, Eberle, and zenhausern (1982), who looked at the relationship between hemispheric preference and other elements of learning style, those with a right hemispheric preference tend to prefer dim light while studying or reading. Like the element of sound, modification of light in the classroom environment is a complicated task.

Few people can learn in either extreme of warmth or cold. Temperature is relative, however, for people react to and achieve divergently in the same conditions (Dunn \& Dunn, 1978). While classroom temperature cannot be modified to meet the variety of student preferences, students can be permitted to wear heavier or lighter clothing. 
The traditional formal classroom design is familiar, and many students respond favorably to it. However, when a person is seated in a hard chair, "fully 75 percent of the total body weight is supported by only four square inches of bone" (Dunn, 1989, p. 3). This is understandably uncomfortable to some students who, for physical comfort, need a more informal posture.

Shea (1983) identified secondary students with preferences for an informal position (i.e., sitting on cushions, pillows, couches, and carpeting while studying) and found that they performed significantly better $(p<.001)$ on an English comprehension test when permitted to work in that manner. Using a seventh-and eighth-grade population, the results of this study were replicated with regard to mathematics by Hodges (1985). A varying design is not commonly seen in schools; however, this element of learning style is relatively easy to modify.

Emotional stimuli

In this category, there are four elements-motivation, persistence, responsibility, and structure. Motivation is an important factor in learning. According to Weiner (1980) who developed the Attribution Theory, success-oriented students attribute their success to ability (a stable characteristic, perceived as affecting achievement in the same way from one task to another) and 
attribute failure to insufficient effort. These types of students see future success as more likely than future failure; they are often intrinsically motivated. On the other hand, students with Iong histories of failure attribute their success to factors beyond their control (e.g., easy questions, luck) and attribute failure to ability. These students may see future failure as more likely than future success. They may not be personally motivated to achieve, feeling that any successes are "flukes."

Implications are that programs are desperately needed to enhance motivation in students, and to boost their feelings of control over learning. One means of increasing motivation, according to ounn (1989), is for students to understand their own learning style.

Persistence is the ability to continue to work at a task despite frustration or loss of interest. It has been found that persistence is related to other elements in the Dunn and Dunn model. Dunn et al. (1982) found a relationship between persistence and hemisphericity and stated, "Students who were persistent scored more Left preferenced than those whose learning styles did not include that element" (p. 293). The implications are that some students can better deal with long-term assignments, while others need short-term objectives and goals. 
Responsibility is the degree to which students can "follow through on a task, complete it to the best of their ability, and often do so without direct or frequent supervision" (Dunn \& Dunn, 1978, p. 10). White (1980) looked at the elements of persistence and responsibility and their relationship to academic achievement in seventh- and eighth-graders and found that persistent and responsible students acquired higher achievement scores than those who had obtained low persistence and responsibility scores on the Learning Style Inventory.

Motivated, persistent, responsible students are in less need of structure; they thrive when offered options for learning or responding, and find it difficult to achieve under imposed rules (Dunn \& Dunn, 1978). Activities providing structure, such as computer assisted instruction, have been found to work well with those students requiring specific directions, sequential tasks, and frequent feedback (Freeley, 1984). With careful planning, teachers can vary the amount of structure in student assignments.

Sociological Stimuli

There is no single best way in which to group students for maximum learning. Some learn best alone, while others concentrate better with peers (in pairs or teams). A third group learns best from direct teacher instruction. A "varied" group learns well in any combination. 
In general, sociological preferences appear to change as children mature. Price (1980) found that very young students (grades $\mathrm{K}-2$ ) prefer to learn directly from their teachers, while students in grades 3-8 appear to learn better in small, well-organized groups. Price also found that students in grades $9-12$ experience a greater need to learn and study alone than during any other time in school. Researchers, including DeBello (1985), Giannitti (1988), Miles (1987), and Perrin (1984), supported the idea that matching students' sociological preferences with method of instruction leads to higher achievement. For those who prefer working in a group situation, there are various cooperative learning strategies which have proven to be effective (Dunn \& Dunn, 1978). Not only can some students learn more, cooperative learning can lead to a supportive classroom atmosphere.

\section{Physical stimuli}

Preference for food during studying (intake), optimal time of day for learning, perceptual preference, and mobility needs are all included within this category of stimuli.

\footnotetext{
According to Dunn (1989), approximately 6 of the population desires intake while concentrating. Concerning time of day she says, "Approximately 28 percent of most elementary children are alert early in the morning; most
} 
'come alive' after 10:00 a.m. and experience energy high between then and 2:00 p.m." (p. 6). At the middle-school and junior high level, only about $30 \%$ are alert in the morning, and at the secondary level, only about 40 s Among adults, one half are early morning preferents (Dunn, 1989). Some children require more mobility when learning than others. A study by Della Valle (1984) showed "the interaction between learning style preference and environmental condition demonstrated statistical significance beyond the .001 level. . . Specifically, pupils who preferred a mobile environment performed statistically better in that condition than students who preferred passivity" (abstract).

Individuals have been recognized as having varying modality preferences. Much research has been done on the Dunns' conception of perceptual channels which includes visual, auditory, tactile, and kinesthetic modes. Dunn (1988a) asserted that a perceptual "preference" is synonymous with a "strength."

According to Dunn et al. (1987), a learner whose primary perceptual strength is visual can recall what has been read or observed. Those who have an auditory preference learn best from a lecture, discussion, or recording and remember three-quarters of what they hear in a 40- to 50-minute period. Students with tactile preferences 
"need to underline as they read, take notes when they listen, and keep their hands busy" (p. 9). Those with kinesthetic preferences require whole-body movement and/or real-life experiences in order to learn. It is important to note that Dunn et al. distinguish between the tactile and kinesthetic modes; some modality researchers do not.

Price (1980) found that children go through various stages as they develop. Initially, they are psychomotor (tactile/kinesthetic) by nature; with time, they become visual, and beginning with grades 5 and 6 , become auditory. In addition, those of low ability and poor readers may remain tactile/kinesthetic learners (Price, Dunn, \& Sanders, 1981). It must be stressed that these are general tendencies and that many interindividual differences exist at any grade or ability level.

What kinds of instruction are most appropriate to meet various perceptual preferences? Dunn et al. (1987) have listed many examples, most of which are obvious. For auditory preferences, it is best to use tapes, videotapes, lectures, discussion, records, radio, stereo, and television; for visual preferences, pictures, filmstrips, films, graphs, transparencies, computer monitors, diagrams, drawings, books, and magazines are useful; for tactile preferences, it is beneficial to use manipulative and threedimensional materials and to encourage students to keep 
written or graphic records; and for kinesthetic preferences, visits, projects, acting, floor games or any other real and active experiences provide for the best learning.

Many studies have verified the positive effects of matching instructional approaches to perceptual preferences. Kroon (1985) utilized the LSI to identify the perceptual preferences of 789 th and 10 th grade industrial arts students. Six lessons--two in each of the auditory, visual, and tactual modes--were presented to students, but in varying sequences. Achievement tests were administered after each lesson; findings revealed that lessons matched to the students' perceptual preferences resulted in significantly higher test scores (at the .01 level). Similarly, Martini (1986) analyzed the effects of matching and mismatching auditory, visual, and tactile instructional methods on the science achievement and attitudes of seventh-graders who had been classified according to their perceptual preferences indicated on the LSI. It was found that students in matched conditions achieved significantly higher scores ( $p<.001)$ than under mismatched conditions. All students achieved significantly higher scores $(p<.001)$ with computer assisted instruction (a visual/tactile method) than with either of the other two methods. The findings of these studies have been replicated at the primary through post-secondary levels (Dunn, 1988a). 
In addition to initial instruction through perceptual preferences, Dunn (1988b) also stressed that the teacher should reinforce through the secondary or tertiary modality and as a final step in the learning process, that the child should engage in some creative project dealing with the information taught. It is obvious that the teacher cannot be held accountable for implementing this process for all individuals; students must be taught to capitalize on their own learning strengths. Prescriptions provided by the Homework Disc guide students to study productively.

Psychological Stimuli

Global/analytic processing, hemisphericity, and impulsive/reflective thinking are included within the psychological stimuli category of the Dunn and Dunn model of learning style. According to Dunn (1989), Right-preferenced people tend to be global processors and impulsive, while Left-preferenced people appear to be analytic and reflective. Although these psychological elements are not directly assessed by the LSI, studies by researchers including Dunn et al. (1982) and Cody (1983) have measured hemisphericity via other inventories and correlated results with those obtained on the ISI.

Hemisphericity is apparently related to other elements of learning style. Dunn et al. (1982) conducted a study to compare the identified learning style 
characteristics of $353 \mathrm{high}$ school students and their

Left/Right dispositions; the ISI was used to assess learning style and Zenhausern's Differential Hemispheric Activation

Test to measure hemisphericity. Results indicated that:

Students who: (1) are not bothered by sound, (2) prefer dim illumination, (3) require an informal design, (4) are unmotivated, (5) are not persistent, (6) prefer learning with peers, and (7) prefer tactile stimulation, scored significantly more Right preferenced than those whose learning styles did not include those elements. . . Thus, Right- and Leftpreferenced students have different environmental and organizational needs within the classroom as well as different motivational and personality characteristics. (p. 293)

$$
\text { Cody (1983) used the LSI to assess learning style }
$$

and Torrance's 1979 Your Style of Thinking and Learning to examine hemisphericity and compared results in three IQ ability groups (average, gifted, and highly gifted). Average students were found to be Left-preferenced and to prefer studying in a warm, quiet environment, late in the day, and with much structure. Gifted students were likely to be Right-preferenced and to prefer studying in a quiet, moderately-heated environment, in the morning, and with less structure. Highly gifted students tended to have the strongest right processing style and to prefer sound, a cool environment, and little structure.

An examination of the findings of these two studies reveals similar correlations between mode of hemispheric processing and preferred elements of learning style. The 
additional information on the relationship between IQ and learning provided by Cody has important implications for teachers of ability-grouped classrooms.

Freeley and Perrin (1987) expanded on the above findings and indicated classroom activities used to accommodate left- and right-processors. They asserted:

It quickly becomes apparent that traditional classrooms were designed with left-processors in mind (by left-oriented designers, no doubt). It's necessary, therefore, to adjust classroom environments so that the learning style preferences of rightprocessors can also be accommodated. (p. 68)

Activities including games, pantomime, simulations, and dramatization would meet the needs of right-processors. Inclusion of such activities is undoubtedly a challenge for teachers at all levels, but would have beneficial results. In general, research conducted with the Learning Style Inventory supports the hypothesis that achievement can be improved by matching instructional approaches and environments to environmental, emotional, sociological, and physical learning style needs. However, there remains some controversy over classroom application; this debate is examined in the following section.

\section{Learning style controversy}

The previous section presented the results of some research utilizing the Dunn and Dunn model of learning style which supports the matching of instruction to student needs. 
Many of these studies, as well as those done that examine other models of learning style, have been criticized (i.e., Curry, 1990) because "they were conducted by Ph.D. students under the direction of a faculty member with a vested interest in substantiating a particular learning style conceptualization" (p. 18). However, Dunn (1990b) asserted that errors would be far less likely to occur in these situations, since a team of people examine each facet of the investigation. This argument is rational.

In a 1990 article and also in telephone conversation (May, 1991), Curry suggested that caution should be employed in interpretation of results of studies utilizing any model of learning style due to three factors: (1) the potential for statistical regression when comparison groups are selected on the basis of extreme scores, (2) the reactive effects of pretesting for learning style which may sensitize students to experimental instructional conditions, and (3) the possibility that students may be reacting to the experimental arrangements instead of the experimental variable (Hawthorne effect). These three factors will be considered in the study at hand.

In spite of the amount of literature in support of instructional matching (i.e., Chalfant \& Flathouse, 1971; Dunn \& Dunn, 1978, Johnson \& Myklebust, 1967), there continues to be some debate about this practice, 
particularly with regard to modality assessment and related instruction. Several research syntheses in the area of special education (i.e., Arter \& Jenkins, 1977; Kampwirth \& Bates, 1980; Tarver \& Dawson, 1978) have reached negative conclusions, as have some in general educational psychology (i.e., Cronbach \& Snow, 1977; Miller, 1981). These discrepancies need to be addressed.

Kavale and Forness (1987) looked at the reasons for varying conclusions and found four: (1) problems of definition and terminology, (2) unsupported expert opinion, (3) a continued emphasis in the general learning literature on the relationship between subject characteristics and performance under specified treatment conditions, and (4) methods used in previous research syntheses. They undertook a quantitative synthesis that used statistical methods and analyses (effect size measurements, which describe the magnitude of gains from any given change in educational practice) applied to summaries of individual studies. Their meta-analysis investigated the "efficacy of the modality model for special education" (p. 229). This included an investigation of modality testing as well as modality teaching.

An initial search located approximately 250 studies on modality-based instruction and testing. Eventually 39 were chosen which adhered to the three standards set by 
Kavale and Forness: use of a standardized instrument for modality assessment, instructional techniques which addressed the assessed preference, and use of a standardized instrument to assess achievement outcomes. Additionally, focus was placed on the most widely used model of individualized instruction for special education (instruction taking advantage of student strengths as evidenced by a preferred learning style), although different terms were used for this concept in the different studies reviewed. Only 2 of the 39 studies utilized Dunn and Dunn's learning style model. These 2, as well as 11 others, supported matched instruction, while the remainder did not.

Demographic data included students of different age, grade, and achievement levels. Twenty studies used "normal" students (p. 230), whereas 19 used students with disabilities (learning disabilities, reading disabilities, or mental retardation). There was no IQ data on one-fourth of the sample (the remainder had average IQ) and there was no gender breakdown in one-third of the studies (of the subjects in the remainder, 62 were male).

The conclusions reached in this study were negative, in that "neither modality testing nor modality teaching were shown to be efficacious" (p. 237). The obtained mean effect size for modality instruction was .14 and for modality testing, . .13. 
60

Are these results irrefutable? Dunn (1990a)

suggested that the Kavale and Forness argument had several

flaws. First, the combined data of both "normal" and disabled students "could have prevented a true analysis for either sample" (p. 353). In fact, the results were never differentiated for the different samples. Additionally, she questioned the findings due to other demographic variables, such as combinations of age, grade, and IQ levels (Dunn has found variations in type of modality preference according to IQ) -

A large portion of Dunn's criticism was related to the definition of terms. Although the model of individualized instruction commonly used in special education was clearly delineated in the kavale and Forness article, Dunn pointed to imprecise interpretations of the terms "auditory," "visual," "tactile," and "kinesthetic" as learning modes. Also, Dunn and Dunn view a perceptual preference as synonymous with a strength, as Rita Dunn (1990b) reasonably asserted, "If learning through your preferences consistently produces significantly better test scores and grades, then your preference is your strength;" however, some researchers (i.e., Barbe \& Swassing, 1979) view preferences as attitudes and strengths as reflections of brain behavior. Furthermore, Dunn and Dunn differentiate between the tactile and kinesthetic modes, while others do 
61

not. These varying views would undoubtedly affect the conditions and treatments set in modality research. Thus, her argument concerning definitions appears to be sound. Dunn also suggested that "the instruments used in the meta-analysis measure different constructs" (p. 354) and that some of the research designs used in the meta-analysis (experimental/control type) were not appropriate for modality research. Dunn and Dunn advocate an experimental design in which subjects serve as their own control, so that the investigation concerns whether individuals, rather than groups, achieve better in comparison with their own baseline data when placed in matched instructional settings.

Kavale and Forness (1990) responded persuasively to Dunn's criticism of their original article, emphasizing that "substance" in the material taught is more important than style (p. 357). However, questions remain and absolutes are difficult to derive from this meta-analysis, just as they were from previous integrative studies. This appears to be largely due to differences of opinion among researchers regarding definitions, methodology, appropriate instrumentation, and instruction. Perhaps the operational definitions developed by the NASSP task force will alleviate some of this problem in future research endeavors. Thus, some criticism has focused on modality-based research; however, according to the wide variety of studies 
evaluated in the previous section, it appears that achievement and test scores will increase when students are taught through their learning preferences.

\section{Learning style and Metacognition}

Vital to any learning situation is the student's application of "metacognition." Broadly, it means thinking about thinking (Armbruster \& Brown, 1984). There are two closely related types of metacognition: knowing about cognition and monitoring cognition (Baker \& Brown, 1985). Awareness is an essential component of a student's knowledge about cognition. Learners must be cognizant of how they learn, as well as personal characteristics which influence learning. Understanding one's own learning style is a large part of this awareness and therefore is a part of metacognition (Gordon, 1990; Pennel1, 1985). According to Pennel1:

$$
\begin{aligned}
& \text { When students become aware that they have preferences } \\
& \text { for and can control learning conditions in the } \\
& \text { environment, such as bright or low light, they have } \\
& \text { taken the first step in metacognition and in taking } \\
& \text { charge of their learning. (p. 132) } \\
& \text { Monitoring and regulating cognition are possible } \\
& \text { when one has acquired this awareness of the learning process } \\
& \text { and learning style. Also required is an understanding of } \\
& \text { the nature of the learning task/materials and strategies } \\
& \text { which can be used to meet varying demands (Vermunt, 1987). } \\
& \text { It appears that the learning style prescriptions of the }
\end{aligned}
$$


63

Homework Disc offer strategies for studying in accordance with this second aspect of metacognition. Prescriptions allow students to take steps to maximize learning.

Significance of Metacognition

as a Study Component

students' abilities to perform cognitive tasks are related to their metacognitive abilities (Glover \& Bruning, 1990). Good readers have been found to have good metacognitive skills in that they monitor their own reading and make adjustments as needed; in contrast, poor readers are often unaware of their own approaches to reading and may not recognize when they are experiencing a problem or how to alleviate it (Cross \& Paris, 1988).

Much of the metacognitive research comes from work with low-achieving students or people with learning disabilities, since cognitive deficits are considered to be central to their academic and/or social problems (Katims \& Alexander, 1987). General findings indicate that handicapped students can be empowered by instruction that promotes a self-managed approach to learning. Furthermore, Paris and oka (1986) suggested, "The skills and attitudes of self-regulated learners will also help to prepare exceptional children for the challenges that they will confront beyond the classroom" (p. 107).

At the elementary level (grades 3 and 4), Rottman 
and Cross (1990) studied a metacognitive reading program with 13 learning-disabled children and found that students increased in performance and awareness of strategies from pre- to posttest.

Pennell (1985) reported on the Academic Intervention (AI) program available to high school students in the Urbana (Ohio) public schools. The program applies brain and learning style concepts in teaching study strategies to students and has a philosophical foundation in the process of metacognition. It involves three categories of objectives--awareness, acceptance, and application:

Awareness includes metacognitive perception of personal learning approaches, recognition of the cognitive processes involved in learning and the variables inherent in classroom learning situations, and knowledge of cognitive brain research and its possible application to learners. Acceptance implies acknowledgment of individual learning differences and a personal approach to learning. Application incorporates executive control of personal learning and/or teaching strategy, collaboration, continual study of the teaching and learning process, and expansion of individuals as teachers and learners. (p. 132)

Results indicated that test scores could be raised for students through the AI program, particularly the reading comprehension scores of learning-disabled students. Many students also improved course grades.

In another study, Hamachek (1990) asserted that getacognition is crucial for the learning-disabled student in that reading is a common problem, processing is often 
hindered or delayed, and memory difficulties frequently stop students from achieving desired goals.

Do these findings hold true for students in the regular classroom? Sheeline (1988) stated that general education students can benefit from explicit instruction in learning strategies which have primarily been used with only learning-disabled students. Strategy training at the elementary and intermediate levels promotes learning empowerment and also prevents secondary level academic failure. Similarly, greater learner control resulted when high school students in two 9 th grade science classes and one 11th grade biology class participated in an intervention program stressing training in metacognition (Baird \& White, 1984). Both Gilbert (1986) and Vermunt (1987) found positive achievement resulted when this type of training was utilized at the post-secondary level. Furthermore, Gilbert emphasized that learners who were given the most explicit instruction in successful cognitive strategies applied these strategies better than those given less direct instruction. This latter finding appears to have direct application at all levels, as was suggested by Gage and Berliner (1988): Although metacognitive skilis usualiy develop slowly as we get older, the process is not simply part of the natural developmental process. Experience and explicit instruction seem to play a much more important role in the development of these crucial cognitive skills than does maturity alone. This means teachers have a responsibility to help students develop their metacognitive skills. (p. 317) 
In summary, research suggests two implications for classroom practice. First, independent learning presupposes metacognition which includes knowledge and monitoring of one's own cognitive processes. Knowledge can be attained partly through an understanding of personal learning style. The ability to monitor or regulate cognition is an outgrowth of this knowledge and is enhanced through feedback about the learning task or situation. Second, direct instruction of metacognitive skills results in students who are better able to apply these skills efficiently. Learning style Inventory profiles and Homework Disc prescriptions are aids in direct instruction and in developing both aspects of the metacognitive process. By providing this information, teachers can facilitate students' learning to learn.

\section{Metacognition and Spelling}

A review of the literature revealed that little attention has been given to the relationship between metacognitive abilities and spelling. Again, research has focused on the academically disabled. Harris, Graham, and Freeman (1988) conducted a study in which 40 learning disabled fourth graders learned to use a spelling study strategy, studied words under varying conditions, and predicted their scores on a subsequent test. Results showed that even without the inclusion of specific metacognitive training components, strategy training produced important 
67

metacognitive improvement and that these skills were an important part of spelling performance. Similarly, Wong (1986) found that sixth-grade students identified as poor spellers benefitted from remedial instruction involving metacognitive approaches.

Clearly, more research on the effects of metacognitive strategies applied to spelling needs to be done, particularly with non-disabled populations.

\section{Summary}

The terms "learning style" and "cognitive style" have been used synonymously in the past. In the early 1980s, the NASSP task force developed a consensus definition which identified learning style as a broader term incorporating cognitive, affective, and physiological style dimensions.

The idea that people learn differently is not new. However, it was not until the 1960 s that extensive research on the concept of learning styles was carried out in the field of education. Researchers such as Kolb, Gregorc, Hill, Dunn and Dunn, Ramirez and Castaneda, Canfield and Lafferty, and schmeck have built a sound basis for theory and instruction through their studies of learning style. The instruments which they developed have been categorized (DeBello, 1989, Keefe, 1982) according to cognitive, affective, physiological, or multidimensional elements. 
The Learning style Inventory (ISI) by Dunn et al. (1975) measures four of the five elements included in Dunn and Dunn's model of learning style. Research utilizing this inventory has provided much information on the environmental, emotional, sociological, and physical stimuli categories. In addition, several correlational studies have been conducted which examine the relationship between the psychological elements (e.g., hemisphericity) of Dunn and Dunn's model as assessed by other instruments and various elements of the LSI.

Many studies revealed that matching learning style preference with instructional/environmental programs resulted in higher levels of achievement. In spite of this finding, there remains controversy over learning styles research in general and the effectiveness of using learning style information, particularly perceptual preference, in maximizing learning. This holds true in both the areas of special and regular education, and can be attributed to differences of opinion among researchers regarding definitions, methodology, appropriate instrumentation, and instruction. However, the weight of evidence supports instructional matching as an effective way of increasing achievement.

Knowledge of one's learning style is a part of metacognition, as is the ability to regulate studying. It 
69

appears that information provided through Learning style

Inventory profiles as well as learning style prescriptions

of the Homework Disc may be aids in helping students to

develop metacognitive ability. It has been found that

metacognition is related to increased general performance at

the elementary, secondary, and post-secondary levels.

Although not studied extensively, these skills have been

linked to achievement in spelling. 
CHAPTER III

\section{METHODOLOGY}

\section{Type of study}

This study examined the effects on speliing of learning style prescriptions of the Homework Disc (Zenhausern, 1991) when applied to fifth-grade students. spelling achievement thus constituted the dependent variable. The independent variable consisted of the factor learning/study strategies and included three levels:

(1) utilizing a traditional approach to studying;

(2) utilizing learning style group profile information with classroom instruction modified to match, as practical, varying perceptual preferences; and (3) utilizing individual learning style profile information, modified classroom instruction, and independent application of prescription Eeedback via spelling homework.

\section{Description of the Population}

The population of this study was comprised of 65 fifth-grade students in an elementary school in South Bend, Indiana. The total school population of 607 consists of 958 Caucasian, 2 Indian, 28 Asian, and $1 \%$ Black students. The 70 
elementary school serves a portion of the middle to uppermiddle class community of Granger, Indiana. Most of the residents of Granger are employed in the city of South Bend or in neighboring Plymouth, Goshen, Elkhart, or the southwestern Michigan cities of Niles or st. Joseph.

After permission for participation was received from parents, intact classes comprising 65 of the fifth-grade students (total in school was 96) were used in this research.

Fifth-graders were selected for this study because this is the level where, according to the literature, students can begin to develop metacognitive skills. Biehler and Snowman (1990) contended that strategic learning is impossible for those under the age of approximately 10 . They stated that:

the youngest school-age children have only limited knowledge of how their cognitive processes work and when to use them. Consequently, primary grade children do not systematically analyze learning tasks, formulate plans for learning, use appropriate techniques of enhancing memory and comprehension, or monitor their progress, because they do not (and some say cannot) understand the benefits of doing these things. As children develop and gain more experience with increasingly complex academic tasks, they acquire a greater awareness of metacognitive knowledge and its relationship to classroom learning. (p. 391)

Thus, it seems appropriate for teachers to begin to guide students at the fifth-grade level toward the use of their metacognitive abilities. These skills could be more fully developed at the middle and high school levels. 


\section{Instrumentation}

The instrument utilized in this study was the Learning Style Inventory (LSI) by Dunn et al. (1975). The latest version (1986) includes 22 subscales zepresenting four areas of stimuli which affect learning: environmental, emotional, sociological, and physical.

The questionnaire includes 104 items with a true/false/unsure answer format for students in grades 3 and 4, and a 5-point iikert scale ("strongly agree" =hrough "strongly disagree") for students in grades 5-12. The time for completion of the questionnaire is approximately 30 minutes.

$$
\text { Answer sheets are computer-scored by ?rice systems }
$$

in Lawrence, Kansas. Results are compiled into a student profile that shows the preferred learning style of the individual. Standard scores of 60 or above =epresent elements that are very influential; elements with scores 59 and below either vacillate in influence depending on the situation (scores 40-59) or should always be aroided when studying (scores 39 and below). Group summaries are also availabie and provide learning style information on entire classes.

Scores from the profile are used with the correlated Fomework Disc computer software program in obtaining learning style prescriptions for individual students. 
Development of the LSI

In the late 1960s, Rita and Kenneth Dunn formulated and revised their notions about elements that affect learning style. The first Learning style Inventory was developed in 1975 by the Dunns and Price through factor analysis, and a 1978 version resulted from further factor analysis. Elimination of confusing or ambiguous items, rewording, and a new administrative format constituted some of the changes in the 1984 and 1986 editions.

Reliability and Validity

There have been many inquiries into the reliability and validity of the Learning style Inventory. In the late 1970s, Ohio State University's National Center for Research in Vocational Education published the results of its 2-year study of instruments that identify learning style and reported that the LSI had established impressive reliability and face validity (Kirby, 1979).

In the 1980s, further research was conducted to establish reliability and validity. In 1986, reliabilities and standard errors were calculated for each LSI area on versions for both grades $3-4$ and grades 5-12. The Hoyt analysis of variance procedure was used to estimate reliability for each subscale; it is equivalent to the kuder and Richardson formula (20) procedure (Dunn et al., 1987). 
It was found that:

Eighty-six percent ( 19 out of 22 ) of the reliabilities . - are equal to or greater than .60 for the likert scale English translation in grades 5 thru [sic] 12. - . Sixty-four percent ( 14 out of 22 ) of the reliabilities. . are equal to or greater than .60 for the Likert scale English translation in grades 3 and 4 . (pp. 30-31)

These coefficients indicate modest levels of reliability. As outlined in chapter 2, Curry (1987) conducted a comparative analysis of the psychometric standards of many instruments measuring learning style. Her rating system ("strong" through "no evidence") reflected the number of well-designed studies that collectively presented acceptable results across a variety of types of reliability and validity of the respective instruments. The ISI was reported to have "good" reliability and validity. This conclusion regarding reliability was based partially on the Hoyt analysis of variance procedure cited above.

The validity rating was based on the findings of several studies investigating the predictive nature of the ISI. Pizzo (1981) reported that matching acoustic environment with individual style significantly increased reading comprehension scores $(p<.01)$. In 1983, shea noted that matching design environment with individual style significantly increased ninth-grade reading comprehension scores $(p<.01)$. Della Valle, Dunn, Dunn, Geisert, Sinatra, and Zenhausern (1986) found that matching mobility 
preferences of seventh-grade students predicted significantly improved performance $(p<.001)$ on recognition and memory tests.

According to the above, the ISI more than meets the minimum standards for educational and psychological testing, which includes acceptable reliability and validity measures.

\section{Procedure for Collecting Data}

In July, 1991, permission was sought from the Human Subjects Review Board at Andrews University to conduct a quasi-experimental study on learning styles at the elementary level. This permission was granted (see notification letter in Appendix A).

Permission was also obtained from the principal of the elementary school where the study was conducted, and from parents of fifth-grade students for this population to participate in the research (permission and correspondence forms, see Appendix A). In early fall of 1991, a meeting was held with cooperating teachers to explain the study.

Three intact fifth-grade classes were randomly assigned to treatment/control groups. As presented in chapter 1, Group 1 was the control group studying in their usual manner. Group 2 was an experimental group which received the Learning style Inventory, an explanation of the group profile, and subsequent spelling instruction modified to match the group's perceptual preferences in which visual. 
auditory, tactile, and kinesthetic modality areas were each emphasized on the basis of the group profile. Group 3 was an experimental group which received the Learning style Inventory, group learning style profiles, the same modified instruction in class as Group 2, and independently applied prescription information for completing spelling homework.

The duration of the study was approximately fourteen weeks in the fall/winter of 1991-92. Achievement on spelling tests during the initial 3 weeks constituted baseline data for all three groups. This pretest information was the covariate and was used statistically to adjust initial group differences.

Students in Groups 2 and 3 were then given the Learning style Inventory following the reading of Braio's (1987) Mission From No style (a book that correlates with the Dunn and Dunn model and explains the learning style concept to students). A "make-up" day was provided for those students who were absent.

The completed questionnaires were sent to Price Systems in Kansas to be computer scored. Upon receipt of the individual and group profiles ( 2 weeks later), scores of students in Group 3 were entered into a computer and prescriptions obtained through the Homework Disc program. Meetings were then held with Group 2 to discuss the group profile and to explain subsequent teaching plans, and with 
Group 3 to discuss group profiles and teaching plans, and to give in-depth training on utilization of their learning style prescriptions (profiles and sample prescription, see Appendix B). Group 3 was also instructed in completion of parent-verified, self-report forms that documented the extent to which prescriptions were followed weekly. During the next 8 weeks, all students were exposed to the treatment conditions detailed above. Students in all groups completed similar exercises and had the same amount and type of spelling homework. Achievement data (spelling test scores) from this 8 -week period were compared with pretest data to determine results.

Nul1 Hypotheses and Statistical Analysis This study tested the following null hypotheses: Hypothesis 1. There is no significant difference between pretest and posttest achievement means of students in Group 1.

Hypothesis 2. There is no significant difference between pretest and posttest achievement means of students in Group 2.

Gypothesis 3. There is no significant difference between pretest and posttest achievement means of students in Group 3.

Hypothesis 4 . There is no significant difference among adjusted posttest means of the three groups where the 
posttest is adjusted for pretest means.

Repeated measures ANOVA and a priori tests were run

for Hypotheses 1 through 3. For Hypothesis 4, 3-way

analysis of covariance was run with the posttest as

criterion and the pretest as covariate. The hypotheses were

tested at the alpha level of .05. 
CHAPTER IV

RESULTS

\section{Introduction}

This research examined the effects on the spelling of fifth-grade students when exposed to learning style prescriptions and/or modality-based instruction. Chapter 4 describes the sample, pretest data, treatment procedure, the tests of the hypotheses, and qualitative observations.

\section{Sample}

The study included three fifth-grade classes at an elementary school in South Bend, Indiana. At the initiation of the study, the three classes included a total of 67 students. Permission from parents was sought, yielding 66 (99\%) positive responses. During the course of the research, one student moved, leaving 65 in the sample ( 33 males and 32 females).

Previously, the three classes had been grouped by language arts ability due to a system-wide adherence to a slight variation of the "Regrouping" plan in ability grouping. In this plan, students are grouped within the grade level (but across classrooms) for various subjects, 
such as language arts and math. Due to strong feelings on the part of the principal and teachers that students continue in this pattern, classes were left intact from the outset and were randomly assigned to treatment groups. Group 1, an average ability group, was the control group; Group 2, the lowest ability group, received instruction nodified to match perceptual preferences; Group 3, the highest ability group, received modified instruction and individualized learning style prescriptions for studying. It is recognized that the use of intact classrooms is a Iimitation of this study.

Table 1 presents a summary of the sample group according to treatment and gender. The sample was $97 \%$ Caucasian and $3 \%$ Asian.

TABLE 1

SAMPLE GROUP ACCORDING TO TREATMENT AND GENDER

\begin{tabular}{cccc}
\hline & Male & Female & Total \\
\hline Group 1 & 10 & 12 & 22 \\
Group 2 & 12 & 4 & 16 \\
Group 3 & $: 1$ & 16 & 27 \\
\hline
\end{tabular}


81

\section{Pretest Data}

After receiving permission from the Human Subjects Review Board at Andrews University and from the principal at the elementary school, a meeting was set with the three fifth-grade classroom teachers to discuss the study. All three teachers appeared to be very caring and dedicated individuals, and happy for the opportunity possibly to help their students through participation in the study. One concern that they had involved the amount of instructional time and types of homework that the students would receive. However, consensus on these matters was easily reached. Also, they agreed to begin to record spelling test scores as percentages (this school district does not use traditional letter grades until students reach middle school).

During the first 3 weeks of September, 1991, spelling test scores from the three groups were recorded as pretest data. The two experimental groups were administered the Learning style Inventory (Dunn et al., 1975) in late September. Inventories were sent to Price systems in Lawrence, Kansas, where they were computer scored. Both individual and group profiles were received, and scores were determined to be reliable due to adequate consistency scores of 70 or above. Learning style prescriptions were then derived from these scores for students in Group 3 through the Homework Disc software program (Zenhausern, 1991). 
Table 2 presents a tally of standard scores that indicate high preferences (scores 60 and above) or low preferences (scores 40 and below) for all sub-groups and the total group. (Scores that fall between 41 and 59 indicate that the individual's preference is neither high nor low and that the particular element is not critical to the learning style.) Several observations from Table 2 are detailed below. (Some perceptual preference information is included below; that which is pertinent to this study is summarized in the "Treatment Procedure" section.)

$$
\begin{aligned}
& \text { Group Comparisons } \\
& \text { of students in Group } 2 \text { (lowest ability level), } 44 \text { \% }
\end{aligned}
$$
indicated a high preference for structure, and 318 had a high preference for learning in late morning. Also, $38 \%$ indicated a low preference for a warm environment when studying. A low preference (25\% each) was evidenced for bright light, learning in several ways, mobility, and parent-figure motivation.

of students in Group 3 (highest ability level), 708 indicated a high preference for responsibility, 37 showed a high motivation level, and $33 \%$ were parent-figure motivated. In addition, preferences were shown for structure (30\%), learning in the afternoon, and bright light ( $26 \%$ each). A low preference was shown for intake (41\%), a warm environment, and a high noise level (33t each). 


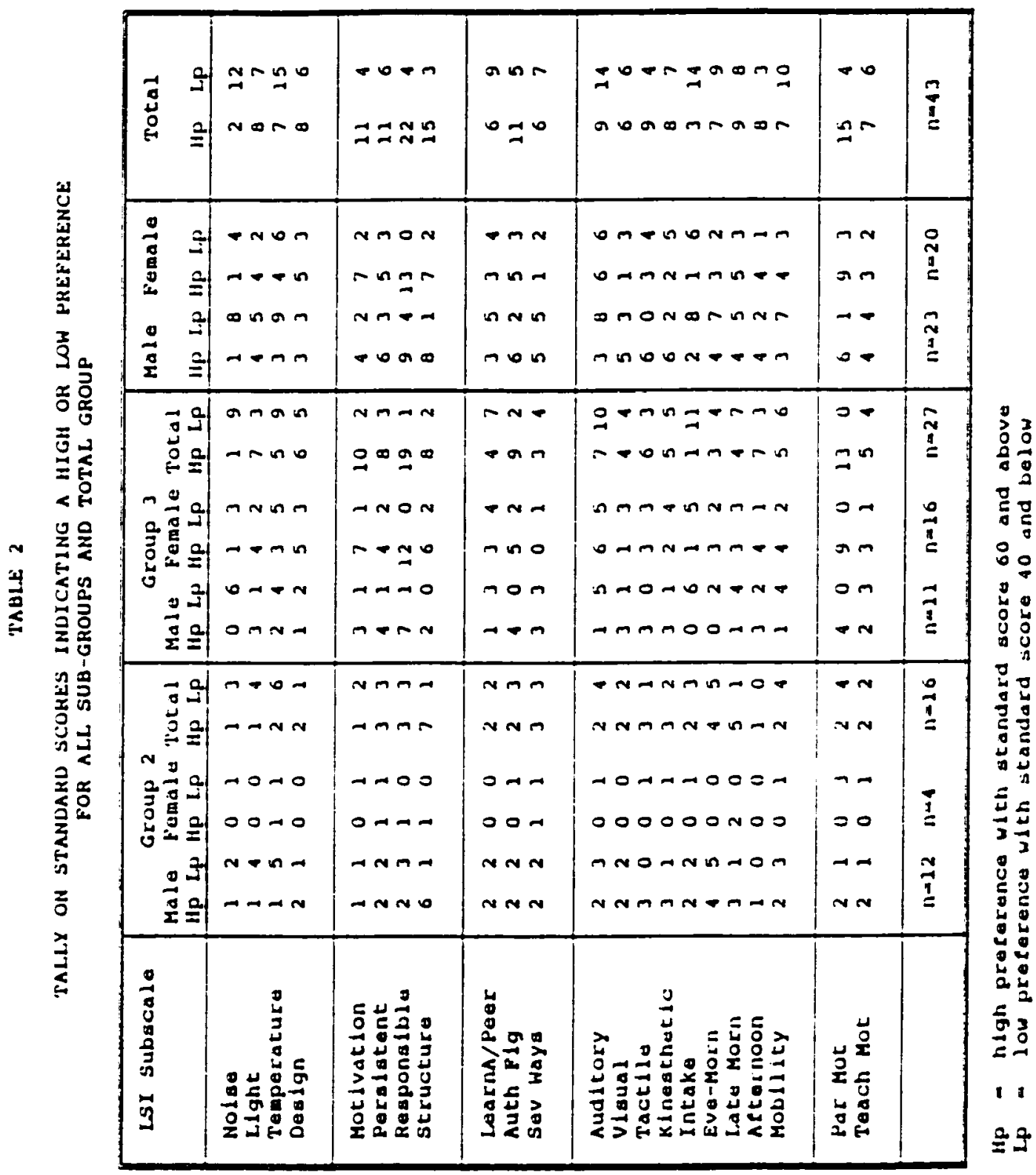


With the exception of a low preference for mobility in the lower-achieving group, it was interesting that these findings are largely in agreement with characteristics of high- and low-achievers found by Dunn in 1979:

Children who read poorly seemed to like working in the midst of activity and noise. They liked learning either with classmates or with the teacher on a one-to-one basis. Strangely, they seemed to like dim rather than bright light, and worked longest on the floor, carpeting, pillows, in an easy chair, and in extremely nonconforming poses. . . . Conversely, academic achievers preferred learning in conventional seats, with bright light, in quiet. often by themselves, and rarely wanted food or liquid intake. (cited in Dunn \& Bruno, 1985, p. 10)

Indeed, there were marked differences in the learning styles of students in the two groups. Perhaps these differences are a cause for the ability grouping that was in place in the school. While this is probably somewhat true, the differences may be intensified as a result of the grouping and the motivation levels that indubitably accompany feelings of success or lack of success.

Males and Females

Total Group

More than one third of the total males indicated a high responsibility level (39\%) and preference for structure (35\%). Also, more than one third showed a low preference for a warm environment (398) and for noise, learning auditorily, and intake (35t each). A low preference was 
also shown for mobility (308).

of total female respondents, $65 \%$ evidenced a high responsibility level. Forty-five percent indicated that they were parent-figure motivated, and $35 \%$ indicated a high motivation level. A low preference was shown for a warm envizonment and intake while studying ( 30 f each).

Although males and females did not differ in their low preferences for a warm environment and intake while studying, females in this study appeared to exhibit a substantially higher responsibility level (65\% for females compared to $39 \%$ for males), motivation level (35\% for females, 17 for males), and level of parent-motivation (45\% for females, $26 \%$ for males). While motivation deals with the desire to achieve academically, responsibility "involves students' desire to do what they think they ought to do" and is related to conformity (Dunn et al., 1987, p. 7). In this case, Eemales' high preferences for both responsibility and parent-motivation seem to indicate external control of their learning.

This finding has been substantiated in the general Iiterature; Hoffman (1972) suggested that girls' school achievements result, at least in part, from their desire to please, while boys appear more interested in working on tasks that interest them and are less concerned about earning approval (cited in Biehler \& Snowman, 1990). In her 
dissertation, Lam-Phoon (1986) concluded that males tend to be more field independent (internally controlled, abstract thinkers) and females, field dependent (externally controlled, concrete thinkers). It is a common perception that these differences are not innate, but rather the result of parental and teacher expectations for the two genders (Biehler \& Snowman, 1990). Hopefully, cognizance of these differences will lead to conscious efforts to treat the two groups equaliy.

Another area of difference merits discussion. Twenty-two percent of the males indicated a strong preference for learning in several ways (i.e., needing variety in working: alone, with peers, or with an authority figure), while only 5 of females indicated such. Also, modality preferences were more evenly divided among males (13\% auditory, $22 \%$ visual, $26 \%$ tactile, and $26 \%$

kinesthetic), while females were largely auditory (30\%) and had much smaller preference percentages among the other areas (5t visual, $15 t$ tactile, 10 kinesthetic). The findings imply that for these students, females might be more satisfied with eraditional lecture or direct instruction type of methodologies, whereas males' style needs would be better met with variation in both sociological and physical stimuli. 


\section{Separate Groups}

Interesting findings resulted when preferences of males and females in the separate groups were examined.

of 12 males in Group 2 (the lowest ability level), 50\% indicated a high preference for structure and 338 , a high preference for learning in the morning. A warm environment was a low preference for $42 \%$ and bright light for 338 of these students. Of 4 females in this group, 50 \% had a high preference for learning in the late morning, and 25 for elements within the emotional stimulus category (persistence, responsibility, structure). Low preferences (25\%) were indicated for such areas as noise, learning in several ways, tactile and kinesthetic learning, and mobility.

of 11 males in Group 3 (the highest ability level), $64 \%$ evidenced a high preference for responsibility. Persistence, parent-motivation, and learning near authority figures were shown to be high preferences for $36 \%$. Low preferences were demonstrated for both noise during study and intake ( $55 \%$ each). There were 16 females in this group; seventy-five percent had a high preference for responsibility and 56\%, a high preference for being parentmotivated. A low preference was indicated for a warm environment, learning auditorily, and intake (31s each).

A close examination of the above reveals that there 
were more preference similarities than differences between high- and low-achieving males. Not specific elements, but rather the emotional stimulus category was a high preference for both; likewise, the environmental stimulus category includes elements that were low preferences for both. Concerning differences, time of day was more important to low-achieving males, while learning near an authority figure was significant for high-achieving males.

The small number of females in the lower-achieving group ( $n=4)$ makes comparisons difficult. However, high- and low-achieving females appear to have similar high preferences for the emotional elements. Low preferences for specific elements differed between the two groups; yet, most of these low preferences fell within the physical stimulus category (e.g. mobility, intake).

It can be concluded that for this group of students, there were more learning style differences between high- and low-achievers in general and also between the genders in general than there were between high- and low-achieving students of the same gender. As previously mentioned, these differences may be a result of experience and education in the American culture.

While the findings for this group may not generalize to the population at large, awareness of the possible effects of teachers' management, skills, strategies, and 
expectations is of considerable importance. Furthermore, given the differences that may exist, flexibility and variation in classroom practices are keys to accommodating the many kinds of learners present in any school setting.

\section{Total Group}

A high responsibility level was indicated by more than one half (5I\%) of the group. A high preference for structure and being parent-figure motivated was shown by more than one third ( 35 each) of the total group. Among the outstanding low preferences were a need for a warm environment (35\%), intake while studying (33\%), and learning auditorily $(338)$.

\section{Treatment Procedure}

During the second quarter of the school year (beginning October 28, 1991), students were exposed for 8 weeks to the treatment conditions described above. Students in the control group continued to receive instruction, study, and complete homework in their usual manner, some using a grade-5-level book and some using a grade-6-level book. Modified instruction for the two experimental groups, provided by the researcher, was based on the respective group's perceptual preference responses on the Learning Style Inventory. Table 3 summarizes these responses by percentage for the two groups. 
TABLE 3

PERCEPTUAL PREFERENCES OF EXPERIMENTAL GROUPS BY PERCENTAGE

\begin{tabular}{lll} 
& Group 2 & Group 3 \\
\hline Auditory & 12.50 & 25.93 \\
Visual & 12.50 & 14.81 \\
Tactile & 18.75 & 22.22 \\
Kinesthetic & 18.75 & 18.52 \\
Total & 62.50 & 81.48 \\
\hline
\end{tabular}

These percentages were converted to fractions of a total weekly instructional time of 60 minutes (the same total amount of time the control group was receiving by their regular classroom teacher). Students and instructors met 3 days a week for 20 minutes each day.

Table 4 presents a summary of time spent in instruction according to each modality area. (The total preference percentages do not sum to $100 \%$ because not everyone has a definite modality preference as indicated by a score of 60 or over on the Learning Style Inventory.) 
TABLE 4

WEEKLY INSTRUCTIONAL MINUTES OF EXPERIMENTAL GROUPS ACCORDING TO PERCEPTUAL PREFERENCES

\begin{tabular}{|c|c|c|}
\hline & Group 2 & Group 3 \\
\hline Auditory & 12 & 19 \\
\hline Visual & 12 & 11 \\
\hline Tactile & 18 & 16 \\
\hline Kinesthetic & 18 & 14 \\
\hline Total & 60 & 60 \\
\hline
\end{tabular}

According to Rita Dunn, sequencing is crucial to learning through perceptual strengths; students should be introduced to new material through their modality preferences and reinforced through secondary or tertiary modalities (1988a). Thus, the order of activities varied during the 8 weeks so that each of the four modality areas twice constituted introductory material. Students' creation of a product related to the lesson (the final step in this sequence according to Dunn) was implemented through homework assignments (further discussed in the "Homework" section below).

Utilizing respective spelling lists (Group 2 used Eifth-grade-level words and Group 3 used sixth-grade-level words), specific activities were identical for the two 
groups. A Minnesota Educational Computing Corporation (MECC) software program, "Spelling Puzzles and Tests" (1990), generated several types of worksheets which were used. Other materials, as suggested by Dunn and Dunn (1978), were handmade. The particular activities described below fit generally into modality categories. However, it is difficult to isolate modality involvement. For example, most games involve visual and auditory elements as well as the tactile or kinesthetic.

\section{Classroom Activities}

Auditory activities included lecture and discussion of common elements of words, presenting definitional clues to students about words which they then had to identify and spell, oral presentation of incomplete sentences in which students had to use context clues to identify the missing spelling word, and having students repeat the spelling of a word they had heard.

Visual activities included "Hangman," word searches, scrambled words activities, configuration clues (with and without context), imbedded spelling words, natching exercises, and language experience activities (see examples in Appendix C).

Tactile exercises are often game-like in nature. These included Bingo, spelling Pictionary, concentration, witing words in sugar, witing words several times each, 
and a hands-on activity in which students unscrambled cut-up letters representing spelling words. As suggested by Dunn and Dunn (1986), students also used "task cards," "flip chutes," and "pik-a-holes." Task cards are small rectangular papers cut into two sections (puzzle-like); on one side is a spelling word which the student must match with the definition on the other side. Flip chutes are computer-like cardboard devices into which students enter a card with a question; they write the answers down and the chute provides for self-correction. Pik-a-holes are also self-correcting mechanisms involving touching and manipulation.

Kinesthetic activities involve whole-body movement. A floor map of a typewriter keyboard was used for students to step on letters of given spelling words. Well-known games such as Seven-Up, Charades, Four Corners, Baseball, and relays were modified to incorporate spelling.

\section{Class Reactions}

In general, the two classes' reactions to these activities varied radically.

Group 3 (the highest ability group) was cooperative and adjusted easily to any learning situation presented. This was probably facilitated by the fact that the environment produced by the auditory approaches that they preferred coincided with several other class preferences, 
like having an authority figure present and structure during study. Also, since the designated spelling time was $2: 20$ p.m., their preference for learning in the afternoon was met.

Classroom management of Group 2 (the lowest ability group) was much more unpredictable. This group had difficulty following directions and could not stay with the assigned task, particularly when playing games (tactile or kinesthetic activities). Many students were uncooperative with classmates, either not wanting to play with particular people or accusing others of playing incorrectly.

since the majority of instructional time was spent utilizing tactile and kinesthetic activities (as dictated by the larger percentages of high preferences in these areas on the group profile, as opposed to visual or auditory activities), a large part of their spelling lesson included many distractions. It was interesting that the very activities preferred by this group were the ones that seemed to cause disorder within the classroom situation.

However, it must be reiterated that although this group preferred these activities, they also preferred (by 448) a high degree of structure and had a low preference (25\%) for mobility. These preferences are not in harmony with the environment imposed by tactile/kinesthetic activities; this fact may have contributed to the behavior 
problems exhibited by this class. Furthermore, while 316 of this group preferred learning in the late morning, the time designated for spelling instruction was 2:45 p.m. Thus, although there was a match between perceptual preference and instructional method, this match and limitations imposed by the setting resulted in an unresolvable mismatch between various other learning style preferences of the group and the instructional situation.

It should also be pointed out that, at least for the second half of the research time, students were looking forward to the christmas holidays. This possibly did not facilitate concentration for either group, but added extra enthusiasm to an already excitable group of students in Group 2 .

Finally, and probably most important, it could be argued that the designation of ability groups is itself a factor which contributes to the self-esteem, motivation, and attitudes of the students involved. Surely, students who know they are in a "high" group are more likely to feel success and thus succeed; those in the "low" group have not met with much school success and may try to achieve recognition through other means, like poor behavior. The regular classroom teachers agreed with this perception and felt that this is an inherent problem with ability grouping. Whatever the cause or combination of causes, the 
96

environment during spelling instruction appeared to be much more conducive to learning in Group 3 than in Group 2 .

\section{Homework}

The same amounts and types of homework were given to the two groups during this time period. The focus of homework was usually the application of acquired spelling skills to creative writing in the form of sentences, stories (open and closed topics), letters, newspaper articles, and dialogues. Students were also required to study at home for tests.

Only Group 3 used their individual learning style prescriptions as an aid in completing homework. They were required to use them consistently and regularly, and were frequently asked how they felt about using them or if they were experiencing any difficulty. Although it took some prompting for students to return their homework forms, parents did verify each week the extent to which students followed their prescriptions (see sample verification form in Appendix A).

Again, students in Group 3 (the highest ability group) were much more consistent and responsible about completing homework. Recovering homework from Group 2 (the lowest ability group) was a continual dilemma for both the regular classroom teacher and the researcher. The teacher often had to withdraw recess periods or free time in order 
for students to complete homework. Due to the limited time and opportunity for follow-through on the part of the researcher, these particular consequences were impossible to apply (i.e., withdrawing students' recess periods would have infringed on the classroom teacher's planning time). However, when participation in the following day's activities was dependent upon complete homework, results were usually positive.

\section{Testing the Hypotheses}

This section includes a summary of the statistical analyses of data and the testing of the null hypotheses. The statistical program employed was BMDP2V, used for analysis of variance and covariance including repeated measures. The .05 level of significance was used as the level of confidence for all tests.

Group 1 constituted the "Control" group, Group 2 was the group receiving modified instruction ("Instructional" group), and group 3 was the "Individualized" group.

\section{Hypotheses $1-3$}

Hyoothesis 1. There is no significant difference between pretest and posttest achievement means of students in the Control Group.

Bypothesis 2. There is no significant difference between pretest and posttest achievement means of students 
in the Instructional Group.

Hypothesis 3 . There is no significant difference between pretest and posttest achievement means of students in the Individualized Group.

These hypotheses were initially analyzed by repeated measures analysis of variance (see means for sub-groups in Table 5 and ANOva tables in Tables 6,7 , and 8). In addition, a priori tests were run to compare the combination of the three pretests against the combination of the eight posttests (see results in Table 9). According to Winer, "The a priori type is always justified whether or not the overall $\mathrm{F}$ is significant" (1971, p. 196). The statistic used in the a priori test has the general form:

$$
F=\frac{n\left(\Sigma c_{f} \bar{x}_{f}\right)^{2}}{\Sigma c_{y}^{2} \cdot M S_{\text {orfor }}}
$$

where $\Sigma c_{j}=0$ (winer, p. 175). 
TABLE 5

PRE- AND POSTTEST MEANS FOR CONTROL, INSTRUCTIONAL, AND INDIVIDUALIZED GROUPS

\begin{tabular}{llll}
\hline Test & $\begin{array}{c}\text { Control } \\
(n=22)\end{array}$ & $\begin{array}{c}\text { Instructional } \\
(n=16)\end{array}$ & $\begin{array}{c}\text { Individualized } \\
(n=27)\end{array}$ \\
\hline 1 & 90.41 & 82.56 & 79.33 \\
2 & 89.77 & 87.0 & 84.0 \\
3 & 91.77 & 68.75 & 84.48 \\
4 & 93.82 & 74.31 & 87.48 \\
5 & 88.18 & 77.44 & 94.26 \\
6 & 91.27 & 97.0 & 93.93 \\
7 & 90.82 & 71.31 & 97.89 \\
8 & 86.73 & 84.94 & 93.89 \\
9 & 93.36 & 75.38 & 85.85 \\
10 & 90.05 & 82.13 & 86.19 \\
11 & 91.5 & 67.5 & 89.32 \\
Marginal & 90.74 & 78.94 & \\
Pretests $=$ & Tests $1-3$ & & \\
Posttests $=$ & Tests 4-11 & &
\end{tabular}

TABLE 6

REPEATED MEASURES ANOVA TABLE FOR CONTROL GROUP

\begin{tabular}{lccccc}
\hline $\begin{array}{l}\text { Source of } \\
\text { Variation }\end{array}$ & $\begin{array}{c}\text { Sum of } \\
\text { Squares }\end{array}$ & $\begin{array}{c}\text { Degrees of } \\
\text { Freedom }\end{array}$ & $\begin{array}{c}\text { Mean } \\
\text { Square }\end{array}$ & $\begin{array}{c}\text { Calculated } \\
\text { F-Ratio }\end{array}$ & $\begin{array}{c}\text { Tail } \\
\text { Prob. }\end{array}$ \\
\hline $\begin{array}{l}\text { Ach. Test } \\
\text { Error }\end{array}$ & $\begin{array}{r}997.47934 \\
15338.15702\end{array}$ & $\begin{array}{c}10 \\
210\end{array}$ & $\begin{array}{l}99.74793 \\
73.03884\end{array}$ & 1.37 & .1980 \\
\end{tabular}


TABLE 7

REPEATED MEASURES ANOVA TABLE FOR INSTRUCTIONAL GROUP

\begin{tabular}{lccccc}
\hline $\begin{array}{l}\text { Source of } \\
\text { Variation }\end{array}$ & $\begin{array}{c}\text { Sum of } \\
\text { Squares }\end{array}$ & $\begin{array}{c}\text { Degrees of } \\
\text { Freedom }\end{array}$ & $\begin{array}{c}\text { Mean } \\
\text { Square }\end{array}$ & $\begin{array}{c}\text { Calculated } \\
\text { F-Ratio }\end{array}$ & $\begin{array}{r}\text { Tail } \\
\text { Prob. }\end{array}$ \\
\hline Ach. Test & $\begin{array}{l}12474.125 \\
28147.14773\end{array}$ & 150 & $\begin{array}{r}1247.41250 \\
187.64765\end{array}$ & 6.65 & $<.00005$ \\
Error & & & & & \\
\end{tabular}

TABLE 8

REPEATED MEASURES ANOVA TABLE FOR INDIVIDUALIZED GROUP

\begin{tabular}{lccccc}
\hline $\begin{array}{l}\text { Source of } \\
\text { Variation }\end{array}$ & $\begin{array}{c}\text { Sum of } \\
\text { Squares }\end{array}$ & $\begin{array}{c}\text { Degrees of } \\
\text { Freedom }\end{array}$ & $\begin{array}{c}\text { Mean } \\
\text { Square }\end{array}$ & $\begin{array}{c}\text { Calculated } \\
\text { F-Ratio }\end{array}$ & $\begin{array}{r}\text { Tail } \\
\text { Prob. }\end{array}$ \\
\hline $\begin{array}{l}\text { Ach. Test } \\
\text { Error }\end{array}$ & $\begin{array}{r}9476.84175 \\
21827.34007\end{array}$ & $\begin{array}{r}10 \\
260\end{array}$ & $\begin{array}{r}947.68418 \\
83.95131\end{array}$ & 11.29 & $<.00005$ \\
\hline
\end{tabular}

TABLE 9

RESULTS OF A PRIORI TESTS FOR CONTROL, INSTRUCTIONAL, AND INDIVIDUALIZED GROUPS

\begin{tabular}{lcc} 
& F-Ratio & Probability \\
\hline Control & 0.011 & .913 \\
Instructional & 0.087 & .766 \\
Individualized & 59.76 & $<.00005 *$ \\
\hline = significant & &
\end{tabular}


101

Results of the ANOVA tables indicate that for the Control Group, the F-ratio of 1.37 was not significant at the .05 level ( $p=.198)$. There were no significant differences among the 11 means. For the Instructional Group, the F-ratio of 6.65 was significant at the .05 level $(p<.00005)$. There were significant differences among the 11 means. For the Individualized Group, the F-ratio of 11.29 was significant at the .05 level $(p<.00005)$. There were significant differences among the 11 means for this group. Using means from Table 5 and the statistic in the a priori test as described above, the F-Ratio for the Control Group (seen in Table 9) was calculated in the following way:

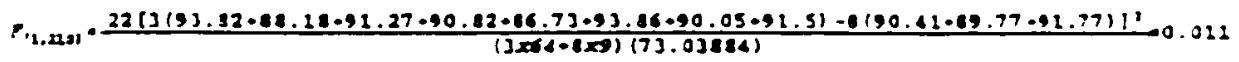

Since for the Control Group, $p=.913$, the F-ratio is not significant; thus, there were no significant differences between the eight posttests and three pretests. It can be seen that a similar result occurred for the Instructional Group. Therefore, Hypotheses 1 and 2 were retained. Since for the Individualized group, the eight posttests were significantly different from the three pretests, Hypothesis 3 was rejected.

Omega squared provides additional information 
concerning the relationship between the independent and dependent variables. This value was calculated as .02 for the Control Group, .26 for the Instructional Group, and .28 for the Individualized Group.

It is concluded that no significant changes in spelling achievement resulted when students either continued to learn/study in their usual manner or received modalitybased instruction. The former conclusion was anticipated. However, the latter is surprising since it contradicts much of the research which has been done in this area and which was cited in chapter 2. From Table 5, it is clear that the significant differences among the means (indicated in Table 7) were not between pretest and posttest blocks of tests, but rather within those two blocks.

As previously mentioned, the discipline problems in this class were extensive. According to the regular teachers, since the situation existed prior to the study, causation cannot be attributed to the research. It seems probable that difficulty was largely a result of the ability grouping already in place and the attitudes accrued by these students over the years. However, in examining the preferences of this class, it also appears that their problems may have been exacerbated by the inconsistency between tactile/kinesthetic activities and a desire for structure and little mobility. The inconsistency could not 
have been eliminated, but perhaps the environment could have been stabilized (i.e, objectives and directions clarified, unnecessary movement prevented) by involving the classroom teacher or other authority figures in supervision of small groups.

Regarding hypothesis 3 , it can be concluded that students' use of learning style prescriptions, in addition to receiving modified instruction, significantly affected spelling achievement. Several factors contributed to this end in this case. First, this was a high-ability class, noted for being cooperative and motivated; indeed, they were receptive to the researcher, instruction, and use of prescriptions. Second, in focusing on particular modality preferences in the classroom situation, the various other preferences of this group (e.g., structure, authority figure) happened to have been met, therefore enhancing the learning environment. Finally, the use of prescriptions resulted in complete individualization, which is difficult if not impossible to achieve in the classroom alone. When students attended to the most important elements of their learning style while studying, efficiency was markedly increased.

\footnotetext{
Although it appears that elements of personality, experiences, and style are intricately connected, the importance of students' awareness of how they best study and
} 
the ability to monitor their habits and environment cannot be underestimated. The implication is that these components of metacognition are extremely important and should be directly taught and regularly incorporated as a part of all content areas. Students' involvement in their own learning is a key to individualization and increases in achievement.

\section{Hypothesis 4}

Hypothesis 4. There is no significant difference among adjusted posttest means of the three groups where the posttest is adjusted for pretest means.

Hypothesis 4 was initially tested by 3-way analysis of covariance with the total of the three pretests as covariate (basic assumptions of ANCOVA, including homogeneity of regression, were examined). The three dimensions were treatment, gender, and the sum of the eight posttests as a repeated measure. (See original means in Table 10, adjusted means in Table 11, and ANCOVA Table in Table 12.)

From the ANCova table, it can be seen that the first covariate was meaningful (i.e., the sum of the three pretests did significantly adjust the posttest means). However, there was a significant interaction between posttest and group $(p<.00005)$ and also between posttest and gender $(p=.0128)$. Therefore the main effects were ignored and 1-way analysis of covariance was run for the separate posttests to examine the simple effects (see Table 13). 
TABLE 10

ORIGINAI MEANS EOR CONTROL, INSTRUCTIONAL, AND INDIVIDUALIZED GROUPS BY GENDER

\begin{tabular}{|c|c|c|c|c|c|c|}
\hline \multirow{2}{*}{$\begin{array}{l}\text { Post- } \\
\text { tests }\end{array}$} & \multicolumn{2}{|c|}{ Control } & \multicolumn{2}{|c|}{ Instructional } & \multicolumn{2}{|c|}{ Individualized } \\
\hline & Male & Eemale & Male & Eemale & Male & Eemale \\
\hline \multirow{9}{*}{$\begin{array}{l}1 \\
2 \\
3 \\
4 \\
5 \\
6 \\
7 \\
8\end{array}$} & 92.2 & 95.17 & 72.42 & 80.0 & 85.82 & 88.63 \\
\hline & 85.5 & 90.42 & 71.5 & 95.25 & 93.45 & 94.81 \\
\hline & 93.2 & 89.67 & 96.33 & 99.0 & 93.82 & 94.0 \\
\hline & 91.2 & 90.5 & 71.33 & 69.75 & 99.0 & 97.13 \\
\hline & 84.8 & 88.33 & 82.42 & 92.5 & 94.64 & 93.38 \\
\hline & 97.5 & 90.83 & 72.83 & 83.0 & 85.18 & 86.31 \\
\hline & 89.1 & 90.83 & 83.42 & 78.25 & 93.55 & 96.31 \\
\hline & 89.7 & 93.0 & 64.17 & 77.5 & 83.45 & 88.06 \\
\hline & $n=10$ & $n=12$ & $n=12$ & $n=4$ & $n=11$ & $n=16$ \\
\hline
\end{tabular}

TABLE 11

3-WAY ANCOVA: ADUUSTED MEANS EOR CONTROL, INSTRUCTIONAL AND INDIVIDUALIZED GROUPS BY GENDER

\begin{tabular}{|c|c|c|c|c|c|c|}
\hline \multirow{2}{*}{$\begin{array}{l}\text { Post- } \\
\text { Lests }\end{array}$} & \multicolumn{2}{|c|}{ Control } & \multicolumn{2}{|c|}{ Instructional } & \multicolumn{2}{|c|}{ Individualized } \\
\hline & Male & Eemale & Male & Eemale & Male & Eemale \\
\hline $\begin{array}{l}1 \\
2 \\
3 \\
4 \\
5 \\
5 \\
7 \\
8\end{array}$ & $\begin{array}{l}88.14 \\
81.44 \\
89.14 \\
87.14 \\
80.74 \\
93.44 \\
85.04 \\
85.54\end{array}$ & $\begin{array}{l}92.98 \\
88.23 \\
87.48 \\
88.31 \\
86.14 \\
88.64 \\
88.64 \\
90.81\end{array}$ & $\begin{array}{r}76.26 \\
75.34 \\
100.18 \\
75.68 \\
86.26 \\
76.68 \\
87.26 \\
68.01\end{array}$ & $\begin{array}{l}78.65 \\
93.9 \\
97.65 \\
68.4 \\
91.15 \\
81.65 \\
75.9 \\
76.15\end{array}$ & $\begin{array}{c}89.58 \\
97.21 \\
97.58 \\
102.76 \\
98.4 \\
88.94 \\
97.31 \\
87.21\end{array}$ & $\begin{array}{l}87.67 \\
93.86 \\
93.05 \\
96.17 \\
92.42 \\
85.36 \\
95.36 \\
87.11\end{array}$ \\
\hline & $n=10$ & $n=12$ & $\mathrm{n}=12$ & $n=4$ & $n=11$ & $n=16$ \\
\hline
\end{tabular}


106

TABLE 12

3-WAY ANCOVA TABLE

\begin{tabular}{|c|c|c|c|c|c|}
\hline $\begin{array}{l}\text { Source of } \\
\text { Variation }\end{array}$ & $\begin{array}{l}\text { Sum of } \\
\text { squares }\end{array}$ & $\begin{array}{l}\text { Degrees of } \\
\text { Freedom }\end{array}$ & $\begin{array}{l}\text { Mean } \\
\text { Square }\end{array}$ & $\begin{array}{l}\text { Calculated } \\
\text { F-Ratio }\end{array}$ & $\begin{array}{l}\text { Tail } \\
\text { Prob. }\end{array}$ \\
\hline G & 8664.55603 & 2 & 4332.27802 & 10.68 & $<.0001$ \\
\hline $\mathbf{s}$ & 22.93914 & 1 & 22.93914 & .06 & .8129 \\
\hline GS & 1021.74254 & 2 & 510.87127 & 1.26 & .2915 \\
\hline lst Cov. & 14923.64449 & 1 & 14923.64449 & 36.78 & $<.00005^{\star}$ \\
\hline Error & 23531.87748 & 58 & 405.72203 & & \\
\hline $\mathbf{P}$ & 4406.10943 & 7 & 629.44420 & 7.53 & $<.00005 \star$ \\
\hline PG & 8918.75849 & 14 & 637.05418 & 7.62 & $<.00005 *$ \\
\hline PS & 1512.33475 & 7 & 216.04782 & 2.58 & $<.0128 *$ \\
\hline PGS & 1561.11480 & 14 & 111.50822 & 1.33 & .1837 \\
\hline Error & 34519.93106 & 413 & 83.58337 & & \\
\hline
\end{tabular}

TABLE 13

SUMMARY OF ANCOVA FOR SEPARATE POSTTESTS

(ADJUSTED MEANS)

\begin{tabular}{|c|c|c|c|c|c|}
\hline Posttest & Control & Instruct. & Individ. & $F(2,61)$ & $P$ \\
\hline 1 & 90.39 & 77.18 & 88.57 & 5.91 & $<.0045$ \\
\hline 2 & 85.68 & 79.53 & 95.06 & 7.62 & $<.0011$ \\
\hline 3 & 88.84 & 99.04 & 94.7 & 10.26 & $<.0001$ \\
\hline 4 & 87.15 & 74.39 & 99.06 & 13.16 & $<.00005$ \\
\hline 5 & 85.18 & 86.23 & 94.38 & 5.78 & $<.0050 x$ \\
\hline 6 & 89.73 & 78.83 & 87.17 & 5.12 & $<.0088$ \\
\hline 7 & 87.82 & 33.99 & 95.89 & 10.90 & $<.0001$ \\
\hline 8 & 88.23 & 70.24 & 87.23 & 14.56 & $<.00005 *$ \\
\hline
\end{tabular}

Reproduced with permission of the copyright owner. Further reproduction prohibited without permission. 
From Table 13, it can be seen that all F-ratio's were significant. The null hypothesis was therefore rejected, since there were significant differences among the groups.

The Newman-Keuls a posteriori tests were additionally done to examine where the differences between ranked means lay. Specific results indicated that the Individualized Group had significantly higher scores than both the Control and Instructional Groups in four of the eight sets of posttests (second, fourth, fifth, and seventh), higher scores than the Instructional Group only in an additional three sets (first, sixth, and eighth), and higher scores than the control Group only in one other instance (third). The Instructional Group was significantly higher than both of the other two groups in only one of the eight sets (the third) and was never significantly higher than either group alone. At no time did the control Group score significantly higher than both the Instructional and Individualized Group; it did, however, score significantly higher than the Instructional Group in four instances (first, fourth, sixth, and eighth).

The Newman-Keuls tests are vital in pinpointing exactly where the significant differences (identified by 1way ANCOVA) existed. These results emphasize that modalitybased instruction alone was not enough to increase 
achievement in this study. Rather, benefits were seen by the independent application of learning style prescriptions by students who were additionally receiving modified classroom instruction. These students scored consistently higher than those in one or both of the other two groups throughout the 8-week period.

\section{Qualitative Observations}

At the conclusion of the 8-week treatment period, students in all three classes were issued an evaluation form (see forms in Appendix A).

More than two thirds of students in all classes indicated that they liked how their spelling class was taught during this period of time $170 \%$ in the control Group; 738 in the Instructional Group; $68 \%$ in the Individualized Group). Specific comments from both the Instructional and Individualized Groups in answer to the question, "Did you like the way your spelling class was taught during the last eight weeks?" and "Did the instruction help you?" follow.

$$
\text { Reactions to Classroom Instruction }
$$

\section{Instructional Group}

Thirty-eight percent of the positive comments from this group related to their enjoyment of the activities:

"Yes, because it was very fun. It helped ne learn a lot in spelling." 
"Yes, I liked it. It helped me because we had a lot of fun and games and it is fun to learn when you do fun stuff like games."

"Yes, I did like it because it was fun and we always played games and stuff."

Two other positive comments (24z) were general in nature, simply indicating that they liked the class and that it had helped them learn more. Additional comments were related to homework (e.g., "Yes, I did. You told us to study. . . My parents try to help me but they never get around to it. So it helped a lot."), to classroom management (e.g., "Yes, I liked it because you could control the class."), and to an attitude change on the part of the student ("Yes, because I learned to care about spelling tests.").

of 3 negative comments, 1 did not indicate a particular dislike, 1 was related to homework ("I did not like getting a lot of homework. I already got too much homework."), and the last to methodology ("Well, I like to work independently, but the games were okay! I wasn't helped a lot because I do better when I write five times each.") .

That two thirds of the students in the Instructional Group were positive was surprising in light of the reactions exhibited both during class time and in response to homework. Evidently, their behavior was not indicative of their dislike for the teaching and/or activities. 
Individualized Group

Concerning classroom instruction, 8 of the 17

positive responses (47\%) from this group related to the

methodology. Some examples were:

"Yes, I liked the activities."

"Yes, I thought it was fun to play and learn at the same time."

"Yes, I did because you played games with us and didn't just give us homework."

Seven responses were general in nature (e.g., "Yes, I did like the class. It helped with my spelling."). The last two students indicated that they liked the class because they got higher grades on their tests.

Negative responses from this group related to the amount of homework given. Further discussion on this is included in the next section.

\section{Reactions to Prescriptions}

Students in the Individualized Group were also

asked: "Did you like to study spelling according to your learning style prescription? Tell why you were or were not helped by having a prescription for studying."

A positive response was given by 56 of this group. of these 14 positive responses, 8 (57\%) were general in nature, 2 ( $14 \%$ ) indicated that using the prescription had improved their grades, and another 4 (298) were particular about a part of the prescription that they liked:

"It was much more relaxing and easier." 
"Yes. - because I like to lay down in soft areas, not hard. I found that I needed light."

"Yes, because I got to watch TV while doing homework."

"I liked my prescription because I like to sit on the floor."

of 11 negative responses, 7 did not specify why they didn't like the prescriptions, 3 stated that they were already studying in the way that their prescription suggested (e.g., "I basically was following my prescription before I had it."), and 1 said that using the prescription made them feel "uncomfortable."

As stated, just over one half (56\%) of the Individualized Group indicated that they liked to study according to their learning style prescriptions. The attitude of those who did not respond favorably could be due to a reluctance to change practices when their perception, in general, was that they were already doing well. Also, since the focus for this group was largely on homework and on completing it in an expeditious manner, it may have seemed to them that their homework now involved extra "work."

\section{Parent Reactions}

A random sample of 8 parents of students in this group were asked their opinion concerning the effectiveness of the program and reactions of their children. All felt that the study was extremely valuable in that students were being shown how to study early in their school experience. 
112

One half of those polled indicated that their children were not positive about the homework that was involved.

\section{Summary}

This research examined the spelling achievement of fifth-grade students studying/learning in a traditional manner and that of students exposed to learning style prescription information and/or modality-based instruction. Three intact, ability-grouped classes comprised the sample. Four hypotheses were examined.

The first three hypotheses concerned the differences between pre- and posttest achievement means of students in three different treatment groups (Control, Instructional, and Individualized) and were tested using repeated measures analysis of variance and a priori tests.

The first two null hypotheses were retained. Since there were no significant differences between pre- and posttests, it is concluded that spelling achievement is not increased when students receive modality-based instruction. One conjecture for failure of modality-based instruction to produce significant results in this case concerned the behavior problems already evident in the Instructional Group which may have been largely attributable to ability grouping. These behavior problems created an environment which appeared to be unfavorable for learning. Thus, 
experience, personality, and learning style affect each other in complex and critical ways.

since for the Individualized Group, the eight posttests were significantly different from the three pretests, the third null hypothesis was rejected.

When students followed an individualized learning style prescription for studying and completing spelling homework (one aspect of metacognition), their achievement was increased. Like the Instructional Group, the behavior of this group probably influenced the results, but in a positive manner. Cooperative and motivated, they responded well to implementation of the changes.

The fourth hypothesis dealt with the differences among posttest means that had been adjusted for pretest means. A I-way analysis of covariance for each posttest was run to examine the simple effects. Since there were significant differences among the groups, the fourth hypothesis was rejected. Newman-Keuls tests were also done to examine differences among ranked means. The value of individualization was again emphasized by the fact that in four of the eight sets of scores, the Individualized Group was significantly higher than both of the other two groups. In one instance, the Instructional Group was higher than both of the other two; at no time did the control Group score significantly higher than both of the other two. 
CHAPTER $V$

SUMMARY, CONCLUSIONS, IMPLICATIONS, AND RECOMENDATIONS

\begin{abstract}
This chapter presents a summary of the research project including the general purpose, overview of related literature, description of the population sample, research design, instrumentation, and discussion of findings. Following this are conclusions, implications, and recommendations for further study.
\end{abstract}

\title{
Summary
}

Purpose

The purpose of this study was to examine the effects on spelling of modified instruction and complete individualization via learning style prescriptions when applied to fifth-grade students. It is hoped that the results will emphasize to elementary teachers the significance of student metacognition (i.e., knowledge of how one learns and self-monitoring while studying/learning) in increasing achievement, and the importance of taking a direct approach to helping students develop these skilis. 
Overview of Related Literature

The chapter which reported on literature and

research related to learning style was divided into six sections.

There is a difference between the terms "learning style" and "cognitive style" which were used synonymously in the literature prior to the 1980s. As defined by the National Association of Secondary School Principals (NASSP) task force which studied learning style in depth, this concept is very broad and incorporates the more specific cognitive, affective, and physiological dimensions. As only one component of learning style, cognitive style refers to the way one perceives, thinks, remembers, and problem solves.

Historically, the idea of individual differences in learning was considered over 2,500 years ago. However, most research has been conducted within this century. Within the field of psychology, researchers such as Jung (1923), Witkin (1962), Kagan (1964) studied various dimensions of personality types and how individuals learn. With the advent of mastery learning developed by $8100 \mathrm{~m}$ in the late 1960s, the learning styles field experienced a transition from psychological to educational focus. Since this time, researchers such as Rolb (1976), McCarthy (1980), Gregorc (1982a), Hill (1970), Hunt (1971), Dunn and Dunn (1978), 
116

Ramirez and Castaneda (1974), Letteri (1982), and Keefe and Monk (1986) have examined (to varying degrees) the three components of learning style in light of the educational implications.

There are many instruments which have been developed to assess learning style. Keefe (1982) and DeBello (1989) both developed taxonomies of instruments which directly collaborate with the present perception of learning style as outlined by the NASSP task force. Those that assess the cognitive component include the cognitive style Interest Inventory (Hill, 1976), Edmonds Learning style Identification Exercise (Reinert, 1976), Group Embedded Figures Test (Witkin, 1971), Inventory of Learning Processes (Schmeck et al., 1977), Learning Style Inventory (Kolb, 1976), and the Matching Familiar Figures Test (Kagan, 1964). Specific affective style instruments include the paragraph Completion Method (Hunt, 1971) and the Myers-Briggs Type Indicator (Briggs \& Myers, 1977). The assessment of affective style is also included in several other instruments which look at one or both of the other dimensions as well. No instrument deals with the physiological component alone. However, the Learning style Inventory (Dunn et al., 1975), the productivity Environmental Preference Survey (Price, Dunn, \& Dunn, 1979), and the NASSP Learning Style Profile (Keefe \& Monk, 1986) 
incorporate the physiological style dimensions as one aspect of their assessment. In fact, these three instruments are the only ones which are deemed multidimensional, including all three components of learning style as defined by the NASSP task force.

Much research has been conducted with the Learning Style Inventory by Dunn, Dunn, and Price. Studies dealing specifically with the environmental, emotional, sociological, and physical stimuli (four of the five categories which are a part of the Dunn and Dunn model of learning style) have largely yielded similar findings: matching instructional methods and environments to learning style preferences has positive achievement results. While psychological elements are not directly assessed by the LSI, several researchers have measured these traits (e.g., hemisphericity) via other instruments and correlated findings with learning style preferences.

In spite of the amount of literature in support of instructional matching, there continues to be some debate about this practice, particularly with regard to modality assessment and related instruction. Conclusions are difficult to derive from these challenges; this is largely due to differences of opinion among researchers regarding definitions, methodology, appropriate instrumentation, and instruction. 
There is a unique relationship between learning style and metacognition, which is made up of awareness and self-monitoring. Cognizance of learning style is a significant part of awareness; once this knowledge is attained, individuals are better equipped to monitor their own learning/study efficiency. Various studies have shown the importance of metacognition in raising achievement levels for students in both regular and special education. Although not studied extensively, these sxills have been linked to achievement in spelling. It is vital that teachers directly teach metacognitive skills to their students.

Sampling, Design, and Instrumentation

The sample for this study was comprised of 65 fifthgrade students in an elementary school in South Bend, Indiana. There were 33 males and 32 females. The sample was $97 \%$ Caucasian and $3 q$ Asian.

Three intact classes, previously grouped for language arts instruction by ability, were used for this quasi-experimental study, and were randomly assigned to treatment conditions. Group 1 (10 males, 12 females) was the control group studying/learning under normal circumstances; Group 2 (12 males, 4 females) was an experimental group receiving the Learning Style Inventory, an explanation of the group profile, and subsequent spelling 
instruction modified to match the group's perceptual preferences in which visual, auditory, tactile, and kinesthetic modality areas were each emphasized on the basis of the group profile; Group 3 (11 males, 16 females) was an experimental group receiving the Learning style Inventory, group profile information, modified instruction, and individual learning style prescription information (derived from Zenhausern's 1991 Homework Disc computer software program) for studying and completing spelling homework independently.

The instrument utilized in this study was the Learning Style Inventory by Dunn and others (1975). It was chosen because it is multidimensional (i.e., assesses the cognitive, affective, and physiological elements which comprise learning style) and is suitable for the elementary students involved in this study. The Learning style Inventory is relatively inexpensive and easy to administer.

\section{Discussion of Findings}

The findings of this study are summarized according to the four null hypotheses which were formulated and tested. The first three hypotheses dealt with the differences between pre- and posttest achievement means of students in the three treatment groups (Control, Instructional, and Individualized), and were tested by repeated measures analysis of variance and a priori 
tests (these tests are appropriate whether or not the overall $\mathrm{F}$ is significant). The fourth hypothesis considered differences among posttest achievement means that had been adjusted for pretest means. statistical testing initially included 3-way analysis of covariance with the total of the three pretests as covariate; because of significant interactions, 1-way analysis of covariance for each of the separate posttests was used to examine the simple effects. In addition, Newman-Keuls tests were completed where there was a significant F-ratio to consider differences among ranked means. The .05 level of significance was used as the level of confidence for all tests.

Hypothesis 1

There is no significant difference between pretest and posttest achievement means of students in the control Group.

This hypothesis was retained. Repeated measures analysis of variance initially revealed that there were no significant differences among the 11 means. Results of the a priori test for this group evidenced a probability level of .913 , indicating that there was no significant difference between the combination of the three pretests and combination of the eight posttests.

Thus, there was no change in student achievement in spelling when students were taught and continued to study in 
their usual manner. This result was anticipated.

\section{Hypothesis 2}

There is no significant difference between pretest and posttest achievement means of students in the Instructional Group.

This hypothesis was also retained. As shown by repeated measures analysis of variance, there were significant differences among the 11 means. However, results of the a priori test for this group revealed a probability level of .766 , indicating that there was no significant difference between the combination of the three pretests and combination of the eight posttests. The significant differences found in the initial test were within posttests and pretests rather than between them.

Thus, there was no change in student achievement in speling when instruction was modified to match the perceptual preferences of the group. As discussed in chapter 4, this finding can possibly be attributed to the fact that students in this Instructional Group were extremely difficult to manage. Control of behavior in all situations, particularly during their participation in tactile or kinesthetic games, was an on-going challenge. since the majority of instructional time was spent utilizing these kinds of activities (as dictated by the larger percentages of high preferences in these areas on the group 
profile), a large part of their instructional time was spent in classroom management.

It was hypothesized that these behavior problems could possibly be attributed to the inevitable mismatch between the environment created by attending to modality preferences and other elements preferred by a large percentage of the group (specifically structure and no mobility). However, since the behaviors existed prior to implementation of the study, it is more likely that they were due to the ability grouping already in place. As a lower achieving unit, this group had met with much frustration (and a resulting lack of motivation) in the course of their schooling that was difficult to counteract. Although the majority of these students indicated that they liked to learn in this new way, it must be concluded that classroom behavior and past experiences are complex issues that have a major impact on the success of educational change.

\section{Hypothesis 3}

There is no significant difference between pretest and posttest achievement means of students in the Individualized Group.

This hypothesis was rejected. Repeated measures analysis of variance revealed that there were significant differences among the 11 means. A probability level less 
than .00005 was revealed by the a priori test for this group, indicating that the eight posttests were significantly different from the three pretests. Thus, complete individualization of spelling learning and studying resulted in a significant increase in achievement for students in this group. Again, the fact that these students were cooperative and eager to learn in most any situation probably contributed to these findings. However, this does not impede emphasis of an important implication: making students aware of how they learn best and of ways to monitor their learning can have very beneficial results. This is the essence of metacognition which must be directly taught from an early grade throughout the school years.

\section{Hypothesis 4}

There is no significant difference among adjusted posttest means of the three groups where the posttest is adjusted for pretest means.

This hypothesis was also rejected. An initial testing by 3-way analysis of covariance revealed that the first covariate was meaningful (i.e., the sum of the three pretests did significantly adjust the posttest means, where p<.00005). However, since there was interaction between posttest and group $(p<.00005)$ and also between posttest and gender $(p=.0128)$, the main effects were ignored and 1-way 
analysis of covariance was run for the eight separate posttests to examine the simple effects. From these separate tests, all significant F-ratio's were determined, meaning that there were significant differences among the posttest scores of the three groups. The Newman-Keuls a posteriori tests were done for each set of ranked means to determine where the differences were. The fact that the Individualized Group had significantly higher scores than both the control and Instructional Groups in four of the eight sets of scores, while the Instructional Group was significantly higher than both of the other two groups in only one of the eight sets, stresses the achievement gains that are possible when students are taught to study according to their strengths in addition to receiving modality-based instruction. At no time did the control Group score significantly higher than both the Instructional and Individualized Groups.

\section{Conclusions}

From an analysis of the findings, the following conclusions were drawn:

1. Spelling achievement is not necessarily increased significantly through modified instruction with regard to perceptual preferences of low-ability, fifth-grade students. 
2. The spelling achievement of high-ability, fifthgrade students can be significantly increased when they follow an individualized program of study and learning via learning style prescriptions, in addition to receiving modified instruction in the classroom.

\section{Implications}

Three implications emerge from the findings of this study. First, while certain learning style traits are characteristic of both high- and low-achieving students, ability-grouping that is done to accommodate those differences may serve to reinforce them and, in fact. may create new attitudes and behaviors that determine how well or badly students react to change.

second, because of the complex interrelationships among learning style variables, one element should not be singled out for study. Doing so can create a mismatched environment with regard to other preferences, which undoubtedly affects learning.

Finally, complete individualization in the classroom through instruction and environmental changes is not practical. Students play a significant part in capitalizing on their own learning style strengths and enhancing their own learning. Pre- and in-service teachers should therefore be instructed on the benefits of metacognition and on showing students how to use their own learning style strengths. 
126

Recommendations for Further study

The following recommendations for further study are proposed, based on the findings and conclusions of this research:

1. In this study, modality-based instruction alone was not found to have a significant effect on achievement. This finding adds to the controversy on learning styles research, and seemingiy contradicts many studies done with the Dunn and Dunn model. This area needs to be further studied.

2. An area for further investigation is the difference between male and female achievement in spelling under the same three treatment conditions used in this study.

3. This study could be replicated with three classes that are not grouped by ability.

4. Another study should examine the effects of the individualized method with lower-ability students and modality-based instruction with higher-ability students.

5. An examination of the use of style prescriptions and/or modality-based instruction at the secondary level would be of considerable interest and importance. 
APPENDICES

Reproduced with permission of the copyright owner. Further reproduction prohibited without permission. 
APRENDIX A

PERMISSION AND CORRESPONDENCE EORMS

Reproduced with permission of the copyright owner. Further reproduction prohibited without permission. 


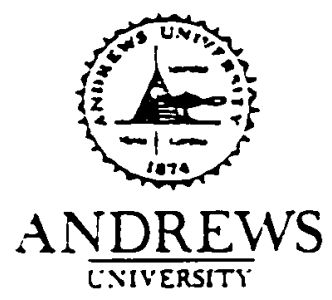

August 27, 1991

Vancy Turner

15633 Hunting Ridge Trail

Granger, IN 46530

Dear Nancy:

The Human Subjects Review Buard has reviewed your proposal, "Learning Styles: A Compurative Study of the Effects of Instructional Modification and Complete Individualization via prescriptions on the Spelling Achievement of Fifth Grade Students," under the exempr review procedure. You have been given clearance to proceed with your research plans. We wish you success on this project.

Sincerely

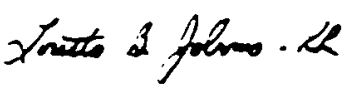

Loretri B. Johns

Assistint to the Director.

Office of Scholariv Research

$k r$

: Roy Naden

P.S. I would suggest that on the cover !etter or approval letter that is sent to the parent. that you include a statement of confidentiality and anonymity. This would be very heartening to many parents. 


\section{Prairie Vista Elementary School \\ 15400 Brick Road Granger. Indiana $\$ 6530.8749$ (219) 271.0055 James E. Hendress. Príncoal}

August 20. 1991

Office of Schoiarly Researcn

Haugney Hall. Rm. 136

Andrews University

Berrien Springs. MI $\div 9104-0355$

To Whom It May Concern:

This is to certify that Nancy Turner. dcctoral Student at Andrews University. has my permission to conduct research on the topic of learning styles at Prairie Vista Elementary School in Granger. Indiana. I understand that her research propect will extent from September through December. 1991.

\footnotetext{
Sincerely.

Oames E. Hewe

Principa!

Prairie Vista Elementary
}

Penn-plarris-Machsoll inhoul l.urporation 
Sept. 3, 1991

Dear parent.

As a doctoral student at Andrews University in

Berrien Springs, Mlchigan, I am investigating how seudents' learning styles can affect their spelling achievement. I strongly believe that the level of learning can be inproved through atcention to learning styles.

I have introduced myself to the fifth-grade students at Prairie Vista Elementary School, explained the nature of the research, and answered their questions. Attached are two copies of an Informed Consent Form, which will review the study for your son/daughter and vill outline it for you. I want to emphasize that all information will gemain confldential. Although the descriptions and findings nay be published, at no time will your child's name be used. please read over this lorm with your child. Keep the first copy attached to this letter and return the bottom copy, dated and signed by you and your child to your child's teacher by sept. 6 .

I have coneidence that participation in this

research will help your child learn how to learn and will maximize spelling achievement! If you have any questions, don't hesitate to call me at 277-3589.




Madrays University

Informetion and Consent Form

Dear student.

I have explained to you that as a doctoral student at Andrews University in Berrien Springs, Michigan, I am investigating how students' learning styles can affect theis spelling achievement. I am asking that you participace in my study! This simply involves my copying your spelling scores during a three-weak period in september and also during an eight-week period fror october through December. Nothing else is required of you! since your participation in this study is voluntary, you may withdraw at any time.

All information will remain confidential. Although the descriptions and lindings may be published, at no time dill your name be used.

There is no cost for participation in this study. Please sign (and also have your parent sign) in the appropriate space below. Return enis copy by sept. 6 to your teacher and keep the second copy for your zecords. 277-3589. If you have any further questions, please call ne at



To be signed by student:

I. , have read and understand the above seacement and have had all my questions answered. : have received a copy of this statement. I agree to participate in this study.

Subject's signature

Date

To be signed by parent:

My child, participare in this study. has permission to

Parent's signature Date

W1tness' signature Date

PLEASE RETURN THIS SIGNED COPY BY SEPT. 6. THANK YOU! 


\section{Andrevs University - school of Education Informed Consent Form}

We all know that everyone learns differently! lour special way of learning is your "learning style." As a student at Andrews University, I am researching how students learning styles can affect their performance on spelifing rests. The benef1t from this study nay be to help your teachers and you to know what can be done to inprove levels of learning.

I would like you to help we with my study!

participation in the study will include:

1. Answezing 104 questions on the Learning style Inventery (Duns, Dunn, and Price, 1975). This will Eequlze approximately 30 minutes of in-school time.

2. Receiving classroom results from the Learning style Inyentory.

3. Receiving experimental spelling instruction during an 8 week period (Oct. 28-Dec. 20) that is modified to match the learning style needs of the class. Spelling test scores from this period will be compared with scores from an earlier three-week period of zegular speling instruction.

4. Racelving training in utilization of learning style prescriptions derived from the Homework Dise

(Zenhausern, 1990) computer software program. These prescriptions will be used for independently completing spelling homework during the same 8-week period. Your parenes dill monitor and help you follow these prescriptions. since your participation in this project is

voluntary, you may withdray at any time.

All information will remain contidential. Although the descriptions and indings nay be published. at no tize will your name be used.

There is no cost lor participation in this study. If you have any fureber questions, please call me at 277-3589.

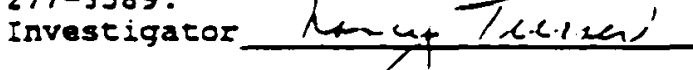

To be signad by studart:

I. have read and understand the above statement and have had all wy questions answered." I have received a copy of this statement. I agree to participate in this study. subject's siqnature

Date

To be signed by parant/guardian (please circle):

My child. in this seudy. I agree to monitor his/her spelling homework completed according to indlvidual learning style prescriptions, which will be sene home in october. I also ag: $3 e$ to complete ( 5 minutes completion time) a jeekly che jkitst on the extent to which he/she follows the prescription (fureher intormation will sollow).

Parent's signacure

Date 'itness' signacure Jace

PLEASE RETURN SIGNED SECOND COPY BY SEPT 5. MHANK YOU! 


\footnotetext{
Andzews Ualversity - gchool of Elucation Informed consent Fore
}

\begin{abstract}
We all know that everyone learns differently! your special way of learning is your "Learning style." As a student at Andrews University, I am researching how students' learning styles can affect their perforance on speliing tests. The benefit from this study aay be to help your teachers and you to know what can be done to improve levels of learning.

I would like you to help me with my seudy!

participation in the study will include:

1. Answering 104 questions on the learning style inventory (Dunn, Dunn, and Price, 1975). This will zequize approximately 30 minutes of in-school time.

2. Receiving classroom results from the learning style Inventory.

3. Recelving experisental spelling instruction during an 8week period (Oct. 28-Dec. 20) that will match the learning style needs of the class. Spelling test scores from this period will be compared with scores from an earlier tnrea-week period consisting of regular spelling instruction.

since your participation in this project is voluntary, you may withdraw at any time.

All information will remain contidential. Although the descriptions and lindings may be published, at no time will your name be used.

There is no cost sor participation in this study.

If you have any further questions, please call ge at

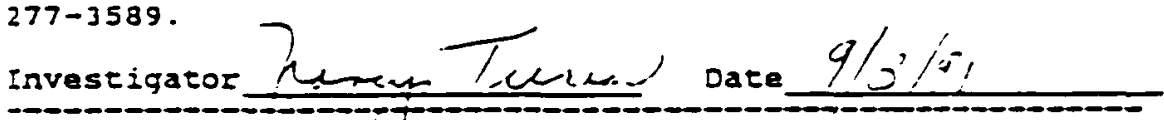
To be signed by stúdónt: I. Ibove statement and have had ali my questions answered." I bave received a copy of this statement. I agree to participate in this study.
\end{abstract}

Subject's signature

Date

To be signed by parent/guardian (please circle): My child. participate in this study. , has permission to

Parent's signature Date

Nitness' signature Date PLEASE RETURN SIGNED SECOND COPY $3 Y$ SEPT 5 . TMANK IOU! 

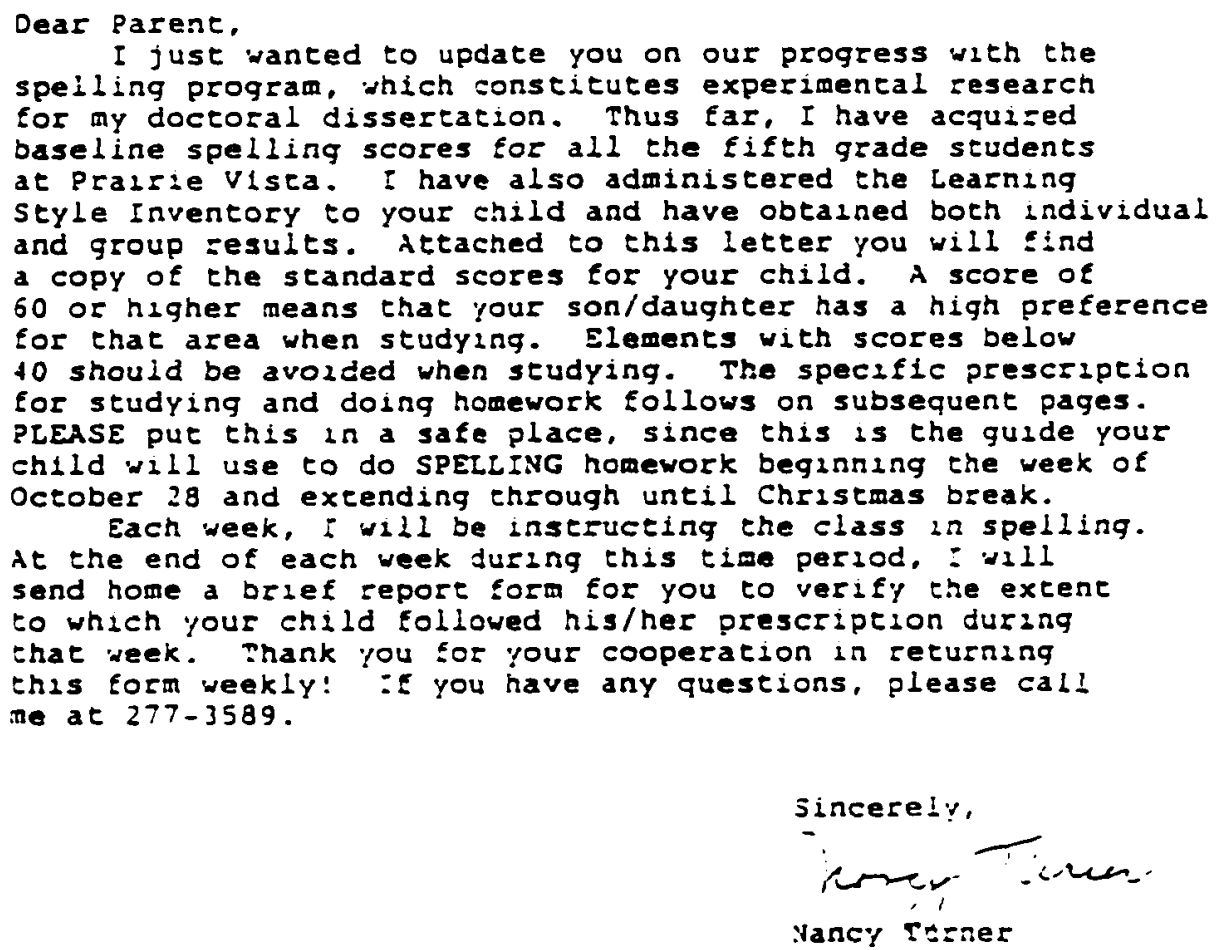


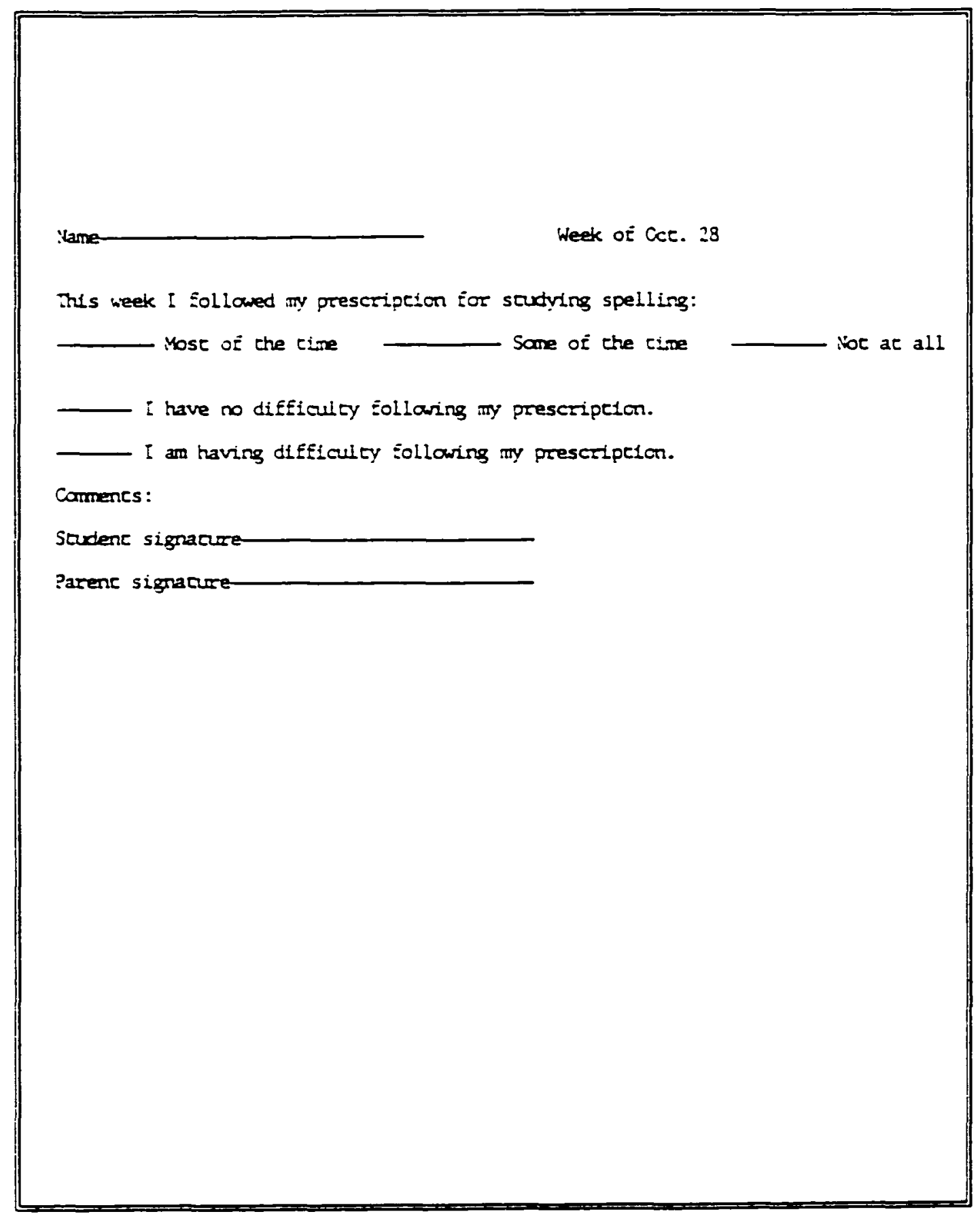




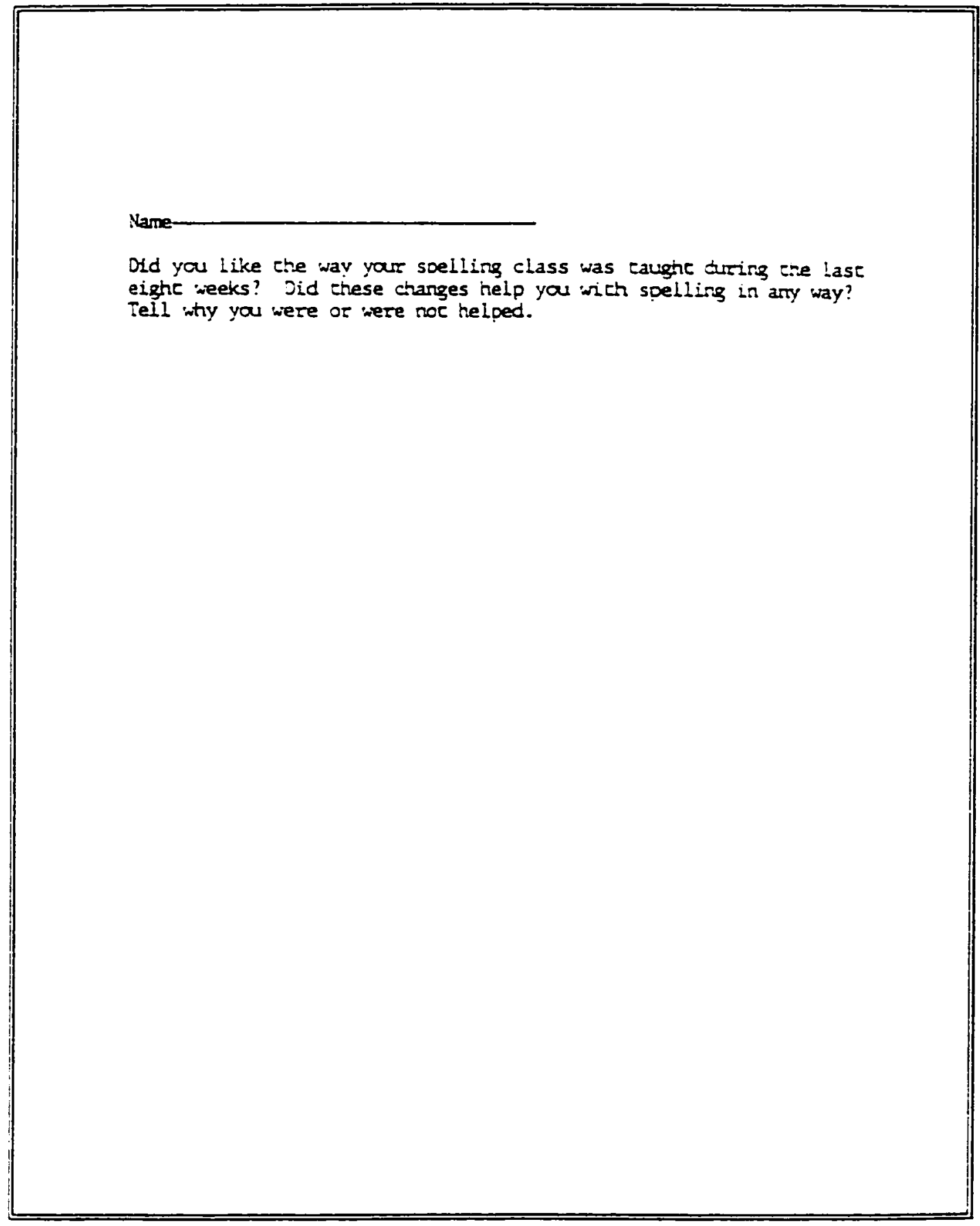




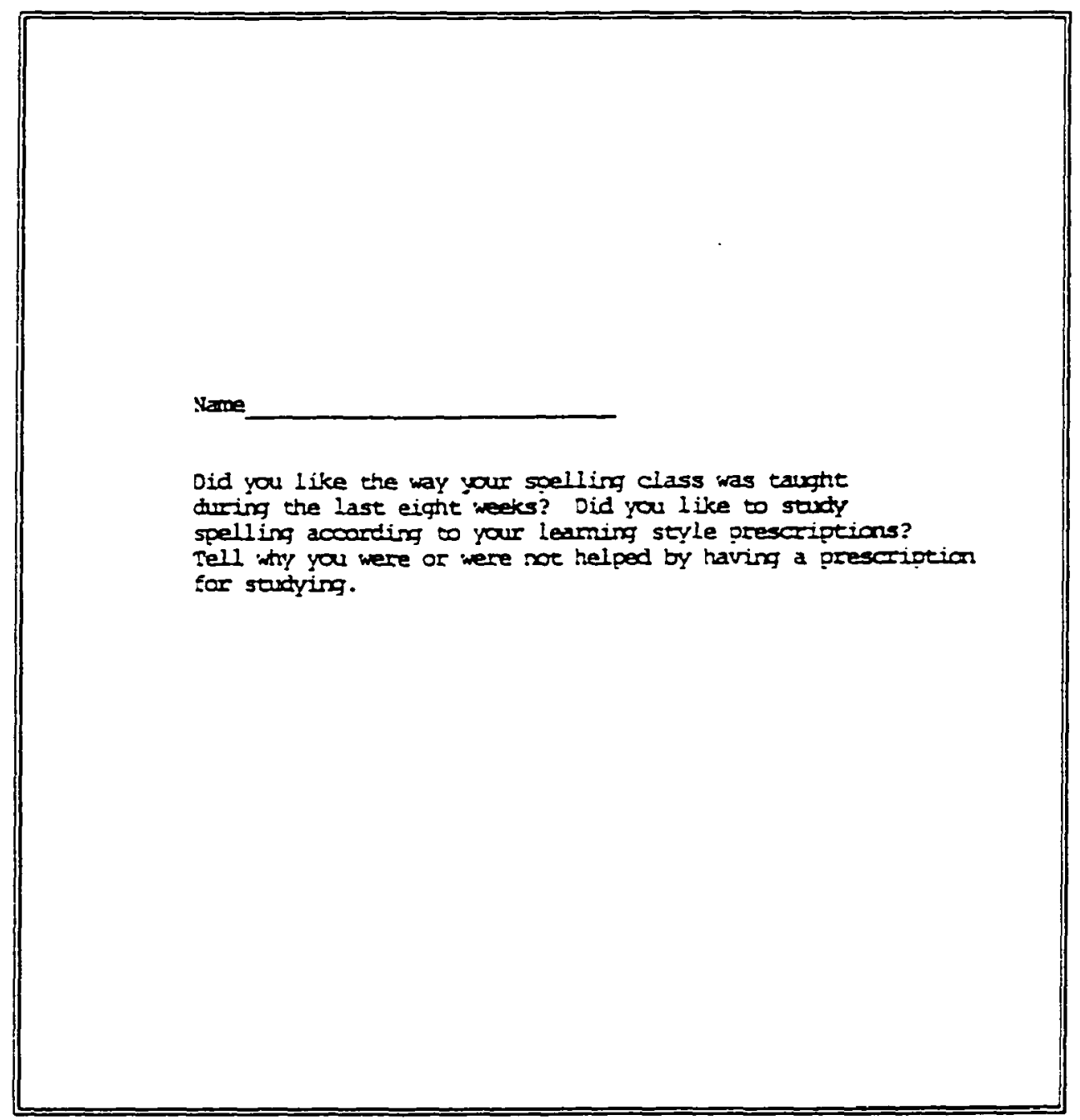


APPENDIX B

SAMPLE LEARNING STYLE PRESCRIPTION, GROUP PROFILES 


$\begin{array}{ll}\text { Name: } & \\ \text { Sex: } & m . \\ \text { Date: } & 10 / 24 / 91 \\ & \\ & \\ \text { SOUND } & 31 \\ \text { IIGHT } & 10 \\ \text { TEMP } & 21 \\ \text { DESIGN } & 56 \\ \text { MOTIVATION } & 67 \\ \text { PERSISTENCE } & 65 \\ \text { RESPONSIBIE } & 72 \\ \text { STRUCTURE } & 58 \\ \text { ALONE } & 52 \\ \text { AUTHORITY } & 71 \\ \text { VARIETY } & 63\end{array}$

Grade:

Teacher: staunton

Time:

03:00 PK

$\begin{array}{ll}\text { AUDITORY } & 69 \\ \text { VISUAI } & 34 \\ \text { TACIIIE } & 57 \\ \text { VINESTHETIC } & 75 \\ \text { INTAE } & 23 \\ \text { TIIE OR DAY } & 42 \\ \text { LAIE MORNING } & 36 \\ \text { AFIERNOON } & 35 \\ \text { MOBIIITY } & 49 \\ \text { PARENT } & 50 \\ \text { TEACHER } & 55\end{array}$




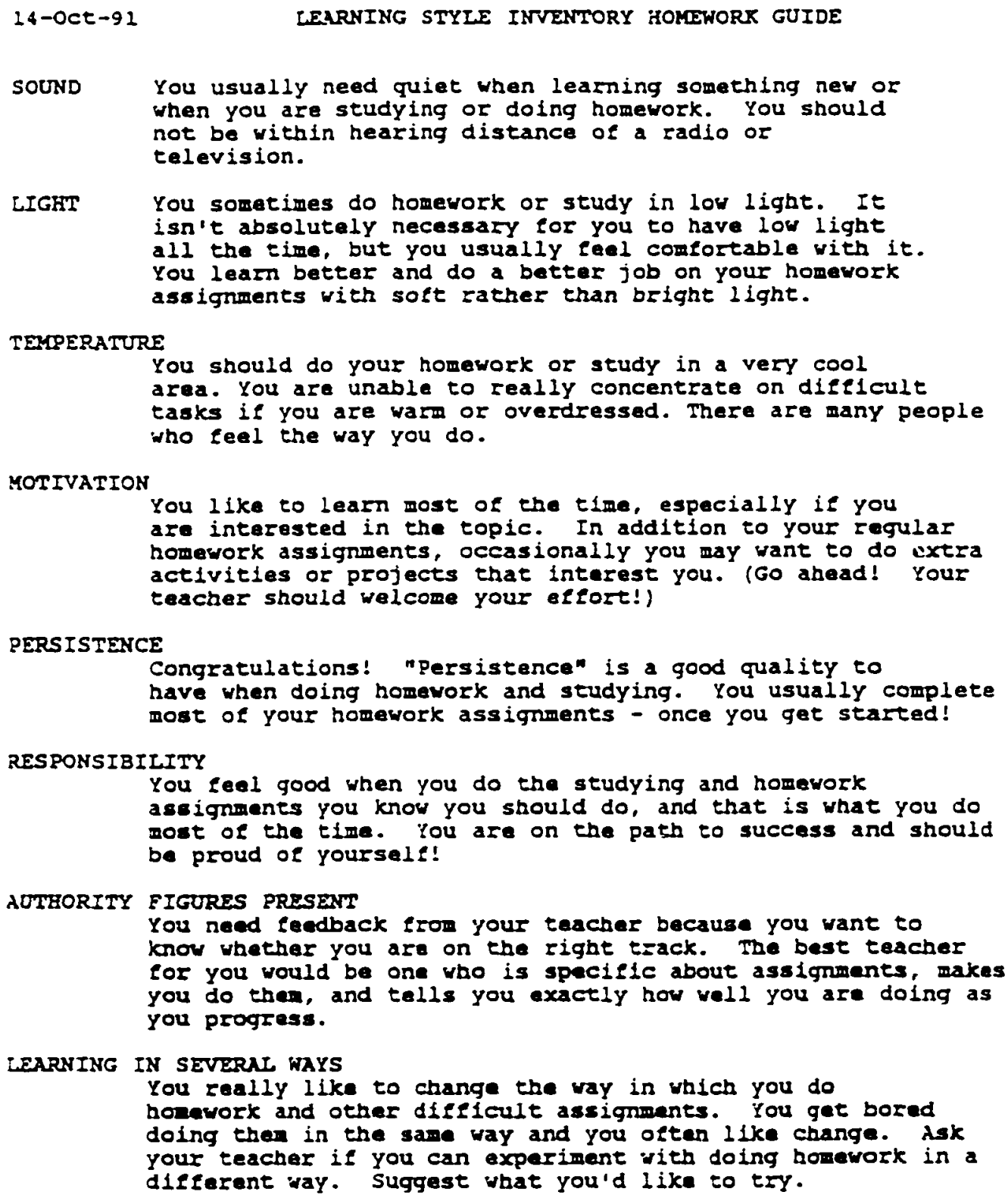


14-OCE-91 LEARNING STYIE INVENTORY HOKEWORK GUIDE

AUDITORY

You usually find it easy to remember much of what you hear, so you probably pay close attention to your teacher's lectures. You have an auditory strength! You find it easy to learn through audiotapes, videotapes, discussions, records, radio, talevision and lectures. You should reinforce what you hear by reading and by then making something creative with the new information in the lecture. (See instructions for making tactual materials in Appendix A.) Try using the information by creating an original poem or a crosaword puzzle.

VISUAL

You really need to concentrate when you ara studying or doing homework that recuires reading. Sometimes you need to reread a page because, although you have read it, you have not absorbed very much. For example. you may need to hear new information first and then read about it. If that is the best pattern for you, be certain to take notes (or underline) whlle you are reading. Follow the note taking by using the nev information you just learned. If your teacher does not lecture on, or discuss the new information in class, try reading the text out loud on to a tape recorder. Then play it back to yourself and take notes from hearing the tape you made.

Important! Find out what your strongest perceptual modality is and tollow the staps as cited in this package on the ChATE, DOING HOHEWORR THROUGH YOUR PERCEPTUAL STRENGTHS (see Appendix $B$ ).

KINESTHETIC

You have a Kinesthetic strength!

You like being active and involved. Do homework

assignments and studying by building in activities that

include trips, experiments, skits, cole playing, acting, loor and action games. Reinforce through tactual, visual, and then auditory resources. See instructions for making tactual materials in Appendix $A$. InIPORTANT! Find out vat your strongest perceptual modality is and follow the stepe as cited in this package on the chart, DOING GOKENORK THROUGE YOOR PERCEPIOAL STRENGTHS in Appendix $B$.

INTARE

You do not need to eat or drink while you are studying or doing homework.

LATE MORNING

You can euncelon, but leaming difficult things does not "cone easily" late in the morning. Mnis is not a good time tor you to do hoverork or study. 

homework. Study then only if there is no other cholce. 


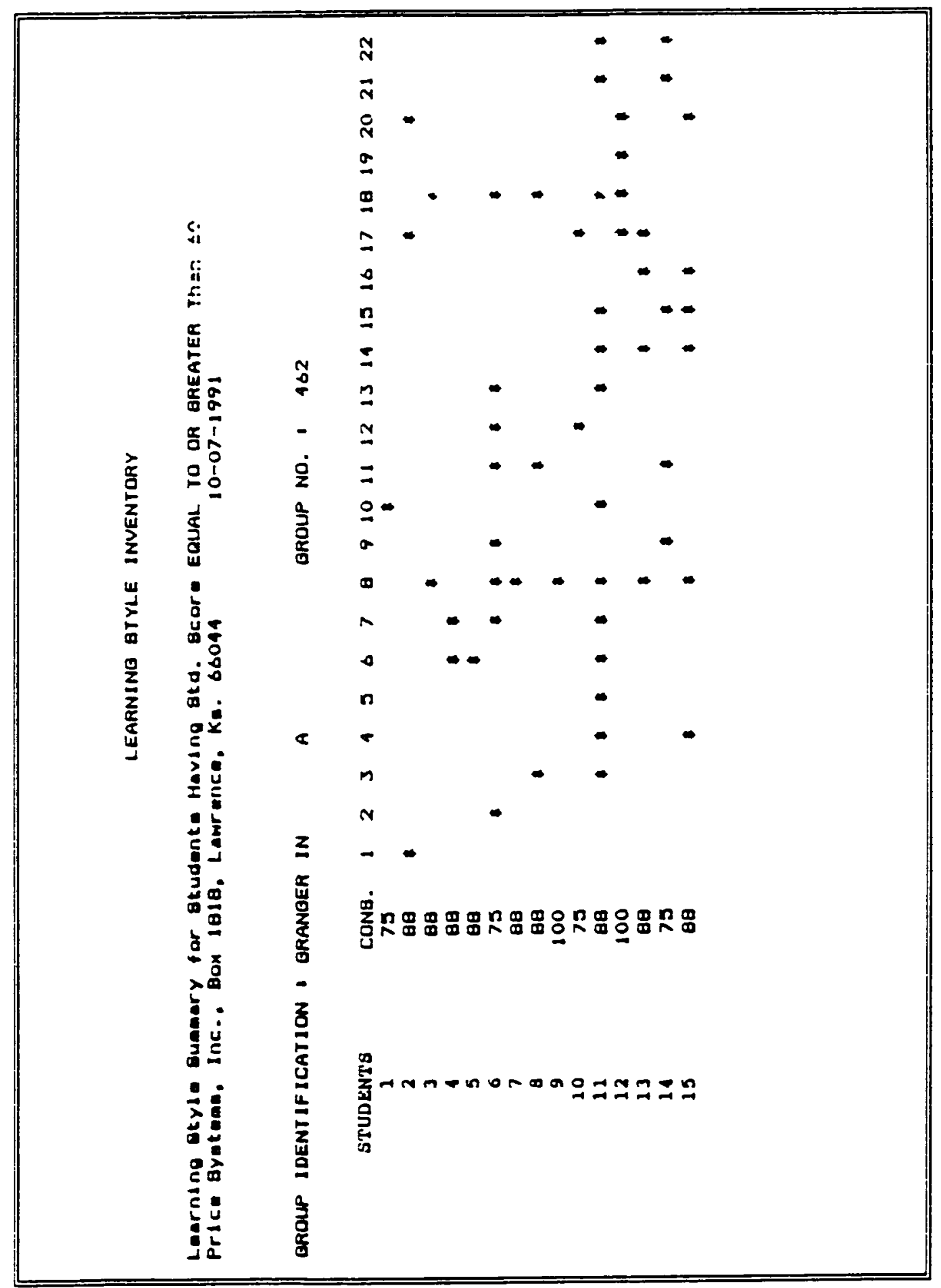


GAOUP IDENTIFICATION \& GRANGER IN

$$
\text { LEI AREA }
$$

MOIBE LEVEL.

LIGHT

TEMPERATURE

DEBION

MOT IVAT JON

PERGIBIENT

KEBPONBIBLE

BTRUCTURE

LEARNING ALONE/PEER DRIENTED

AUTHORITY FIGUREB PRESENT

LEARN IN GEVERAL WAYS

AUDI TURY

VIGUAL

TACT ILE

KINEBTHETIC

REOUIRES INTAKE

EVENING-MORNING

LAIE MORNING

AF TERNOON

NEEDG MOBILITY

PARENT FI GURE MOTIVATED

TEACIER MOTIVATED

INIAL NUMBER OF BIUDENTS ,
GROUP NO. 4462

gubscale
1
2
3
4
5
6
7
8
9
10
11
12
13
14
15
16
17
18
19
20
21
22

PERCENTAGe

$$
\begin{array}{r}
0.25 \\
6.25 \\
12.50 \\
12.50 \\
6.25 \\
18.75 \\
18.75 \\
13.75 \\
12.50 \\
12.50 \\
18.75 \\
12.50 \\
12.50 \\
18.75 \\
18.75 \\
12.50 \\
25.00 \\
31.25 \\
6.25 \\
18.75 \\
12.50 \\
12.50
\end{array}
$$

TOTAL REGPONGE : 56 


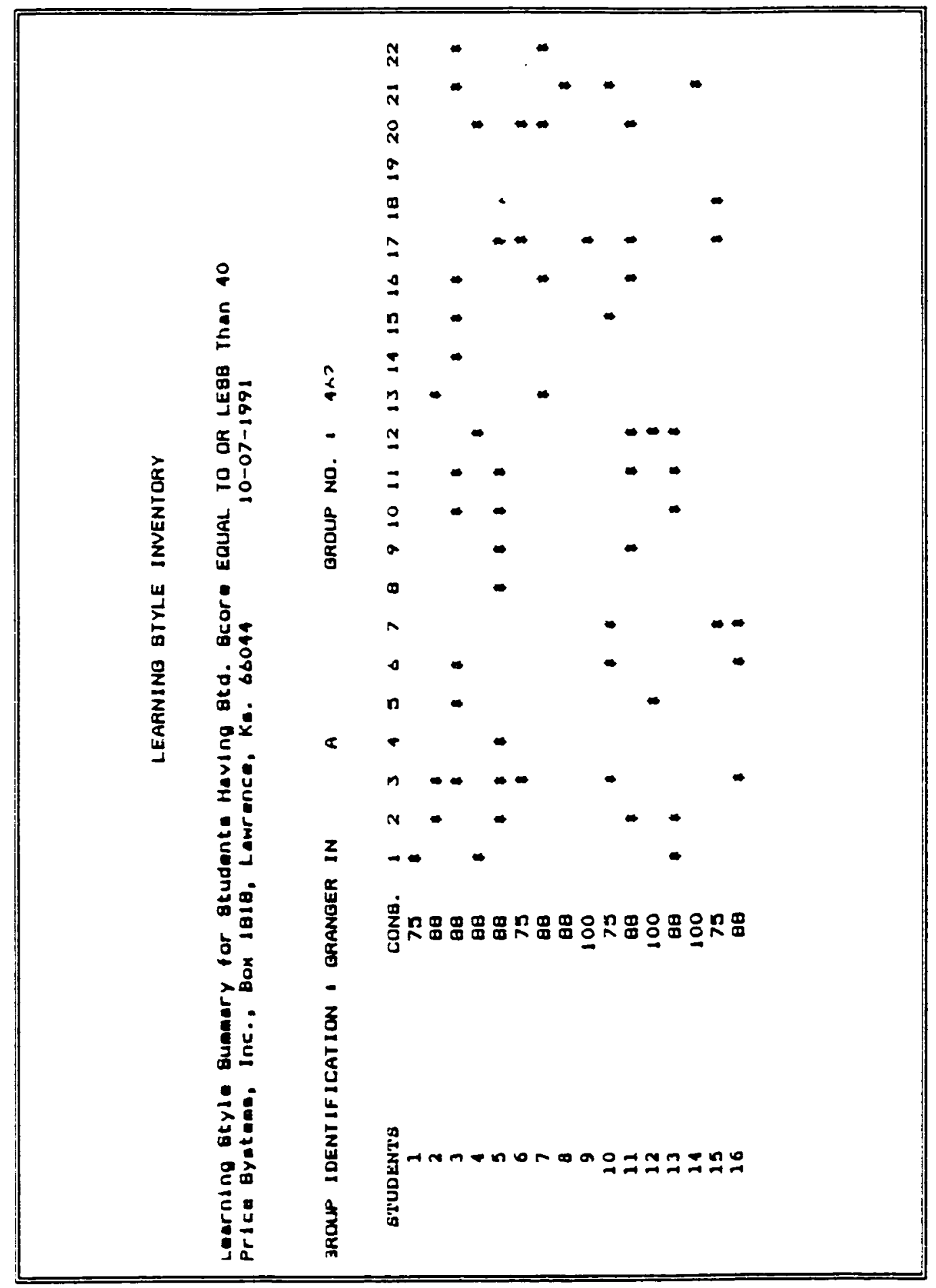


LEARNING BTYLE INVENTORY

JOTAL REBPONBEB OY GUBBCALE FOR BTANDARD BCORE EQUAL TO DR LEGB THAN 40

$10-07-1991$

GROUP IDENTIFICAIION I BRANGER IN

LBI AREA

NO18E LEVEL

LIBHT

IEMPERA TURE

DEBION

MOT IVATION

PERBIGTENT

REBPONGIBLE

BTRLCTLAE

LEARNING ALONE/PEER ORIENTED

AUTHORITY FIBUREB PRESENT

LEARN IN GEVERAL WAYB

ALDI TORY

VIGUAL.

TACTILE

KINEBTHETIC

REDUIREG INTAKE

EVENINO-MORNING

LATE MORNINO

AF TERNOON

NEEDB MOBILITY

PARENT FIBURE MOTIVATED

TEACHER MOTIVATED

SUBBCALE

GROUP NO. 462

REGPONGEG FERCENTAGE

1
2
3
1
5
6
7
8
9
10
11
12
13
14
15
16
17
18
19
20
21
22

IOIAL IMMMER OF BIUDENTB IO 


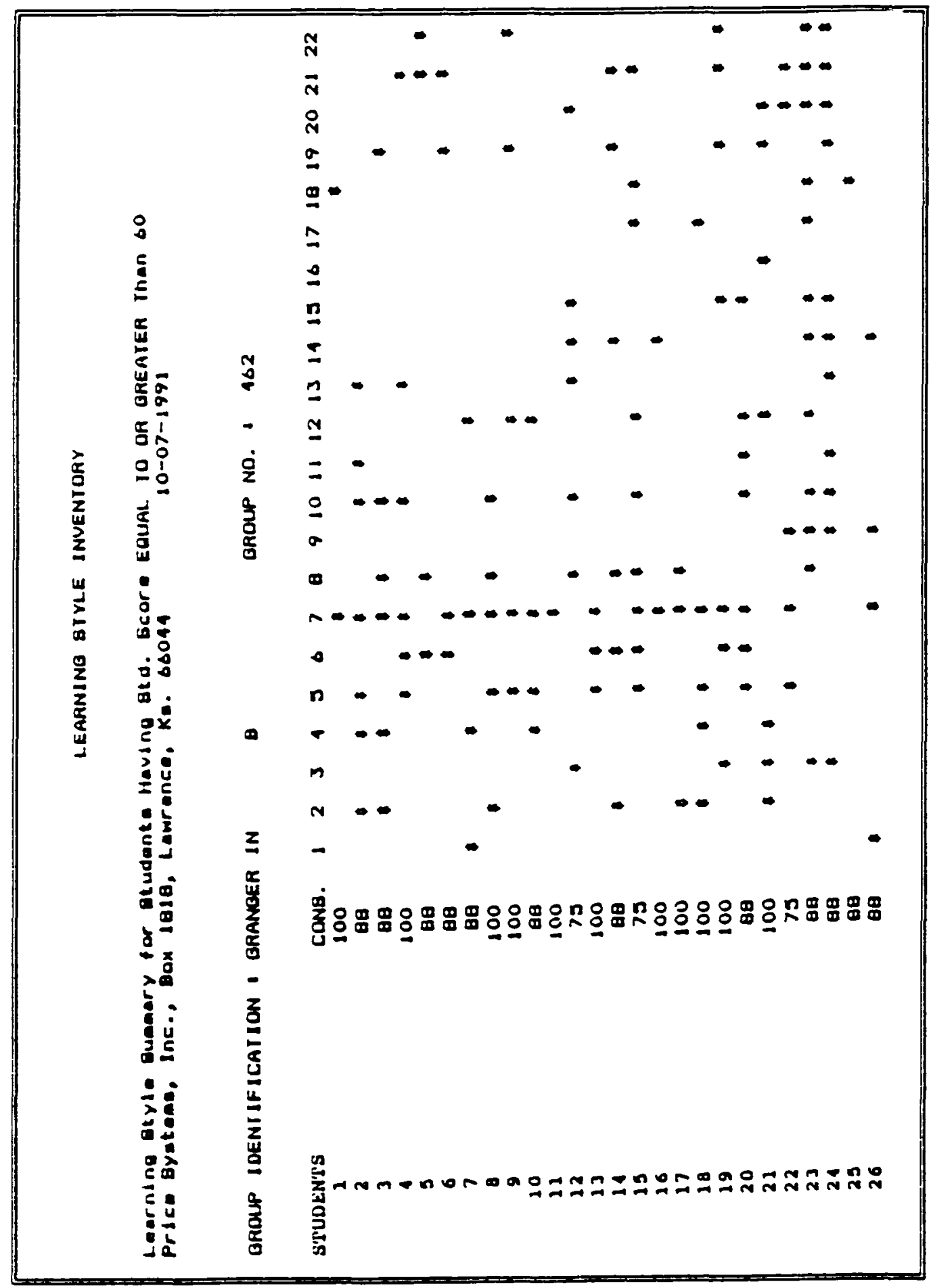


LEARNING BTYLE INVENTORY

IOIAL FEBPOHBE BY GUBGCALE FOA GIANDARD GCOAE EQUAL TO OR GREATER IHAN 60

$10-07-1991$

GKOUP IDENIIFICAIION : GRANGER IN

L8I AREA

NOIBE LEVEL

LIBHT

TEMPERATURE

DEBIGN

MOTIVAIIION

PERBIGIENT

REBPangible

gTRLCTURE

LEARMING ALONE/PEER DAIENTED

AUTHORITY FIBUAEG PREBENT

LEARN IN BEVERAL WAYB

ALDI TORY

VIBUAL

TACTILE

KINEBTHETIC

REQUIREB INTAKE

EVENING-MORNIMO

LATE MORNINB

AFTERNOON

MEEDS MOBILITY

PARENI FIGURE MOTIVATED

PEACIEK MOT IVATED

B

BugBCAL
1
2
3
1
5
6
7
6
9
10
11
12
13
11
15
16
17
10
19
20
21
22

BLBBCALE

BROUP NO. \& 162

REgPONSEG

percentabe

2
7
5
6
1
8
1
6
4
9
3
7
4
6
5
1
3
1
7
5
9
5

7.41

25.93

18.52

22.22

37.04

29.63

70.37

29.63

14.01

33.33

11.11

25.93

14.81

22.22

18.52

3.70

11.11

14.81

25.93

18.52

33.33

10.52

TOIAL MUMGER OF BTUDENTE , 27 





LEARNING BTYLE INVENTORY

IOIAL REgPCNBEB OY GUBGCALE FOR BTANDARD GCORE EQUAL TO OH LEGB IMAN 40

$10-07-1991$

GKOUP IOENIIFICATION I GRANGER III

$$
\text { LBI AHEA }
$$

NOIGE LEVEL

LIOHT

TEMPERATURE

DEBIBN

MOTIVATION

PERBIBIENT

REBPONGIBLE

GTRLCTURE

LEARNING ALONE/PEER ORIENTED

AUTHOAITY FIELAAE PREBENT

LEARN IN GEVERAL WAYB

AUDITORY

VIBUAL

TACTILE

KINEBTHET IC

REDUIREB INIAKE

EVENINO-MORNINE

LATE MORNING

AF IERNOON

NEEDG MOBIL.ITY

PARENT FIGLAE MOTIVATED

TEACHEA MOTIVATED

IOIAL NHMBER OF BIUDENIG , 27
GROUP NO. \& 462

gugbcale respongeg PERCENtage

9
3
9
5
2
3
1
2
7
2
1
10
4
3
5
11
1
7
3
6
0
4

33.33

11.11

33. 33

19.52

7.41

11.11

3.70

7.41
25.93

7.41

14.81

37.04

14.81

11.11

18.52

40.74

14.81

25.93

11.11

22.22

22.22

14.01

TOTAL REgPONGEG 104 
APPENDIX C

SAMPLE STUDENT ACTIVITIES

Reproduced with permission of the copyright owner. Further reproduction prohibited without permission. 
: :ame

כate

write ent tetter or wur soeiling wors that matches sach derinition.
3. aDUS:
o. amuse
i. cure
ง. curious
i. extuse
i purious
g. menu
ก. mural
1. musician
1. Dreview
k. refuse
l. review
m. secure
ก. univers
o. view

\footnotetext{
- I lo uo uver ejoi incormacion

_ $\therefore$ one wno viavs music

j. a plece of sader wnich lists jvallaole meals

- + a war to make sumeone peol secter

- 5. 10 see anead or irme

_. a larọe drawing

- ine wnote riration

3. unary

- an uniustirlés reason to get suc or sometning

10. nure

11. not allow

12. sare

_ 15. incerested

- 14. siene

- 5. heeo entertaineo
} 


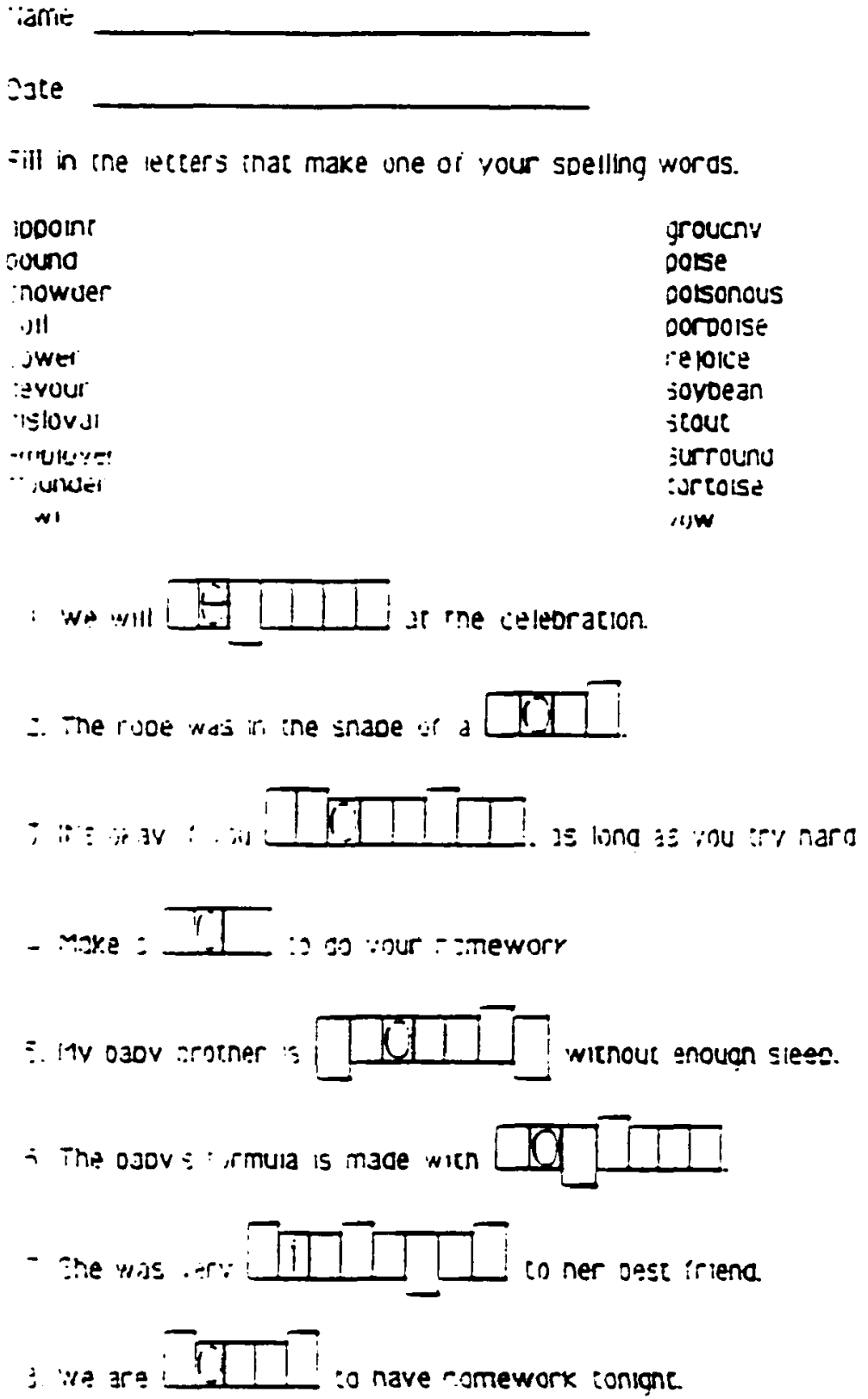


APPENDIX D

DATA EIIE

Reproduced with permission of the copyright owner. Further reproduction prohibited without permission. 
FORMAT FCR SAMPLE CE 65 SUBJECTS

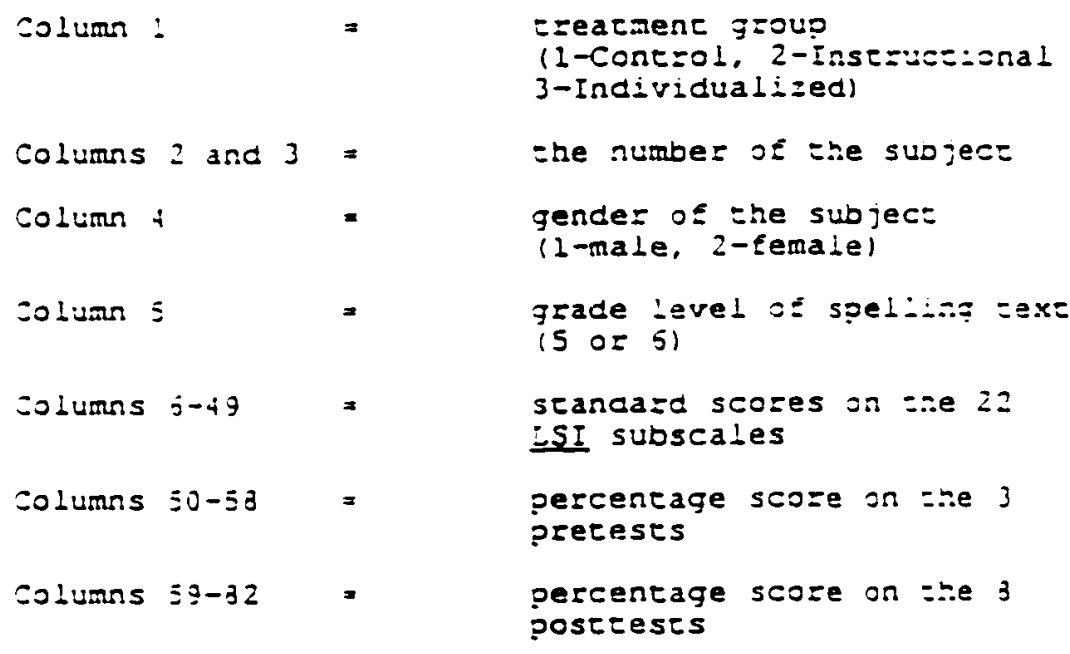

Reproduced with permission of the copyright owner. Further reproduction prohibited without permission. 
10126

10215

10316

10425

10526

10626

10626

10725

10825

10926

11025

11116

11216

11326

11416

11626

11626

11815

11926

12015

12115

12226
080080093097077087097094093097097 093096100087077090084090097094090 100100092100100100097094100080100 100068097097087077070060094083090 093097097100087097097097093100097 10008003000970970900094090093 080060070087087077084087097083087 100100100090100087100094100100100 100100097100100100097093090090090 060092092097097087057080080093087 080083093097100100097097100100094 093097100097097097080100090090090 100090097097100100097100097100097 100090093100097097097097100097100 080097093097087097097097097077090 100100092100100100100094100097097 100093100100100087100070100090090 100084100080053097080077094073070 070076064077053067090087055057087 080100088087067090090073097100090 080092084077077077090053100090083 100100093100100100100094097100094

2231540434456535451585467475449595044425359575055045070020075065090030090060072055 2241567312044494354495045545434544651625650605046085070060085045100085080068094065 2252552573844392951614632355445343336516047443037073080085062100096010088076062050 2262536544659556160524448514049494153535356305858085096092092100100100100098096095 2271558343836556151403438235845444649293947555452092096081096092100100100096085070 2281554603550574772616151637263574657356059224255100100088100092100100094096096095 2291543494656554354615458444434575340555653285440050100065015030100020060044062035 2302552436047514348525845604745545547516053463043095088073081085100073088072006080 (1)

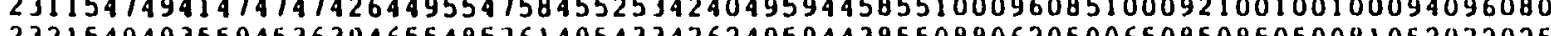
2331554296361696069643274323367696523316344226265100080058088077096077094086090080 2341558574956315454465258442952425044628062654643065100065060070100040060062086070 2351540405850554742644738384052645360624941445852073092055055075100090070086092070 2362552494656475848465748514449494142464656443846100092088085096100096094086069085 2371545494941494336556651635852546049352953556268100085045060055085095080068074060 2381549572473553630674945415856646364574653605858070085090070080100075080062082065 3392670403041495860346345542952675347403938555852096061089096100093100096079100093 


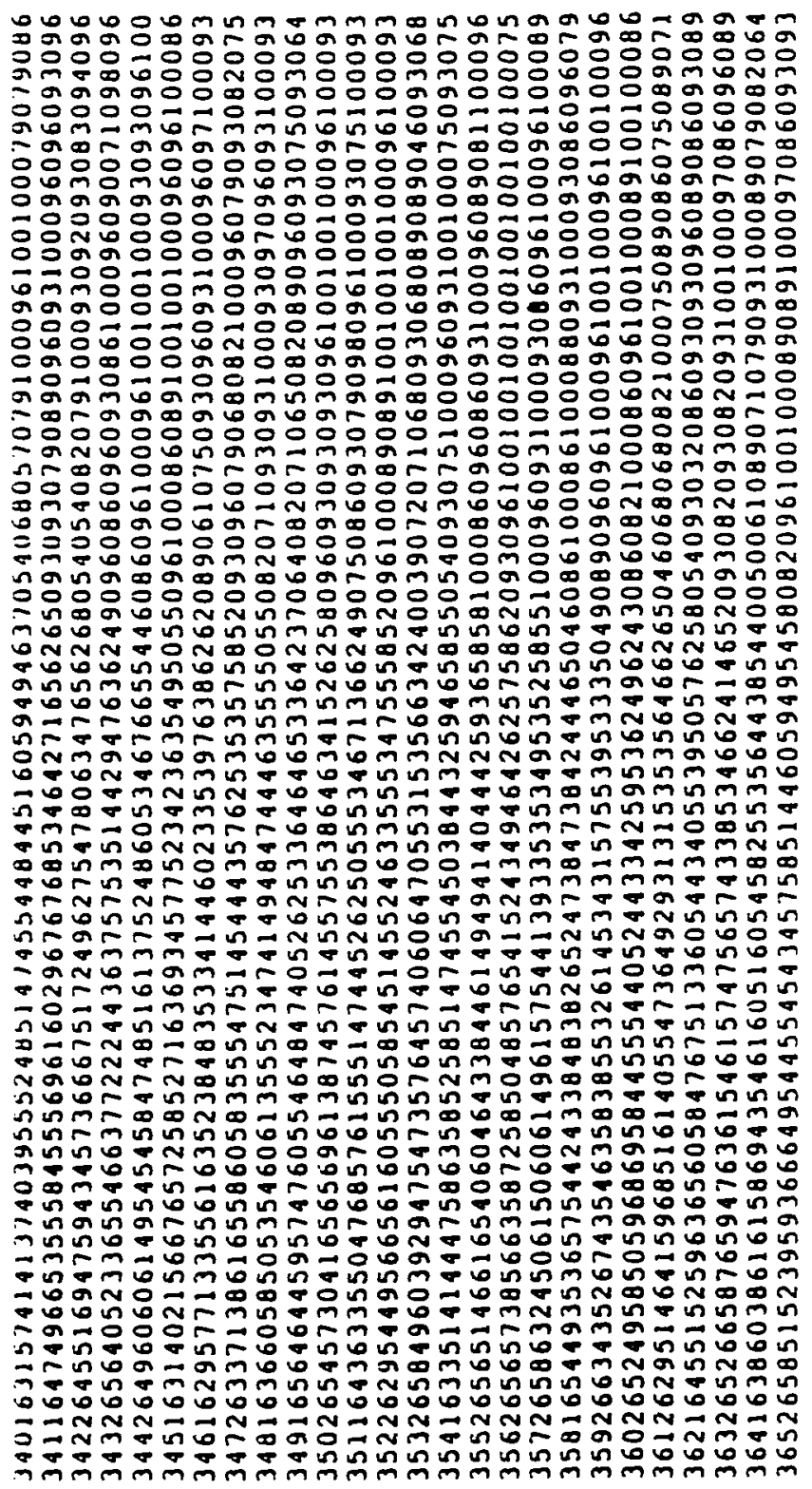


REFERENCE LIST

List includes sections on books, articles, and additional sources.

\section{BOOKS}

Armbruster, R. B., \& Brown, A. L. (1984). Learning from reading: The role of metacognition. In $\mathrm{R}$. $\mathrm{C}$. Anderson, $J$. Osborn, \& R. J. Tierney (Eds.), Learning to read in American schools (pp. 273-281). Hillsdale, NJ: Erlbaum.

Baker, L., \& Brown, A. (1985). Metacognitive skills of reading. In $D$. Pearson (Ed.), handbook of reading research (pp. 231-272). New York: Longman.

Barbe, W. B., \& Swassing, R. H. (1979). Teaching through modality strengths: Concepts and practices. Columbus, OH: Zaner-Bloser.

Biehler, B. F., \& Snowman, J. (1990). Psychology applied to teaching ( 6 th ed.). Boston: Houghton Mifflin.

Braio, A. C. (1987). Mission from no style: Wonder and Joy meet the space children. Jamaica, NY: St. John's University's Center for the Study of Learning and Teaching styles.

Carbo, M. (1986). Teaching students to read through their individual learning styles. Englewood Cliffs, NJ: Prentice-Hall.

Chalfant, J. C., \& Flathouse, V. E. (1971). Auditory and visual learning. In $\mathrm{H}$. Mykelbust (Ed.), progress in learning disabilities (Vol. 2). New York: Grune \& stratton.

Cronbach, I. J., \& Snow, R. E. (1977). Aptitudes and instructional methods: A handbook for zesearch and interaction. New York: Irvington.

Dunn, R., \& Dunn, K. (1972). Practical approaches to individualizing instruction. New York: PrenticeHall. 
Dunn, R. \& Dunn, K. (1978). Teaching students through their individual learnina styles: A practical approach. Englewood Cliffs, NJ: Prentice-Hall.

Gage, N. L., \& Berliner, D. C. (1988). Educational psychology (4th ed.). Boston: Houghton Mifflin Company.

Glover, J. A., \& Bruning, R. H. (1990). Educational psychology: Principles and application (3rd ed.). Glenview, IL: Scott, Foresman.

Hill, J. E. (1970). Cognitive style as an educational science. Bloomfield Hills, MI: Oakland Community College Press.

Hunt, D. E., \& Sullivan, E. V. (1974). Between psychology and education. Hinsdale, IL: The Dryden Press.

Johnson, D. \& Myklebust, H. (1967). Learning disabilities: Educational principles and practices. New York: Grune \& Stratton.

Joyce, B., \& Weil, M. (1986). Models of teaching (3rd ed.). Englewood Cliffs, NJ: Prentice-Hall.

Jung, C. G. (1923). Psychological types of the psychology of individuation. London: Pantheon Books.

Keefe, J. W. (Ed.). (1979). Learning style: An overview. student learning styles: Diagnosing and prescribing programs. Reston, VA: National Association of Secondary School Principals.

Kirby, P. (1979). Cognitive style, learning style, and transfer skill acquisition. Columbus: The onio state University's National Center for Research in Vocation Education.

Kolb, D. A. (1979). Organizational psychology: An experiential approach (3rd ed.). Englewood cliffs, NJ: Prentice-Hall.

Lowenfeld, V., \& Brittain, W. (1975). Creative and mental growth ( 6 th ed.). New York: Macmillan.

Mccarthy, 8. (1980). The 4MAT system: Teaching to learning styles with right/left mode techniques. Barrington, IL: Excel. 
McMillan, J. H., \& Schumacher, S. (1984). Research in
education: A conceptual approach. Brown.

Ramirez, M., \& Castaneda, A. (1974). Cultural democracy, bicognitive development, and education. New York: Academic Press.

Restak, R. (1979). The brain: The last frontier. New York: Doubleday.

Sperry, L. (1972). Learning performance and individual differences: Essays and readings. Glenview, IL: Scott, Foresman.

Thies, A. P. (1979). A brain-behavior analysis of learning style. In J. W. Keefe (Ed.), student leacning styles: Diagnosing and prescribing programs (pp. 55-61). Reston, VA: National Association of secondary School Principals.

Weiner, B. (1980) . Human motivation. New York: Holt, Rinehart, \& Winston.

winer, B.J. (1971). Statistical principles in experimental design. New York: McGraw-Hill.

witkin, H., Dyk, R., Faterson, D., Goodenough, D., s Karp, S. (1962). Psychological differentiation. New York: John Wiley \& Sons.

Witkin, H., Lewis, H. B., Hertzman, M., Machover, K., Meissner, P. B., \& Wapner, S. (1954). Personality through perception: An experimental and clinical study. Westport, CT: Greenwood Press.

\section{ARTICLES AND PERIODICALS}

Arter, J. A., \& Jenkins, J. R. (1977). Examining the benefits and prevalence of modality consideration in special education. Journal of Special Education, 11, 281-298.

Carroll, J. B. (1963). A model of school learning. Teachers College Record, 64, 723-733. 
Cross, D. R., \& Paris, S. G. (1988). Developmental and instructional analyses of children's metacognition and reading comprehension. Journal of Educational Psychology, 80, 131-142.

Della Valle, J., Dunn, K., Dunn, R., Geisert, G., Sinatra, R R., \& Zenhausern, R. (1986. May/June). The effects of matching and mismatching students' mobility preferences on recognition and memory tasks. Journal of Educational Research, 79(5), 267-272.

Dunn, R. (1988a, January) . Commentary: Teaching students through their perceptual strengths or preferences. Journal of Reading, 31(4), 304-309.

Dunn, R. (1988b, Winter). Introduction to learning styles and brain behavior: Suggestions for practitioners. The Association for the Advancement of International Education, 15(6), 6-12.

Dunn, R. (1989, May/June). Can schools overcome the impact of societal ills on student achievement? The research indicates-yes. The Principal, 34(5), 115.

Dunn, R. (1990a, January). Bias over substance: A critical analysis of Kovale and Forness' report on modality-based instruction. Exceptional Children, $\underline{56}(4), 352-356$.

Dunn, R. (1990b, October). Rita Dunn answers questions on learning styles. Educational Leadership, 15-18.

Dunn, R., \& Bruno, A. (1985, September). What does the research on learning styles have to do with Mario? The Clearing house, 59, 9-12.

Dunn, R., Cavanaugh, D. P., Eberle, B., \& Zenhausern, R. (1982, May). Hemispheric preference: The newest element of learning style. The American Biology Teacher, 44(5), 291-294.

Dunn, R., \& Dunn, K. (1986, March). The look of learning styles. Early Years, 49-52.

Dunn, R., Krimsky, J. S., Murray, J. B., \& Quinn, P. J. (1985, May). Light up their lives: A review of research on the effects of lighting on children's achievement and behavior. The Reading Teacher, 38 , 863-869. 
Fizzell, R. L. (1984, Spring). The status of learning styles. Educational Forum, 48(3), 303-312.

Freeley, M. E., \& Perrin, J. (1987, August/September). Teaching to both hemispheres. Teaching $\mathrm{K}-8,18(1)$, $67-69$.

Gordon, J. (1990, May). Learning how to learn. Training, $\underline{27}(5), 51-54$.

Harris, K. R., Graham, S., \& Freemen, S. (1988, January). Effects of strategy training on metamemory among learning disabled students. Exceptional Children, $\underline{54}(4), 332-338$.

Kagan, J., Moss, H., \& Siegel, I. (1963). Psychological significance of styles of conceptualization. Monographs of the Society for Research in Child Development, 28, 73-112.

Kampwirth, T. J., \& Bates, M. (1980, May). Modality preference and teaching method: A review of research. Academic Therapy, 15, 597-605.

Kavale, K. A., \& Forness, S. R. (1987, November). Substance over style: Assessing the efficacy of modality testing and teaching. Exceptional Children, $54(3)$, $228-239$.

Keefe, J.W. (1985, Spring). Assessment of learning style variables: The NASSP task force model. Theory into Practice, 24(2), 138-144.

Miller, A. (1981). Conceptual matching models and interactional research in education. Review of Educational Research, 51, 33-84.

Paris, S. G., \& Oka, E. R. (1986, October). Self-regulated learning among exceptional children. Exceptional Children, 53(2), 103-108.

Pennell, L. (1985, Spring). Academic Intervention program: Applying brain and learning styles concepts. Theory into practice, 24(2), 131-134.

Price, G. (1980). Which learning style elements are stable and which tend to change? Learning styles Network Newsletter, $4(2), 38-40$. 
Price, G. E., Dunn, R., \& Sanders, W. (1981). Reading achievement and learning style characteristics. The clearing House, 54(5), 223-226.

Reinert, H. (1976). One picture is worth a thousand words? Not necessarily! The Modern Language Journal, 60 (4), 160-168.

Reinert, H. (1982). Gotta beef? Try Elsie. Learning Styles Network Newsletter, $3(2), 4$.

Rosenfeld, R. L. B. (1977). Setting the stage for learning. Theory into practice, 16(3), 167-173.

Rottman, T. R., \& Cross, D. R. (1990, May). Using informed strategies for learning to enhance the reading and thinking skills of children with learning disabilities. Journal of Learning Disabilities, $\underline{23}(5), 270-278$.

Schmeck, R., \& Lockhart, D. (1983, February). Introverts and extroverts require different learning environments. Educational Leadership, 40(5), 54-55.

Schmeck, R., Ribich, F., \& Ramanaiah, N. (1977). Development of a self-report inventory for assessing individual differences in learning processes. Applied Psychological Measurement, 1, 413-431.

Tarver, S. G., \& Dawson, M. M. (1978). Modality preference and the teaching of reading: A review. Journal of Learning Disabilities, 11, 5-17.

Wong, B. Y. L. (1986, October). A cognitive approach to teaching spelling. Exceptional Children, 53(2), $169-173$.

Wurtman, R. (1968). Biological implications of artificial illumination. Illuminating Engineering Society Journal, 63, 523-529.

\section{ADDITIONAL REFERENCES}

Baird, J. R., \& White, R. T. (1984). Improving learning through enhanced metacognition: A classroom study. Paper presented at the annual meeting of the American Educational Research Association, New Orleans, LA. (ERIC Document Reproduction Service No. ED 249250$)$. 
Bloom, B. S. (1968). Learning for mastery. Evaluation Comment, 1(2), Los Angeles: Center for the Study of Evaluation of Instructional Programs, University of California.

Briggs, K. C., \& Myers, I. 8. (1977). Myers-Briggs type indicator. Palo Alto, CA: Consulting Psychologists Press.

Canfield, A. A., \& Lafferty, J. C. (1970). Learning style inventory. Detroit: Humanics Media.

Carbo, M. (1981). Reading style inventory. New York: Learning Research Associates.

Claxton, C. S., \& Murrell, P. H. (1987). Learning styles: Implications for improving educational practice (Ashe-ERIC Higher Education Report No. 4). washington, DC: The George Washington University.

Cody, c. (1983). Learning styles, including hemispheric dominance: A comparative study of average, gifted, and highly gifted students in grades five through twelve (Doctoral dissertation, Temple University, 1983). Dissertation Abstracts International, 44, $1631 \mathrm{~A}$.

Curry, I. (1983). An organization of learning styles, theories and constructs. Paper presented at the annual meeting of the American Educational Research Association, Montreal, Canada.

Curry, L. (1987). Integrating concepts of cognitive learning style: A review with attention to psychometric standards. Ontario, Canada: Canadian College of Health Service Executives.

Curry, L. (1990). Learning styles in secondary schools: A review of instruments and implications for the if use. Madison, WI: Wisconsin Center for Educational Research. (ERIC Document Reproduction Service No. ED 317283$)$.

DeBello, T. (1985). A critical analysis of the achievement and attitude effects of administrative assignments to social studies writing instruction based on identified eighth-grade students' learning style preferences for learning alone, with peers, or with teachers (Doctoral dissertation, st. John's University, 1985). Dissertation Abstracts International, $47,68 \mathrm{~A}$. 
DeBello, T. (1989). Comparison of eleven major learning styles models, variables, appropriate populations, validity of instrumentation, and the research behind them. Paper presented at the National Conference of the Association for Supervision and Curriculum Development, orlando, FL. (ERIC Document Reproduction Service No. 312093 ).

Della valle, J. (1984). An experimental investigation of the word recognition scores of seventh grade students to provide supervisory and administrative guidelines for the organization of effective instructional environments (Doctoral dissertation, st. John's University, 1984). Dissertation Abstracts International, 45, 359A.

Dunn, R., Dunn, K., \& Price, G. E. (1975). Learning style inventory. Lawrence, KS: Price systems.

Dunn, R., Dunn, K., \& Price, G. E. (1987). Learning style inventory manual. Lawrence, KS: Price Systems.

Fizzell, R. L. (1982, October). The status of styles. Paper presented to the annual conference of the midwest association of teachers of educational psychology. (ERIC Document Reproduction Service No. ED 223611 ).

Freeley, M. E. (1984). An experimental investigation of the relationships among teachers' individual time preferences, inservice workshop schedules, and instructional techniques and the subsequent implementation of learning style strategies in the participants' classrooms (Doctoral dissertation, st. John's University, 1984). Dissertation Abstracts International, 46, 403A.

Giannitti, M. C. (1988). An experimental investigation of the relationships among the learning style sociological preferences of middle-school students (grades $6,7,8$ ), their attitudes and achievement in social studies, and selected instructional strategies (Doctoral dissertation, St. John's University, 1988).

Gilbert, L. C. (1986, April). Inducements of metacognitive learning strategies: Task knowledge, instructions, and training. Paper presented at the annual meeting of the American Educational Research Association, San Francisco, CA. (ERIC Document Reproduction Service NO. ED 271486$)$. 
Gregorc, A. F. (1982a). An adult's quide to style (First in a series of monographs on personality and mind qualities). Maynard, MA: Gabriel systems.

Gregorc, A. F. (1982b) Gregorc style delineator:

Developmental, technical, and administrative manual. Maynard, MA: Gabriel systems.

Guild, P. B., \& Garger, S. (1985). Marching to different drummers (Association for Supervision and Curriculum Development Publications).

Hamachek, A. I. (1990). Memory and study strategies for optimal learning. Paper presented at the Conference of the Learning Disabilities Association of America, Anaheim, CA. (ERIC Document Reproduction Service No. ED 320347 ).

Hill, J. E. (1976). Cognitive style interest inventory. Bloomfield Hills, MI: Oakland Community College.

Hodges, H. (1985). An analysis of the relationships among preferences for a formal/informal design, one element of learning style, academic achievement, and attitudes of seventh and eighth grade students in remedial mathematics classes in a New York City junior high school (Doctoral dissertation, st. John's University, 1985). Dissertation Abstracts International, 45, $2791 \mathrm{~A}$.

Hunt, D. E. (1971). Matching models in education. Toronto: ontario Institute for Studies in Education.

Kagan, J. (1964). Matching familiar figures test. Cambridge, MA: Harvard University.

Katims, D. S., \& Alexander, R. N. (1987). Cognitive strategy training: Implications, applications, limitations. Paper presented at the Annual Convention of the Council for Exceptional Children, Chicago, IL. (ERIC Document Reproduction Service No. ED 303936).

Keefe, J. W. (1982). Student learning styles and brain behavior: Programs, instrumentation, research. Reston, VA: National Association of Secondary School Principals. (ERIC Document Reproduction Service NO. ED 292 772). 
Keefe, J. W. (1988). Profiling and utilizing learning style. Reston, VA: National Association of Secondary School Principals. (ERIC Document Reproduction Service No. ED 292772 ).

Keefe, J. W., \& Monk, J. S. (1986). NASSP Learning style profile. Reston, VA: National Association of Secondary School Principals.

Knapp, B. (1990). An investigation of the influence of learning style factors on college students' retention and achievement (Doctoral dissertation, st. John's University, 1990).

Kolb, D. A. (1976). Learning style inventory. Boston: McBer.

Krimsky, J. (1982). A comparative analysis of the effects of matching and mismatching fourth grade students with their learning style preferences for the environmental element of $l$ ight and their subsequent reading speed and accuracy scores (Doctoral dissertation, St. John's University, 1982). Dissertation Abstracts International, 43, $66 \mathrm{~A}$.

Kroon, D. (1985). An experimental investigation of the effects on academic achievement and the resultant administrative implications of instruction congruent and incongruent with secondary, industrial arts students' learning style perceptual preference (Doctoral dissertation, st. John's University, 1985). Dissertation Abstracts International, 46, $11 \mathrm{~A}$.

Lam-Phoon, S. (1986). A comparative study of the learning styles of southeast Asian and American caucasian college students of two Seventh-day Adventist campuses (Doctoral dissertation, Andrews University, 1986).

Letteri, C. A. (1975). Coqnitive style profile. Burlington, Vermont: University of Vermont.

Letteri, C. A. (1982). Information processing model. Paper presented to the NASSP Learning Styles Task Force, Reston, VA. 
Letteri, C. A. (1988). The NASSP learning style profile and cognitive processing. In $J$. W. Keefe (Ed.), Profiling and utilizing learning style (pp. 29-40). Reston, VA: National Association of Secondary School Principals.

Martini, M. (1986). An analysis of the relationships between and among computer-assisted instruction, learning style perceptual preferences, attitudes, and the science achievement of seventh grade students in a suburban, New York school district (Doctoral dissertation, St. John's University, 1986). Dissertation Abstracts International, 47 , $877 \mathrm{~A}$.

Messick, S. (1969). The criterion problem in the evaluation of instruction. Princeton, NJ: Educational Testing Services.

Miles, B. (1987). An investigation of the relationships among the learning style sociological preferences of fifth and sixth grade students, selected interactive classroom patterns, and achievement in career awareness and career decision-making concepts (Doctoral dissertation, St. John's University, 1987). Dissertation Abstracts International, 48 , $2527 \mathrm{~A}$.

Myers, I. B., \& McCaulley, M. H. (1985). Manual: A quide to the develooment and use of the Myers-Brigas type indicator. Palo Alto, CA: Consulting Psychologists Press.

Perrin, J. (1984). An experimental investigation of the relationships among the learning style sociological preferences of gifted and non-gifted primary children, selected instructional strategies, attitudes, and achievement in problem solving and rote memorization (Doctoral dissertation, st. John's University, 1984). Dissertation Abstracts International, $46,342 \mathrm{~A}$.

Pizzo, J. (1981). An investigation of the relationships between selected acoustic environments and sound, an element of learning style, as they affect sixthgrade students' reading achievement and attitudes (Doctoral dissertation, st. John's University, 1981). Dissertation Abstracts International, 42 . $2475 \mathrm{~A}$. 
Price, G. E., Dunn, R., \& Dunn, K. (1979). Productivity environmental preference survey. Lawrence, KS: Price Systems, Inc.

Shea. T. C. (1983). An investigation of the relationship among preferences for the learning style element of design, selected instructional environments, and reading achievement with ninth grade students to improve administrative determinations concerning effective educational facilities (Doctoral dissertation, St. John's University, 1983). Dissertation Abstracts International, 44, $2004 \mathrm{~A}$.

Sheeline, M. C. (1988). Positive effects of implementing special education strategies in the general clessroom. (ERIC Document Reproduction Service No. ED 297534 ).

Torrance, E. P. (1979). Your style of learning and thinking. Bensenville, IL: Scholastic Testing Service.

Vermunt, J. D. H. M. (1987, April). Learning styles and self-requlation. Paper presented at the annual meeting of the American Educational Research Association, Washington, DC. (ERIC Document Reproduction Service NO ED 285900 ).

White, R. (1980). An investigation of the relationship between selected instructional methods and selected elements of emotional learning style upon student achievement in seventh grade social studies (Doctoral dissertation, st. John's University, 1980). Dissertation Abstracts International, 42 , $995 \mathrm{~A}$.

Witkin, H. (1971). Group embedded fiqures test. Palo Alto, CA: Counseling Psychologists.

Zenhausern, R. (1991). Homework disc. Jamaica, NY: Learning Styles Network.

Zenhausern, R. (1980). Differential hemispheric activation test. Jamaica, NY: Learning styles Network. 
VITA

$\begin{array}{ll}\text { Name: } & \text { Nancy D'Isa Turner } \\ \text { Place of birth: } & \text { Youngstown, Ohio } \\ \text { Date of birth: } & \text { March 28, } 1956 \\ \text { Marital Status: } & \text { Married to John J. Turner } \\ \text { Education: } & \\ 1978 & \text { Bowling Green State University, } \\ & \text { Bowling Green, Ohio } \\ & \text { B.S. in Ed. (Summa cum laude) } \\ & \text { Youngstown State University, } \\ & \text { Youngstown, Ohio } \\ & \text { M.S. in Ed. (Reading) } \\ & \text { Andrews University, } \\ & \text { Berrien Springs, Michigan } \\ \text { Ed.D. (Curriculum \& Instruction, } \\ \end{array}$

Experience:

1978-82

Teacher, South Range East Elementary School North Lima, Ohio

1983-84 Teacher, Charlotte Academy

Charlotte, North Carolina

1984-86 Teacher, Northwestern High School

Rock Hill, South Carolina

1986-89 Substitute Teacher and Tutor

Charlotte, North Carolina and

South Bend, Indiana

1989-90 Coordinator, Teaching and Learning Center. Bethel College

Mishawaka, Indiana

1989-90 Doctoral Intern, Saint Mary's College

Notre Dame, Indiana

(in conjunction with Andrews University)

1990-present Part-time Lecturer in Education,

Saint Mary's College

Notre Dame; Indiana

171 
Professional

Memberships:

1991

Member, Learning styles Network

1991

Member, Indiana Association of Teacher Educators

1992

Member, Association for Supervision and Curriculum Development

Appointment:

1992

Visiting Assistant Professor of Education, Saint Mary's College

Notre Dame, Indiana 